
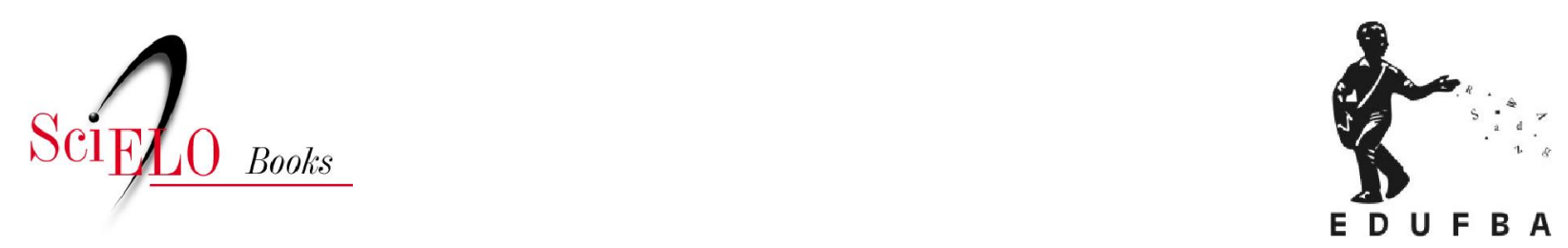

\title{
Desafios para a saúde coletiva no século XXI
}

\author{
Jairnilson Silva Paim
}

PAIM, JS. Desafios para a saúde coletiva no século XXI [online]. Salvador: EDUFBA, 2006, 154p. ISBN 978-85-232-1177-6. Available from SciELO Books $<$ http://books.scielo.org $>$.

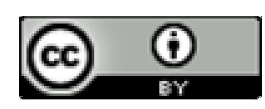

All the contents of this work, except where otherwise noted, is licensed under a Creative Commons Attribution 4.0 International license.

Todo o conteúdo deste trabalho, exceto quando houver ressalva, é publicado sob a licença Creative Commons Atribição 4.0.

Todo el contenido de esta obra, excepto donde se indique lo contrario, está bajo licencia de la licencia $\underline{\text { Creative }}$ Commons Reconocimento 4.0. 


\section{Desafios para a Saúde Coletiva no Século XXI}




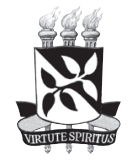

UNIVERSIDADE FEDERAL DA BAHIA

Reitor

NAOMAR MONTEIRO DE ALMEIDA FILHO

Vice-reitor

FRANCISCO JOSÉ GOMES MESQUITA

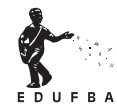

EDITORA DA UFBA

\section{Diretora}

FLÁVIA GOULART MOTA GARCIA ROSA

\section{Conselho Editorial}

Angelo Szaniecki Perret Serpa

Carmen Fontes Teixeira

Dante Eustachio Lucchesi Ramacciotti

Fernando da Rocha Peres

Maria Vidal de Negreiros Camargo

Sérgio Coelho Borges Farias

\section{Suplentes}

Bouzid Izerrougene

Cleise Furtado Mendes

José Fernandes Silva Andrade

Nancy Elizabeth Odonne 


\section{Desafios para a Saúde Coletiva no Século XXI}

\section{Jairnilson Silva Paim}

Professor Titular em Política de Saúde do Instituto de Saúde Coletiva da

Universidade Federal da Bahia

(ISC-UFBA). Pesquisador 1-A do CNPq.

EDUFBA

Salvador-Ba

2006 
(C)2006 by Jairnilson Silva Paim

Direitos para esta edição, cedidos à Editora da Universidade Federal da Bahia.

Feito o depósito legal.

Capa e projeto gráfico

Angela Garcia Rosa

Revisão

Denise Coutinho

Tânia de Aragão Bezerra

Magel Castilho de Carvalho

Biblioteca Central Reitor Macêdo Costa - UFBA

P143 Paim, Jairnilson Silva.

Desafios para a saúde coletiva no século XXI / Jairnilson Silva Paim. - [Salvador]: EDUFBA, 2006.

$154 \mathrm{p}$.

ISBN 85-232-0395-8

1. Saúde pública - Brasil. 2. Sistema Único de Saúde (Brasil). 3. Política de saúde Brasil. 4. Política social - Brasil. I. Título.

\section{EDUFBA}

Rua Barão de Geremoabo, s/n

Campus de Ondina

40170-115 Salvador Bahia

telefax (71) 32636160

www.edufba.ufba.br

www.edufba@ufba.br 
Ao Luca, meu neto, nossa alegria, a sua mamãe Marcele, dindo Maurício, vovó Teca e bisa Zazá 



\section{Sumário}

Epidemiologia e planejamento: a recomposição das práticas epidemiológicas na gestão do SUS

O objeto e a prática da Saúde Coletiva: o campo demanda um novo profissional?

Movimentos no campo social da saúde

Nova Saúde Pública ou Saúde Coletiva? 



\section{Apresentação}

\section{A coletânea Desafios para a Saúde Coletiva no}

Século XXI inspira-se no título de um seminário internacional promovido pela Organização Pan-Americana de Saúde, em agosto de 2005, visando a articulação daqueles que defendem a construção de sistemas de saúde universais, equitativos e de natureza pública.

Tendo sido convidado, naquela oportunidade, para discutir a proposta da Nova Saúde Pública, ressaltei que a Saúde Coletiva latino-americana encontrava-se em condições de contribuir com princípios e estratégias para o desenho dos referidos sistemas. Registrei, além disso, que o projeto da Reforma Sanitária Brasileira possibilitou, a duras penas, implantar o Sistema Único de Saúde (SUS), cujos princípios e diretrizes poderiam servir de referência em torno dos seguintes valores: universal, público, democrático, culturalmente sensível, igualitário, ético, equitativo e solidário.

Os textos aqui publicados discutem políticas públicas e movimentos ideológicos que têm influenciado o campo social da saúde. Nessa perspectiva, a Saúde Coletiva representa uma aposta em novos pressupostos, métodos e práticas sociais, em vez de contentar-se em fazer do mesmo jeito, como tem ocorrido com a saúde pública convencional. Projetos, sonhos, engenho, trabalho e arte transcendem a produção de bens e a prestação de serviços de saúde. Podem compor movimentos contra-hegemônicos capazes de constituir sujeitos públicos comprometidos com novos modos de vida.

Estes são os motivos que impulsionaram a composição deste livro. A sua publicação, no entanto, tornou-se possível com o apoio de Isabela Pinto e Flávia Goulart, além do generoso e dedicado trabalho de revisão efetuado por Denise Coutinho. Aproveito o ensejo desta Apresentação para expressarthes a minha gratidão. 



\section{Atenção à saúde no Brasil ${ }^{1}$}

\section{Introdução}

A atenção à saúde pode ser examinada basicamente mediante dois enfoques: a) como resposta social aos problemas e necessidades de saúde; b) como um serviço compreendido no interior de processos de produção, distribuição e consumo. Como resposta social, insere-se no campo disciplinar da Política de Saúde, sobretudo quando são analisadas as ações e omissões do Estado no que tange à saúde dos indivíduos e da coletividade. Como um serviço ${ }^{2}$, a atenção à saúde situa-se no setor terciário da economia e depende de processos que perpassam os espaços do Estado e do mercado ${ }^{3}$. Mas ao tempo em que é um serviço, a atenção à saúde engendra mercadorias produzidas no setor industrial a exemplo de medicamentos,

'Texto originalmente publicado em: Brasil. Ministério da Saúde.

Saúde no Brasil Contribuições para a Agenda de Prioridades de Pesquisa. Brasília Ministério da Saúde, 2004. p. 15-44. imunobiológicos, equipamentos, reagentes, descartáveis, alimentos dietéticos, produtos químicos de diversas ordens etc. Nesse caso, o sistema de serviços de saúde configura-se como lócus privilegiado de utilização dessas mercadorias e, como tal, alvo de pressão para o consumo, independentemente da existência ou não de necessidades. No estudo desta dinâmica é imprescindível o recurso à Economia Política (AROUCA, 1975; BRAGA \& GOES de PAULA, 1978).

A atenção à saúde pode sofrer as influências do perfil epidemiológico da população, que depende, fundamentalmente, das condições e estilos de vida (modo de vida) e se expressa em necessidades (sofrimento, doença, agravos, riscos, vulnerabilidade ou ideais de saúde) e demandas por consultas, 
vacinas, informações, exames e hospitalizações. Ao mesmo tempo, é um setor estratégico para os negócios das empresas industriais produtoras de insumos, de empreiteiras da construção civil, de agências de publicidade, de serviços de consultorias e de treinamento de recursos humanos, empresas de seguros, bancos etc.

No BRASIL, a atenção à saúde sofreu profundas transformações no século 20, especialmente na década de 1990 com a implantação do Sistema Único de Saúde (SUS) e com a expansão da assistência médica suplementar. Desde a década de 1970, todavia, inúmeros estudos (MELLO, 1977; BRAGA \& GOES DE PAULA, 1978; Cordeiro, 1984) apontavam para a crise do setor quando a atenção à saúde encontrava-se subordinada a um sistema de serviços de saúde que se caracterizava pela insuficiência, descoordenação, má distribuição, ineficiência e ineficácia (BRASIL, 1975). A medicina liberal transformava-se em medicina tecnológica (SCHRAIBER, 1997), incorporavam-se equipamentos de alta densidade de capital nos serviços médico-hospitalares e os custos crescentes da atenção impunham organizações complexas para a sua gestão. $\bigcirc$ Estado atuava mediante a medicina previdenciária e os serviços públicos federais, estaduais e municipais, enquanto a iniciativa privada buscava alternativas de consolidação e expansão, quer vendendo serviços para a Previdência Social, quer buscando nichos de mercado em torno da medicina liberal, quer estruturando a assistência suplementar por meio da medicina de grupo, das cooperativas médicas, dos planos de autogestão e do seguro-saúde.

Distintas políticas racionalizadoras foram empreendidas no período autoritário na tentativa de responder à crise do setor saúde, tais como: a criação do Sistema Nacional de Saúde (Lei n 6.229/75), a implantação de programas de extensão de cobertura de serviços de saúde em áreas rurais e periferias urbanas, a organização de sistemas de vigilância epidemiológica e sanitária, o Plano de Reorientação da Assistência à Saúde no Âmbito da Previdência Social (conhecido como Plano do Conasp) e a estratégia das Ações Integradas de Saúde (AIS). Tais políticas, entretanto, não foram suficientes para responder aos problemas da atenção à saúde no BRASIL, de modo que movimentos sociais passaram a propugnar a criação de um Sistema Único de Saúde e o desencadeamento da Reforma Sanitária BRASILeira como integrantes do processo de democratização do Estado e da sociedade (PAIM, 2002).

Com a conquista da democracia, a sociedade participou ativamente na formulação de proposições políticas para a saúde durante a $8^{a}$ Conferência Naci-

12 onal de Saúde, realizada em 1986, cujas recomendações foram incorporadas 
em grande parte pela Constituição de 1988. A implementação do Sistema Unificado e Descentralizado de Saúde (SUDS), como estratégia-ponte para a implantação do SUS, cujos dispositivos legais foram aprovados em 1990 (Lei $n^{\circ} 8.080 / 90$ e 8.142/90), dava seqüência à reforma do sistema e dos serviços de saúde, inspirada nos princípios e diretrizes da integralidade, eqüidade, descentralização e participação (BRASIL, 2003a). Nesse particular, buscavase a ampliação do acesso e qualidade das ações e serviços, além da concepção e experimentação de modelos de atenção à saúde, que contemplassem aqueles princípios e diretrizes (PAIM, 2002).

Ao tempo em que tais esforços eram empreendidos, foi sendo engendrado um Sistema de Assistência Médica Supletiva (SAMS), a partir do qual a assistência suplementar se apresentava como alternativa para os problemas da atenção à saúde verificados no SUS, chegando a anunciar uma cobertura de 31 milhões de brasileiros no ano de 1989 (MENDES, 1993). Este setor privado, aparentemente paralelo ao SUS, dispõe de várias conexões com o setor público, tornando o sistema de serviços de saúde no BRASIL mais complexo e segmentado, com distintos padrões de acesso, qualidade e integralidade da atenção.

O presente texto tem os seguintes propósitos: a) realizar uma caracterização panorâmica das questões referentes à integralidade, acesso, eqüidade e qualidade da atenção à saúde; b) apresentar, de forma crítica, a evolução histórica na década de 1990 e tendências, considerando o SUS, a assistência suplementar, as reformas setoriais e os modelos de atenção; c) identificar diferenças regionais e particularidades; d) apresentar uma visão crítica das políticas em curso; e) elaborar algumas proposições referentes a grandes linhas de alternativas políticas sobre atenção à saúde.

\section{Integralidade}

A integralidade constitui um princípio e, ao mesmo tempo, uma diretriz para a organização do SUS, segundo a Constituição de 1988. Deriva, originariamente, de uma noção proposta pela chamada Medicina Integral [Comprehensive Medicine]. Vincula-se a um movimento de idéias que gerou a proposta de Medicina Preventiva nas escolas médicas americanas na passagem da década de 1940 para a de 1950 (AROUCA, 1975).

O processo saúde-doença era visto em dois momentos - o patogênico e o pré-patogênico, a partir do modelo da história natural das doenças (CLARK, 
1967; LEAVELL \& CLARK, 1976). No momento pré-patogênico, ou seja, antes da ocorrência da doença, seria possível desenvolver um conjunto de ações inespecíficas e específicas para evitar o aparecimento do problema. Essas medidas eram conhecidas como prevenção da ocorrência ou prevenção primária, compreendendo as açães de promoção e de proteção da saúde. No momento patogênico, poder-se-iam identificar uma fase anterior ao horizonte clínico, no qual a detecção precoce da doença seria realizada mediante triagem [screening] e exames periódicos de saúde; uma etapa em que os sinais e sintomas permitiriam o diagnóstico e a limitação do dano por meio da clínica; e, finalmente, um estágio em que poderiam restar seqüelas para as quais caberiam ações com vistas a atingir uma adaptação possível. As medidas adotadas neste momento podem ser identificadas genericamente como prevenção da evolução (HILLEBOE \& LARIMORE, 1965) ou como prevenção secundária (recuperação da saúde) e prevenção terciária (reabilitação da saúde).

Assim, a medicina integral seria aquela capaz de articular esses cinco níveis de prevenção (promoção, proteção, diagnóstico precoce, limitação do dano e reabilitação) sobre o processo saúde-doença. Já a Medicina Preventiva, como proposta de reforma em saúde das mais parciais, fundamentava uma política que separava a promoção e proteção da saúde para as agências estatais de saúde pública e as demais ações para a medicina privada. Como tentativa de preservação da medicina liberal contra a intervenção estatal, a Medicina Preventiva produziu o dilema preventivista (AROUCA, 1975), ou seja, a dificuldade de implantação do seu projeto em sociedades capitalistas, especialmente naquelas que não realizavam transformações profundas na organização dos serviços de saúde.

O movimento sanitário brasileiro efetuou uma crítica à Medicina Preventiva e a outros movimentos de reforma em saúde fundamentada em diversos estudos (AROUCA, 1975; DONNÂNGELO, 1976; PAIM, 1986). Diante das insuficiências teóricas e políticas desses movimentos, tornou-se necessário transformar muitas das suas noções em conceitos teóricos e proposições políticas. Assim, a noção de integralidade poderia ilustrar este esforço e, ao mesmo tempo, os conseqüentes desafios teóricos, políticos, culturais, metodológicos e técnico-operacionais.

Os textos que alimentaram as discussões da $8^{a}$ Conferência Nacional de Saúde apontavam para o princípio da integralidade e o Relatório Final a contemplou (Conferência Nacional de Saúde, 1987). Todavia, a Constituição, ao 14 apresentar as diretrizes para o SUS, concebe-o como "atendimento integral, 
com prioridade para as atividades preventivas, sem prejuízo dos serviços assistenciais" (BRASIL, 2003a, p. 20). Esta retórica contorcionista pode refletir uma visão de sistema de saúde que identifica ações preventivas com a saúde pública institucionalizada (Estado) e serviços assistenciais com atenção médica individual (iniciativa privada) ou a busca de conciliação entre um modelo de atenção clinicamente orientado e aquele vinculado ao trabalho programático em saúde.

No que pese esta solução de compromisso, tentando uma coexistência pacífica entre a demanda espontânea e a oferta organizada ou entre os princípios do impacto e da não-rejeição da demanda (PAIM, 1993), a Constituição e a Lei Orgânica da Saúde valorizaram as noções de promoção e proteção da saúde, reforçando a concepção de integralidade da atenção (BRASIL, 2002b). Esta lei estendeu a noção para os distintos níveis de complexidade do sistema de serviços de saúde, incorporando a idéia de continuidade da atenção.

Em conseqüência, as bases conceituais da Reforma Sanitária BRASILeira (PAIM, 1997) contemplaram originalmente a integralidade em pelo menos quatro perspectivas: a) como integração de ações de promoção, proteção, recuperação e reabilitação da saúde compondo níveis de prevenção primária, secundária e terciária; b) como forma de atuação profissional abrangendo as dimensões biológica, psicológica e social; c) como garantia da continuidade da atenção nos distintos níveis de complexidade do sistema de serviços de saúde; d) como articulação de um conjunto de políticas públicas vinculadas a uma totalidade de projetos de mudanças (Reforma Urbana, Reforma Agrária etc.) que incidissem sobre as condições de vida, determinantes da saúde e dos riscos de adoecimento, mediante ação intersetorial.

Nesse processo político e técnico-assistencial, distintas propostas alternativas de modelos de atenção valorizaram o princípio da integralidade buscando formas de operacionalização (PAIM \& TEIXEIRA, 1992; PAIM, 1993; TEIXEIRA, PAIM e VILASBÔAS, 2002; CAMPOS, 2003). Assim, diferentes sentidos e significados passaram a ser atribuídos a este princípio (PINHEIRO \& MATTOS, 2001).

A integralidade, como noção polissêmica, pode ser vista como imagemobjetivo ou bandeira de luta, como valor a ser sustentado e defendido nas práticas dos profissionais de saúde, como dimensão das práticas e como atitude diante das formas de organizar o processo de trabalho (MATTOS, 2001). Nessa perspectiva, haveria a possibilidade de esclarecimento e construção de acordos em torno da integralidade no propósito de estabelecer princípios 
organizadores da assistência (CAMARGO JR., 2001). Finalmente, pode-se considerar uma definição ampliada de integralidade a partir de uma taxonomia de necessidades de saúde centrada em quatro conjuntos: a) "boas condições de vida", decorrentes dos fatores do ambiente ou dos lugares ocupados no processo produtivo; b) acesso a toda tecnologia capaz de melhorar e prolongar a vida; c) "vínculos (a)efetivos" entre cada usuário e equipe/profissional de saúde; d) graus crescentes de autonomia no modo de levar a vida (CECÍLIO, 2001).

Constata-se na literatura recente um esforço de reflexão teórica (PINHEIRO \& MATTOS, 2001; MATTOS, 2003), bem como pesquisas empíricas voltadas para o estabelecimento de critérios que contemplem a integralidade da atenção (GIOVANELA et al. , 2002). Assim, os sistemas de serviços de saúde organizados na perspectiva da integralidade da atenção adotariam certas premissas: primazia das ações de promoção e prevenção; garantia de atenção nos três níveis de complexidade da assistência médica; a articulação das ações de promoção, prevenção, cura e recuperação; a abordagem integral do indivíduo e famílias (GIOVANELA et al., 2002). Contudo, caberia certa precaução crítica no sentido de evitar que o redimensionamento conceitual possa resultar no esvaziamento teórico do próprio conceito, pois se a integralidade fosse tudo, perderia o seu potencial heurístico.

Portanto, ao lado do trabalho de investigação teórica e empírica, cabe ampliar o espaço de intervenção voltado para a integralidade, mediante ações desenvolvidas no território e nos serviços de saúde, considerando os aspectos relativos à construção do conhecimento, à formulação de políticas e à redefinição de práticas de saúde (CAMPOS, 2003). Este autor, tomando como referência o princípio constitucional da integralidade da atenção à saúde, examinou certos desafios da sua implementação, analisando a proposta da vigilância da saúde e as mudanças promovidas pelo Ministério da Saúde no âmbito da atenção básica e, especialmente, do Programa de Saúde da Família (PSF). Reconheceu que a construção coletiva e social da prática sanitária decorre de um processo dialético no qual se envolvem instâncias distintas com dimensão política e técnica.

No que tange à dimensão política, podem ser identificadas condições institucionais que possibilitam a construção de consensos, a regulamentação dos dispositivos legais e os mecanismos de financiamento. No caso da dimensão técnica, vincula-se ao conhecimento produzido segundo modelos teóri16 cos e permite orientar a organização e a gestão do sistema de saúde, 
bem como combinar tecnologias oferecidas pela ciência no sentido de atender às necessidades de indivíduos, famílias e comunidades. Tratando-se, portanto, de um fenômeno social e histórico, a trajetória de uma política de saúde não se faz de forma linear:

Tem como ponto de partida uma construção de propósitos de grupos em luta, os quais, a cada momento, influenciam a conformação do sistema. Esse sistema resulta, portanto, dos embates e dos consensos e dissensos que ocorrem entre os grupos. E por ser histórico leva-se sempre em consideração a herança recebida, desde a existência de uma cultura institucional arraigada em unidades de saúde com diferentes conformações e espaços de prática, a refletirem uma determinada concepção histórica. Tudo isso, se não determina, ao menos condiciona os propósitos futuros (CAMPOS, 2003, p. 570).

A partir deste referencial teórico o autor considera que a construção e a implementação da integralidade representam, talvez, o maior desafio da saúde no BRASIL e reconhece a proposta da vigilância da saúde (PAIM \& TEIXEIRA, 1992) como uma via para vencer este desafio. Conclui considerando que o princípio da integralidade implica dotar o sistema de condições relacionadas às diversas fases da atenção à saúde, ao processo de cuidar, ao relacionamento do profissional de saúde com os pacientes. Indivíduos e coletividades devem dispor de um atendimento organizado, diversificado e humano. Esse princípio, portanto, não exclui nenhuma das possibilidades de se promover, prevenir, restaurar a saúde e reabilitar os indivíduos (CAMPOS, 2003, p. 577).

Na perspectiva do planejamento e da gestão, o desenvolvimento da Programação Pactuada Integrada na Atenção Básica (PPI/AB) tem possibilitado, a partir de 2001, a construção e aperfeiçoamento de um instrumento capaz de contribuir com a realização do princípio da integralidade. Nesse sentido, tem-se procurado superar a lógica da programação baseada em série histórica e, utilizando o diagrama da vigilância da saúde (PAIM, 2003d) para fins de avaliação da PPI/AB nos anos de 2001 e 2002, há evidências que apontam um aumento de ações e atividades classificadas como "controle de causas" em comparação com as relativas ao "controle de riscos" e "controle de danos" (SAMPAIO, 2002). A partir deste estudo, pode-se considerar um caminho aberto para a operacionalização da diretriz da integralidade tendo em vista duas das premissas antes mencionadas: a primazia das ações de promoção e prevenção e a articulação das ações de promoção, prevenção, cura e recuperação (GIOVANELA et al., 2002). 


\section{Modelos de atenção}

Modelos de atenção, modelos assistenciais ou modos de intervenção em saúde podem ser definidos como combinações tecnológicas estruturadas em função de problemas de saúde (danos e riscos) que compõem o perfil epidemiológico de uma dada população e que expressam necessidades sociais de saúde historicamente definidas (PAIM, 2003e). Durante a $11^{a}$ Conferência Nacional de Saúde foram discutidos os limites dos modelos de atenção à saúde vigentes no BRASIL e certas experiências em busca da concretização dos princípios e diretrizes do SUS com destaque para as seguintes propostas alternativas: ações programáticas de saúde, acolhimento, vigilância da saúde, cidades saudáveis e promoção da saúde (TEIXEIRA, 2002).

Nesse particular, a intervenção mais ampla realizada no BRASIL visando à modificação do modelo de atenção hegemônico talvez possa ser creditada à reorganização da atenção básica, particularmente por meio do PSF, vinculado à vigilância da saúde. Estas duas propostas alternativas de modelo de atenção têm sido reconhecidas como eixos reestruturantes do SUS (MENDES, 1996; CAMPOS, 2003). Entretanto, cabe ressaltar que muitas das propostas mencionadas são relativamente complementares e convergentes. Assim, o PSF progressivamente tem-se articulado com a vigilância da saúde e com o acolhimento, dispondo, ainda, de uma grande potencialidade de ajudar na construção da viabilidade de ações programáticas, da promoção da saúde e das cidades saudáveis.

No caso da vigilância da saúde, de acordo com a sua proposta original, apóia-se na ação intersetorial e procura reorganizar as práticas de saúde no âmbito local com as seguintes características: a) intervenção sobre problemas de saúde (danos, riscos e/ou determinantes); b) ênfase em problemas que requerem atenção e acompanhamento contínuos; c) utilização do conceito epidemiológico de risco; d) articulação entre ações promocionais, preventivas e curativas; e) atuação intersetorial; f) ações sobre o território; g) intervenção sob a forma de operações (TEIXEIRA et al., 2002). A sua operacionalização tem recorrido aos seguintes passos: microlocalização dos problemas de saúde; intervenção no âmbito populacional pautada no saber epidemiológico; apropriação de informações acerca do território-processo mediante "oficinas de territorialização"; e utilização da geografia crítica e do planejamento e programação local de saúde (TEIXEIRA et al., 2002). Esses passos expressam

18 certas dimensões técnicas visando à integralidade, intersetorialidade, efetividade 
e eqüidade, além de permitirem um diálogo dessa proposta com outras alternativas de modelos de atenção e de organização de serviço.

A partir desse referencial teórico e metodológico, a vigilância da saúde tem sido identificada com os seguintes aspectos:

- Esforço para integrar a atuação do setor saúde nas várias dimensões do processo saúde-doença, especialmente do ponto de vista da sua determinação social.

- Operacionalização dos sistemas de saúde de forma a se respeitar uma visão que se pretende mais totalizadora.

- Eixo reestruturante da maneira de se agir em saúde, buscando enfrentar problemas de saúde de forma integrada por setores que historicamente têm trabalhado de forma dicotomizada.

- Consideração dos determinantes sociais, os riscos ambientais, epidemiológicos e sanitários associados e os desdobramentos, em termos de doença.

- Novo olhar sobre a saúde levando em conta os múltiplos fatores envolvidos na gênese, no desenvolvimento e na perpetuação dos problemas.

- Envolvimento de todos os setores governamentais, vendo o indivíduo e a comunidade como sujeitos do processo.

- Princípio da territorialidade como sua principal premissa.

- Território entendido como o espaço onde vivem grupos sociais, suas relações e condições de subsistência, de trabalho, de renda, de habitação, de acesso à educação e seu saber preexistente, como parte do meio ambiente, possuidor de uma cultura, de concepções sobre saúde e doença, de família, de sociedade etc.

- Definição de problemas e prioridades e obtenção de recursos para atender às necessidades de saúde da comunidade, considerando cada situação específica (CAMPOS, 2003).

Tais formulações permitem uma aproximação da vigilância da saúde às concepções contemporâneas da promoção da saúde (TEIXEIRA, 2002; BRASIL, 2002b; Freitas, 2003; PAIM 2003e), envolvendo instâncias externas ao setor saúde, agendas públicas com diversos atores e participação de "pessoas e comunidades para se alcançar mais saúde e uma melhor qualidade de vida" (CAMPOS, 2003, p. 578). Deste modo, a atualização do diagrama da vigilância (PAIM, 2003d), concebido inicialmente para orientar intervenções sobre o coletivo - ambientes, 
populações e o social como campo estruturado de práticas (DONNÂNGELO, 1983) - e dialogando com os cinco níveis concebidos para a atuação individual da medicina preventiva (HILLEBOE \& LARIMORE, 1967; LEAVELL \& CLARK, 1976), visa a contemplar a promoção da saúde em todo o eixo horizontal do esquema, inclusive no controle dos danos. Essa concepção ampliada abrange medidas inespecíficas (CLARK, 1967), determinantes de saúde que antecedem riscos e danos até o reforço à autonomia e ao empoderamento dos sujeitos (BRASIL, 2002), sejam idosos, deficientes, sadios ou até mesmo doentes.

Para facilitar a compreensão de suas múltiplas dimensões, a proposta de vigilância da saúde tem sido abordada segundo três níveis: a) os determinantes do processo saúde-doença; b) os riscos; c) os danos à saúde (PAIM \& TEIXEIRA, 1992). No caso dos determinantes, são destacadas as proposições do movimento da promoção da saúde a partir da CARTA DE OTTAWA (CZERESNIA \& FREITAS, 2003). Com relação à prevenção dos riscos de adoecimento, enfatizase a busca de novas interfaces entre os programas de saúde e as áreas ligadas à vigilância sanitária, epidemiológica e ambiental. Finalmente, no que se refere à assistência propriamente dita, ressalta-se o vínculo das equipes de saúde às pessoas inseridas no território, além da continuidade da atenção. Desse modo, o PSF e as atribuições das suas equipes "guardam grande coerência e sintonia com os princípios da vigilância da saúde", cuja lógica deveria ultrapassar a atenção básica e "disseminar-se por todos os serviços, desde as unidades básicas até as unidades hospitalares" (CAMPOS, 2003, p. 581).

Portanto, as mudanças no perfil epidemiológico e a transição demográfica observados no BRASIL exigem, simultaneamente, vincular a vigilância da saúde à atenção de média e alta complexidade, sobretudo em serviços de urgência, de emergência e de cuidados intensivos.

\section{Assistência suplementar}

A chamada assistência suplementar envolve um conjunto de modalidades assistenciais cuja característica básica reside no pré-pagamento por parte de empresas e/ou usuários para assegurar a assistência médica quando necessário. Não ocorre, portanto, desembolso direto após a prestação de serviços de saúde. Presentemente, podem ser identificadas quatro modalidades assistenciais compondo o Sistema de Assistência Médica Suplementar (SAMS): planos de autogestão, medicina de grupo, cooperativas médicas e seguro saúde. 
Os planos de autogestão (planos próprios de empresas empregadoras) correspondem a formas de organização da prestação de assistência médica por uma empresa ou sindicato, em serviços próprios ou contratados, para seus filiados e, eventualmente, familiares. A sua origem remonta à década de 1940, com a criação da Caixa de Assistência aos Funcionários do Banco do BRASIL, conhecida como Cassi (BAHIA, 1999).

A medicina de grupo tem início na década de 1960, com a instalação de empresas multinacionais, como a indústria automobilística, deslocando seus empregados da medicina previdenciária e contratando empresas médicas para atender aos diversos segmentos de trabalhadores e dirigentes, geralmente em redes próprias, mediante planos diferenciados que iam do standard ao executivo. Até o início da década de 1980, as grandes empresas do setor industrial ou de serviços que optavam por essa modalidade assistencial eram dispensadas de recolher integralmente sua contribuição previdenciária (convênios médicos), o que revelava um incentivo ou subsídio para a sua consolidação e expansão (OLIVEIRA \& TEIXEIRA, 1978; CORDEIRO, 1984).

As cooperativas médicas partiam de uma crítica ao "empresariamento" da medicina e se desenvolveram ao longo da década de 1970 com as Unimeds. Tinham como característica a filiação voluntária de médicos cuja prestação de serviços era remunerada pela divisão de cotas ao final de um período de trabalho. Seus "produtos" também eram vendidos a empresas industriais e de serviços para atender a funcionários e gerentes e/ou a consumidores individuais no mercado (MELLO, 1977).

A modalidade seguro-saúde aparece, também, naquela mesma década, vinculada a empresas seguradoras e a grandes bancos, e cujo funcionamento inicial era semelhante a um seguro comum mediante reembolso de despesas, ou seja, devolvendo aos seus filiados os valores por eles pagos a médicos, hospitais e laboratórios em episódios de doença. A sua normatização ocorreu a partir da Resolução n ${ }^{\circ} 11$ do Conselho Nacional de Seguros, em 1976 (BAHIA, 2001). Posteriormente, passaram a vender os seus "produtos" a empresas e a consumidores individuais e seus familiares tendo a sua disposição uma rede de serviços credenciados.

Na passagem da década de 1980 para a década seguinte, verificou-se um grande crescimento dessas modalidades assistenciais, especialmente aquela correspondente ao seguro saúde:

A revelação da existência de um grande mercado de planos de saúde, no final da década de oitenta, ocorreu simultaneamente a uma importante 
intensificação da comercialização de planos individuais, a decisiva entrada de grandes seguradoras no ramo saúde, adesão de novos estratos de trabalhadores, particularmente, funcionários públicos da administração direta, autarquias e fundações à assistência médica supletiva e uma inequívoca vinculação da assistência privada ao financiamento da assistência médica suplementar (BAHIA, 2001, p. 332).

Enquanto alguns autores buscam explicar tal expansão, considerando uma suposta negligência dos atores políticos da Reforma Sanitária brasileira que, ao privilegiar a construção do SUS, não atentaram para as transformações em curso no mercado dos serviços de saúde supletiva, outros a atribuíam às insuficiências do SUS, ampliadas artificialmente pela mídia e pela publicidade das empresas de planos de saúde numa conjuntura de expansão da onda neoliberal e de retração de cerca de um terço dos gastos federais com a saúde (MENDES, 1993). Nesse contexto, surgiam queixas do tipo "só fica no SUS quem não tem recursos para comprar um plano" ou racionalizações como "se quem pode pagar tem plano de saúde, dá para o SUS cuidar melhor dos pobres", supondo uma clivagem entre as respectivas redes assistenciais (BAHIA, 2001).

Enquanto se travava esse debate ideológico, algumas iniciativas governamentais permitiram o reconhecimento do seguro saúde como um "plano de saúde" e não como "prêmio", pago ao usuário após o sinistro da doença. Outras, originárias da Receita Federal, reconheceram os gastos com tais modalidades como despesas de assistência médica, incluídas na dedução de Imposto de Renda de Pessoas Físicas e Jurídicas, configurando uma renúncia fiscal que favorecia sua expansão mediante tal subsídio. Ocorria, na realidade, uma estrutural e extensa interface público-privada, cabendo "questionar as relações de autonomia e dependência das empresas de planos de saúde com o SUS e conseqüentemente alguns pressupostos que orientaram o processo de regulação governamental da assistência médica suplementar" (BAHIA, 2001 , p. 330).

Até o final da década de 1990 não havia, praticamente, fiscalização para tais modalidades, possibilitando uma grande quantidade de abusos, apesar das denúncias de usuários e médicos, bem como das tentativas de regulamentação pelo Conselho Federal de Medicina (CFM). Basta lembrar que as cooperativas médicas eram "controladas" pelo Ministério da Agricultura e as empresas de seguro saúde pelo Ministério da Fazenda, por intermédio da

22 Superintendência de Seguros Privados (SUSEP). 
A aprovação da Lei dos Planos de Saúde em 1998 (Lei n 9.656), depois de uma longa, tortuosa e polêmica tramitação no Congresso Nacional, representou uma tentativa de regular o setor mediante uma série de medidas provisórias e portarias, culminando com a criação da Agência Nacional de Saúde Suplementar (ANS). Trata-se de uma autarquia especial vinculada ao Ministério da Saúde, instituída pela Lei n 9.961, de 28 de janeiro de 2000, com as seguintes finalidades: regular, normatizar, controlar e fiscalizar as atividades de saúde suplementar prestadas pelas operadoras de planos e seguros privados de saúde (BRASIL, 2003a).

Esta agência, em parte resultante de disputas entre as burocracias do Ministério da Fazenda e da Saúde (BAHIA, 2001) e respectivos titulares, tem buscado acompanhar o funcionamento desse mercado de planos de saúde e organizar um sistema de informações que permita o exercício da regulação. Em 2001, atuavam 2.708 operadoras, das quais 36,9\% correspondiam à medicina de grupo, 16\% à autogestão, 14,4\% à cooperativa médica e 1,6\% ao seguro-saúde. Na tabela 1, apresenta-se a cobertura da assistência médica supletiva por regiões, bem como a distribuição percentual de usuários e de operadoras. Constata-se, assim, o peso do SAMS na região Sudeste, onde se concentram $60,5 \%$ de usuários e $71 \%$ das operadoras, alcançando uma cobertura de $33,0 \%$, e a sua menor expressão no Nordeste, onde se localizam $2,2 \%$ dos usuários e $3,1 \%$ das operadoras.

\section{Tabela 1}

Distribuição percentual de usuários e operadoras ativas por região, Brasil, 2002.

\begin{tabular}{lccc}
\hline Região & Usuários (\%) & Operadoras (\%) & Cobertura(\%) \\
\hline Centro-Oeste & 4,4 & 6,4 & 12,7 \\
Norte & 11,3 & 12,9 & 8,0 \\
Nordeste & 2,2 & 3,1 & 5,8 \\
Sudeste & 71,0 & 60,5 & 33,0 \\
Sul & 11,0 & 17,1 & 14,7 \\
\hline
\end{tabular}

Fonte: Diretoria de Desenvolvimento Setorial da ANS 
Apesar dos esforços visando a conhecer e regular este mercado, os planos de saúde continuam sendo alvo de críticas dos consumidores e suas organizações, da mídia, dos médicos e hospitais, crescendo as disputas judiciais entre as operadoras e a ANS. Assim, no ano de 2003 tais conflitos chegaram a motivar a instalação de uma CPI sobre o tema. Presentemente, existem 35.315.942 beneficiários da assistência suplementar, dos quais 64,1\% ainda dispõem de contratos anteriores à Lei n ${ }^{0} 9.656 / 98$, com potenciais problemas de exclusão de coberturas assistenciais, especialmente os $25,7 \%$ de usuários de planos individuais antigos (MONTONE, 2003).

\section{Eqüidade e reforma do sistema e serviços de saúde}

As reformas setoriais ${ }^{5}$ empreendidas na América Latina e no Caribe ao longo da década de 1990 (PEGO \& ALMEIDA, 2002; HERNANDEZ, 2002; LABRA, 2002; BELMARTINO, 2002; MITJAVILA et al. , 2002), sob o patrocínio e direção de organismos internacionais a exemplo do Banco Mundial e Banco Interamericano de Desenvolvimento, vinculadas aos pacotes de ajuste macroeconômico, apresentam alguns elementos comuns: modificação de regras de financiamento, participação de agentes públicos e privados, embora com maior presença dos últimos, e separação das funções de financiamento, provisão e regulação (ALMEIDA, 2002).

No Brasil, todavia, a agenda de reformas desses organismos internacionais encontrou certa resistência ou oposição aberta, por contrariar o caráter universal das políticas de saúde projetadas pelo movimento da Reforma Sanitária desde a década de 1970, além de ameaçar os preceitos constitucionais e a legislação sanitária. Contudo, muitas das incursões desses organismos internacionais voltadas para a descentralização e focalização das ações de saúde e para a segmentação do sistema de serviços de saúde encontraram certos espaços de viabilidade, implicando a implantação contraditória do SUS (PAIM, 2002).

Presentemente, o sistema de serviços de saúde do Brasil é composto por três subsistemas: o SUS, que tem natureza pública e é integrado por serviços estatais dos municípios, estados e União, além dos contratados (filantrópicos e lucrativos); o SAMS, com caráter privado e dispondo de diversas modalidades assistenciais que utilizam, em grande parte, a mesma rede de serviços privados, filantrópicos e universitários vinculados ao SUS; e o Sistema de 
Desembolso Direto (SDD), talvez mais uma forma de pagamento do que uma organização, que se relaciona com hospitais e serviços privados com alta tecnologia e médicos com autonomia preservada (MENDES, 1996).

O SUS é destinado a toda a população e corresponde à única possibilidade de atenção à saúde para mais de 140 milhões de brasileiros com baixos rendimentos, empregos precários ou desempregados. OSAMS tem registrados 35 milhões de BRASILeiros vinculados a planos coletivos de grandes empresas e a planos individuais adquiridos no mercado pela classe média-alta e alta que, em determinadas situações, também recorrem ao SUS. Já o SDD é utilizado por pessoas de alta renda para serviços eventualmente não cobertos pelos planos de saúde ou para realização de consultas e exames com profissionais de prestígio não-vinculados ao SUS e ao SAMS. Tanto o SAMS quanto o SDD são subsidiados pelo governo federal mediante renúncia fiscal via abatimentos de despesas médicas de pessoas físicas e jurídicas no imposto de renda.

A atenção à saúde, como expressão do cuidado às pessoas - individualmente e coletivamente -, sofre as influências desses arranjos de organização, gestão e financiamento, além da disponibilidade da infra-estrutura de recursos. Esses recursos apresentam uma distribuição desigual entre estratos sociais e entre regiões, estados e municípios, áreas urbanas e rurais e, nas cidades, entre periferia e centro, conforme será apresentado mais adiante. Daí a eqüidade constituir-se, numa sociedade extremamente desigual como a BRASILeira, em outro grande desafio da atenção à saúde e do SUS.

Diversas iniciativas têm procurado reduzir a iniqüidade na distribuição de recursos do próprio SUS, seja combinando critérios técnicos da alocação para uma "Municipalização Solidária" (LIMA et al., 2002), seja favorecendo o desenvolvimento de metodologias para a análise das desigualdades em saúde (SZWARCWALD et al., 2002) e a realização de investigações em política e economia da saúde (JUNQUEIRA et al. , 2002; PORTO, 2002) que auxiliem a formulação de políticas de saúde orientadas para a eqüidade. Outros receiam "que as fórmulas adotadas tornem-se complexas e de difícil compreensão, podendo não trazer ganhos reais no âmbito da eqüidade" (CAZELLI et al., 2002). Embora algumas evidências apontem para uma discreta redução das desigualdades na distribuição de recursos do SUS (ALMEIDA et al., 2002; NEGRI, 2002; BRASIL, 2002a), ainda se faz necessária uma redistribuição geográfica de recursos financeiros em favor das regiões Norte e Nordeste (PORTO, 2002). 


\section{Acesso e qualidade das ações e serviços}

As questões referentes ao acesso e à qualidade das ações e dos serviços de saúde expressam os limites dos modelos de atenção vigentes no sistema de saúde brasileiro. Ainda que guardem íntimas relações com os problemas referentes à infra-estrutura, ao financiamento, à organização e à gestão, revelam toda a crueza do modelo de desatenção hegemônico. Assim, o acesso e a qualidade das ações e serviços são condicionados pela distribuição desigual da infra-estrutura do sistema de serviços de saúde e pelos demais elementos que estruturam um sistema de serviços de saúde acima mencionados.

Este modelo de desatenção tem a sua expressão fenomênica em um caleidoscópio de maus tratos e de desrespeito ao direito à saúde: filas vergonhosas para a assistência médica desde a madrugada ou o dia anterior; descortesia nos guichês dos SAMEs de hospitais e unidades de saúde; desatenção de seguranças, recepcionistas, auxiliares e profissionais de saúde diante de pessoas fragilizadas pelas doenças; corredores superlotados de macas nos serviços de pronto-socorro; disputas por fichas para exames complementares tantas vezes desnecessários; longas esperas em bancos desconfortáveis para a realização de uma consulta ou exame; via crucis do paciente entre diferentes unidades de saúde, médicos e especialistas; "cortejo fúnebre" de vans e ambulâncias em frente aos hospitais públicos para transferência de doentes e familiares de outros municípios; pagamento por consulta e exames em clínicas particulares de periferias por preços "módicos" ou "por fora" nos serviços do SUS; mercantilização da doença e do sofrimento por planos de saúde e prestadores privados; discriminação dos usuários do SUS em clínicas e laboratórios contratados ou hospitais universitários e filantrópicos por meio de "dupla entrada" e do confinamento em instalações de segunda categoria.

Este "rosário de problemas", desfiado tantas vezes de forma espetacular pela mídia, é muito conhecido pelos usuários de serviços de saúde no país. As exceções de praxe não conseguem escamotear as iniqüidades que perseguem o sistema de saúde brasileiro. E a Reforma Sanitária, cuja generosidade do projeto original abraçava o propósito de superar a crise sanitária, deparou-se nos últimos quinze anos com os obstáculos contrapostos pelas políticas econômicas neoliberais, pelo aumento das desigualdades sociais e pela realização de uma cidadania restrita, não obstante a formalização de direitos garantidos pela Constituição e pelas leis do país. 
Pesquisas de opinião realizadas em 1998 e 2002 apontam para a percepção de que a qualidade do atendimento prestado pelo SUS estava "piorando", embora o percentual dessa resposta tivesse reduzido de 32\% para $14 \%$. Entre os que achavam que a qualidade dos serviços "continua igual" constata-se um aumento de 18\%, em 1998, para 48\%, em 2002. O problema mais perceptível continua sendo as filas de espera para a marcação de consultas (BRASIL, 2003b). Assim, o acesso universal e igualitário às ações e serviços de saúde representa muito mais uma imagem-objetivo para os que investem em um sistema de saúde digno e de qualidade do que, propriamente, uma evidência.

As variações sociais no acesso e no consumo de serviços de saúde também podem indicar desigualdades na qualidade da atenção. Os mais pobres esperam mais que o dobro do tempo para ser atendidos (82,52 minutos em média), enquanto o tempo de espera dos que dispõem de seguro saúde é cerca de metade do tempo que aguardam as pessoas que não o possuem (TRAVASSOS et al., 2000).

Diante dos problemas acumulados na infra-estrutura, financiamento, organização e gestão do sistema de saúde brasileiro, as questões referentes à qualidade da atenção à saúde foram, de certo modo, secundarizadas como política de governo. Esforços esparsos podem ser identificados em projetos de humanização da atenção, em práticas de acolhimento e na experimentação de novos modelos de atenção, seja para a melhoria do acesso e da qualidade das ações e serviços, seja para alcançar a integralidade e a eqüidade na atenção (BRASIL, 2002a). Tais iniciativas, contudo, ainda não foram suficientes para a mudança do modelo de desatenção vigente. Mesmo nos planos de saúde privados os usuários representam o segmento mais vulnerável: não têm instrumentos para coibir os abusos, têm baixa capacidade de negociação e pouco podem "influir nas questões referentes à melhoria de qualidade do atendimento de saúde" (MONTONE, 2001, p. 29).

Ainda que se observe uma relativa escassez de proposições, estudos e pesquisas sobre qualidade da atenção à saúde no BRASIL (SALA, 1993; NOGUEIRA, 1994; UCHIMURA \& BOSI, 2002), algumas iniciativas esparsas podem ser reforçadas no sentido de obter maior ressonância dessa temática na agenda política de saúde, a exemplo do que se tem construído em relação à integralidade e às desigualdades em saúde. Nesse particular, podem ser mencionadas" conferências de consenso", voltadas para discussão e obtenção de pautas diagnósticas, terapêuticas e preventivas para determinadas 
doenças e agravos, e a adoção de "protocolos assistenciais" para o desenvolvimento de melhores práticas nos processos de trabalho em saúde.

Não obstante certas críticas a tais tecnologias em virtude da possibilidade de reforçarem políticas voltadas para o managed care, caberia recuperar o seu potencial de agregar qualidade às práticas de saúde como dispositivo racionalizador, pedagógico, avaliador e indutor de pesquisa na atenção à saúde. As últimas Normas Operacionais de Assistência à Saúde (NOAS, 200 e 2002), além de definirem conteúdos para a atenção básica e redefinirem procedimentos de média e alta complexidade, propõem a criação de protocolos para a assistência médica (VIANA et al., 2002). Do mesmo modo, as iniciativas voltadas para a humanização da assistência ao parto e para o apoio técnico-pedagógico às equipes de saúde da família devem ser avaliadas no sentido de expandi-las para outros espaços de práticas do SUS e para a regulação da assistência suplementar. Portanto, além da avaliação técnico-científica, centrada em padrões estabelecidos pela comunidade científica e nos elementos do processo de trabalho em saúde, cabe incorporar a visão dos usuários e de outros atores sociais que constituam "grupos de qualidade" no sentido de aprimorar o atendimento e elevar a satisfação dos cidadãos (SERAPIONI, 1999).

\section{Políticas de saúde nos anos 1990}

Apesar dos constrangimentos impostos ao desenvolvimento das políticas de saúde no Brasil durante a última década século 20, o País conseguiu manter os instrumentos legais que asseguram o direito à saúde, particularmente no que se refere à universalização da atenção à saúde (ALMEIDA et al. , 2002). Ao contrário de outras políticas sociais que, diante das restrições impostas ao gasto público, apresentaram um caráter focalizado e seletivo, a política de saúde manteve a sua abrangência "em razão da capacidade de intermediação de interesses na arena setorial" (COSTA, 2002, p. 13). As contradições do processo, entretanto, aprofundaram a segmentação do sistema de saúde brasileiro (NORONHA \& SOARES, 2001).

A implantação do SUS concomitantemente à expansão da assistência médica suplementar expôs a fragilidade e a insuficiência de instâncias e ferramentas de gestão, seja a atuação da ANS, seja a utilização da PPI (Programação Pactuada Integrada) que não leva em conta o mercado de usuários do seguro-saúde, nem a oferta de prestadores de serviços de saúde às operadoras de saúde su-

28 plementar. A dissociação normativa e de planejamento fortalece a possibilidade 
de se segmentar o consumo de serviços de saúde em múltiplos mercados internos de saúde, com competição regulada pela ANS e pela SAS, até agora, seguindo critérios e diretrizes independentes entre as duas instituições (CORDEIRO, 2001, p. 323).

Na ausência de políticas que se contraponham a tal tendência é possível, segundo este autor, identificar cenários caracterizados pela fragmentação e segmentação entre diversas clientelas de consumidores de serviços de saúde. Nesse particular, a assistência médica supletiva e especialmente a participação do seguro privado no sistema de saúde brasileiro "atua no sentido de acentuar as desigualdades no consumo de serviços de saúde" (TRAVASSOS et al., 2000, p. 144).

Mesmo assim, a política de saúde na década de 1990 foi marcada pela construção do SUS; descentralização das ações, serviços e da gestão; melhorias na gerência e na capacidade de regulação; redução das desigualdades na distribuição dos tetos financeiros da assistência à saúde entre as regiões; ampliação do acesso à assistência; e aumento da cobertura de imunizações das crianças (NEGRI, 2002). Na passagem da década de noventa para o século XXI foram, ainda, produzidos fatos político-institucionais com conseqüências não desprezíveis para as políticas de saúde:

- Expansão do PSF para uma cobertura de aproximadamente 50 milhões de brasileiros;

- Criação da Agência Nacional de Vigilância Sanitária (ANVISA).

- Aprovação da Lei dos Medicamentos Genéricos (Lei n 9.787/99).

- Implantação do Sistema de Informação do Orçamento Público em Saúde (SIOPS).

- Adoção do Cartão SUS em alguns municípios.

- Implementação do Programa de Interiorização do Trabalho em Saúde (PITS).

- Atualização da Relação Nacional de Medicamentos Essenciais (RENAME).

- Estabelecimento da Emenda Constitucional (EC-29).

- Realização da $11^{a}$ Conferência Nacional de Saúde em 2000 e da I Conferência Nacional de Vigilância Sanitária (PAIM, 2003c).

Ainda que tais iniciativas não tenham alterado significativamente a atenção à saúde no Brasil, representam passos importantes para a reestruturação do sistema de serviços de saúde no sentido da melhoria da assistência. 


\section{Diferenças regionais e particularidades}

Os indicadores de oferta podem contemplar a capacidade instalada (ambulatorial e hospitalar) e recursos humanos (profissionais de saúde). No BRASIL, persistem desigualdades na infra-estrutura da atenção à saúde entre as diferentes regiões, conforme se pode observar na tabela 2 .

Enquanto o país possuía em média 3,0 leitos disponíveis para o SUS, 2, 1 privados e 1,4 médico por mil habitantes, a região Norte apresenta os seguintes indicadores: 2,1 leitos SUS, 1,2 leito privado e 0,6 médico por mil habitantes, correspondendo a cerca da metade dos valores exibidos pela região Sudeste. No caso dos odontólogos, as regiões Sudeste e Centro-Oeste exibem valores quatro vezes superiores ao Norte e duas vezes ao Nordeste. Já a distribuição dos enfermeiros se faz com menos disparidades, de modo que a região Nordeste dispõe de valores semelhantes ao Sul, enquanto as regiões Norte e CentroOeste possuem indicadores superiores à média nacional (NUNES et al., 2001).

Embora a disponibilidade de três leitos vinculados ao SUS por 1.000 habitantes esteja próxima ao valor médio observado nas Américas (2,9 leitos por 1.000 habitantes) e abaixo da média descrita para a América do Norte (4 leitos por 1.000 habitantes), verifica-se uma grande variação entre os estados brasileiros, ou seja, de 1,8 a 4,5 leitos por 1.000 habitantes (DUARTE et al., 2002). Já em relação ao número de unidades ambulatoriais por 10 mil habitantes, constata-se uma distribuição menos assimétrica (NUNES et al., 2001).

Estas desigualdades na oferta de recursos de saúde reproduzem-se no consumo diferenciado de serviços de saúde. Ainda que o consumo seja função de necessidades e de comportamentos de indivíduos, é também condicionado pela oferta de serviços e recursos disponíveis para a população bem como pelas formas de financiamento (TRAVASSOS et al, 2000; NERY \& SOARES, 2002).

Cinco indicadores de acesso/utilização dos serviços de saúde, com periodicidade anual, têm sido utilizados no Brasil: internações hospitalares SUS/ 100 habitantes, consultas médicas SUS/habitante, cobertura vacinal DPT (3a dose), cobertura vacinal sarampo $\left(1^{a}\right.$ dose $)$ e cobertura vacinal poliomielite ( $3^{a}$ dose). Assim, em 1999, o País produziu 7,19 internações SUS por 100 habitantes, 2,19 consultas/habitante e coberturas vacinais de 94,6\% (DPT), 99,5\% (AS) e 99,1\% (AP) (NUNES et al. , 2001).

A análise das desigualdades geográficas e sociais na utilização de serviços de saúde indica uma taxa geral de utilização de 19,49 por 100 mil habitantes para a região Sudeste e 13,01 na região Nordeste em 1989, antes da 
implantação do SUS. Com a implementação do SUS ocorreu uma redução dessa disparidade, pois em 1996/1997 as diferenças entre tais regiões deixaram de ser estatisticamente significantes (TRAVASSOS et al., 2000).

Ao se analisarem essas taxas de utilização para os grupos com e sem morbidade, constatam-se diferenças significativas desfavoráveis ao Nordeste. Quando se introduz na análise a renda, como proxy das condições sociais, verifica-se uma tendência de diminuição do acesso aos serviços de saúde, penalizando os mais pobres de ambas as regiões. $O$ percentual de busca de atendimento nos últimos trinta dias por quintil de renda cresce progressivamente de $47,2 \%$ no primeiro para $68,9 \%$ no quinto quintil (REIS, 2002).

Pesquisa de opinião de caráter nacional, realizada pelo lbope em 1998, revelou que $58 \%$ dos 2.000 entrevistados utilizavam o SUS de forma exclusiva ou freqüente, enquanto $22 \%$ o faziam de forma eventual. Apenas $15 \%$ declararam-se não usuários do SUS, ou por consumirem exclusivamente serviços particulares ou por não utilizarem serviços de saúde. Neste levantamento, as diferenças regionais também foram reveladas: enquanto no Nordeste $51 \%$ da população usava o SUS de modo exclusivo, no Sul o indicador correspondia a $32 \%$ e no Sudeste a $33 \%$. O SUS também era mais utilizado de forma exclusiva na maioria dos municípios de pequeno (44\%) e de médio porte (41\%) e na população com menor escolaridade (70\%) ou com renda de até dois salários mínimos (76\%) (REIS, 2002).

\section{Tabela 2}

Leitos hospitalares* segundo tipos, leitos SUS*, unidades ambulatoriais**, médicos*, odontólogos* e enfermeiros*, segundo regiões, Brasil, 1998.

\begin{tabular}{lccccccc}
\hline Região & $\begin{array}{c}\text { Leitos } \\
\text { Públicos }\end{array}$ & $\begin{array}{c}\text { Leitos } \\
\text { Privados }\end{array}$ & Leitos SUS & $\begin{array}{c}\text { Unidades } \\
\text { ambulatoriais }\end{array}$ & Médicos & Odontólogos & Enfermeiros \\
\hline Norte & 1,0 & 1,2 & 2,1 & 3,74 & 0,6 & 0,21 & 0,54 \\
Nordeste & 1,1 & 1,7 & 2,8 & 3,74 & 0,8 & 0,43 & 0,34 \\
Sudeste & 0,8 & 2,3 & 3,2 & 2,48 & 2,1 & 0,89 & 0,42 \\
Sul & 0,7 & 2,6 & 3,2 & 4,92 & 1,4 & 0,73 & 0,34 \\
Centro-Oeste & 1,0 & 2,5 & 3,5 & 4,02 & 1,3 & 0,86 & 0,63 \\
Brasil & 0,9 & 2,1 & 3,0 & 3,40 & 1,4 & 0,69 & 0,41 \\
\hline
\end{tabular}

*Por mil habitantes (unidades ambulatoriais, número de odontólogos e de enfermeiros correspondem ao ano de 1999).

Fonte: MS, Ripsa (MELLO JORGE et al., 2001); PNAD, 1999 (NUNES et al., 2001). 
Já em 2002, os "não-usuários" do SUS decresceram para 8,7\%, o mesmo ocorrendo com os "usuários exclusivos", que caíram para 28,6\%, sugerindo o uso de combinação com outras modalidades assistenciais. Persiste a tendência de os usuários do SUS avaliarem de forma mais positiva o SUS do que os não-usuários. Constata-se, ainda, entre os entrevistados, uma satisfação maior na medida em que cresce a complexidade dos serviços utilizados (BRASIL, 2003b).

No caso da cobertura hospitalar, verifica-se que a região Sudeste exibe uma menor taxa de internação pelo SUS (tabela 3). Portanto, a redução de 22,2\% de internações pelo SUS observada entre 1995 e 1999 (NUNES et al., 2001) poderia ser interpretada como decorrente de medida administrativa para contenção de gastos assistenciais do setor público, eventualmente compensada pelos gastos particulares via planos de saúde, ou como indício de mudança do modelo de atenção na medida em que se ampliam a assistência ambulatorial e a atenção básica, especialmente com a expansão do PSF.

No que diz respeito às consultas médicas, constata-se também no quadro 3 que o indicador utilizado apresenta um gradiente crescente, acompanhando o desenvolvimento das regiões, embora a região Sul apresente valor inferior àquele verificado no Centro-Oeste. Entre 1995 e 1999, o número de consultas médicas por habitante cresceu em todas as regiões, de modo que o valor médio nacional passou de 1,91 para 2,19 (NUNES et al., 2001). Esta tendência pode estar expressando a política de prioridade para a atenção básica e a tentativa de reversão do modelo assistencial "hospitalocêntrico".

A variável renda também influi no acompanhamento médico. Embora a existência de problema crônico de saúde (15,4\% da população) não varie tanto entre os estratos de renda (12,3\% entre os mais pobres e 16,6\% entre os mais ricos), as diferenças se revelam na assistência. No primeiro quintil (mais pobres) $54,7 \%$ dos indivíduos são acompanhados por médicos, enquanto no quinto quintil (mais ricos) 82,9\% dos portadores de doenças crônicas dispõem de acompanhamento médico. Estes últimos também realizaram exames periódicos com maior freqüência (REIS, 2002). 


\section{Tabela 3}

Número de internações hospitalares SUS/100 habitantes e número de consultas médicas SUS/habitante segundo regiões, Brasil, 2000.

\begin{tabular}{lcc}
\hline Região & Internações SUS & Consultas SUS* \\
\hline Norte & 7,37 & 1,48 \\
Nordeste & 7,70 & 1,95 \\
Sudeste & 6,41 & 2,55 \\
Sul & 8,02 & 2,00 \\
Centro-Oeste & 7,88 & 2,03 \\
Brasil & 7,19 & 2,19 \\
\hline
\end{tabular}

*Dados de 1999.

Fonte: Ministério da Saúde/Datasus (NUNES et al., 2001).

Outros motivos de procura de serviços de saúde também guardam uma relação com a renda. Enquanto os de menor renda apresentavam um indicador de $7,0 \%$, os de maior renda praticamente correspondiam ao dobro $(13,5 \%)$. Dois serviços revelam muito bem tais discrepâncias: checkup, que variou entre $13,9 \%$ e $28,5 \%$, e odontologia, cuja procura passou de 1,8\% no primeiro quintil para 12,6\% no quinto quintil (REIS, 2002).

Em outro estudo sobre desigualdades na atenção à saúde, foram utilizadas, além do número de médicos e de leitos hospitalares por mil habitantes, a razão de leitos de UTI vinculados ao SUS, a percentagem de municípios que atingiram a meta de cobertura da vacina tríplice (DPT) e a proporção de pacientes atendidos por terapia renal substitutiva (TRS). Assim a cobertura de DPT poderia indicar a situação dos procedimentos de baixa complexidade, enquanto a TRS representaria um indicador de cobertura de procedimentos de alta complexidade, envolvendo hemodiálise e transplante renal (DUARTE et al., 2002).

No caso dos leitos de UTI disponíveis para o SUS, a média nacional era 6,8 leitos por 100.000 habitantes enquanto a maioria dos estados da região Norte e Nordeste apresentavam valores inferiores ao nacional, com destaque negativo para Rondônia $(0,5)$ e Bahia $(1,3)$. Quanto à cobertura de DPT, cujo cálculo foi restrito à vacinação de rotina no sentido de refletir o acesso à atenção básica, as medianas desse indicador nas regiões Sul e Sudeste superaram o valor nacional, enquanto os valores médios regionais e estaduais são comparados àqueles observados nos países desenvolvidos. Finalmente, no que diz respeito ao indicador de cobertura de procedimentos de alta complexidade 
(TRS), verificou-se no ano 2000 uma taxa de 32,0 por 100.000 habitantes para o país, ainda que a utilização esperada, segundo o Ministério da Saúde, devesse ser de 40,0 por 100.000. As taxas de todos os estados das regiões Sul e Sudeste estão próximas ou acima da média nacional, porém as demais regiões apresentam valores muito baixos desse indicador, a ponto de o Sudeste atender cinco vezes mais pacientes do que o Norte (DUARTE et al., 2002).

Essas disparidades regionais e particularidades examinadas no presente tópico, além de apontarem possíveis relações entre as desigualdades de saúde e as iniqüidades sociais (NERY \& SOARES, 2002), revelam a multiplicidade de fatores que interferem no padrão de consumo de serviços de saúde e o imbricamento perverso entre eles no BRASIL, resultando em um quadro de desigualdades cumulativas que evidenciam o quão distante encontra-se o sistema de saúde do país dos princípios igualitários enunciados na sua formulação (TRAVASSOS et al., 2000, p. 143).

\section{Uma visão crítica das políticas em curso}

As políticas em curso centram-se nas diretrizes e metas estabelecidas pelo Ministério da Saúde para 2003, tais como:

- Melhoria do acesso, da qualidade e da humanização da atenção à saúde: ampliação do acesso da população aos serviços de saúde.

- Combate à fome: atendimento às carências nutricionais.

- Atendimento a grupos com necessidade de atenção especial: atenção à saúde da criança, da mulher e do idoso. Prevenção, controle e assistência aos portadores de DST e Aids.

- Controle da dengue e outras doenças endêmicas e epidêmicas. Combate a endemias e doenças transmitidas por vetores (prioridade para a dengue e a malária).

- Acesso a medicamento: garantia de acesso a estes produtos.

- Qualificação dos trabalhadores do SUS. Qualificação dos trabalhadores da saúde (BRASIL, 2003d).

Em consonância com tais diretrizes, podem ser destacadas as seguintes ações realizadas em 2003: expansão da atenção básica, com ampliação de recursos e de equipes de saúde da família; convocação da $12^{a}$ Conferência Nacional de 
Saúde em caráter extraordinário; ampliação de credenciamento para leitos de UTI; apoio financeiro aos hospitais universitários redefinindo suas relações com o SUS; reajuste nos repasses para consultas especializadas (196\%) em hospitais públicos em estados e municípios de gestão plena; avanço na política de medicamentos incluindo apoio aos laboratórios oficiais, isenção de ICMS para medicamentos de alto custo, reforço aos genéricos, 18 novas resoluções da Anvisa e condenação de antigripais e hepatoprotetores; capacitação de profissionais de saúde e seleção de médicos para o PIT (BRASIL, 2003d).

Nos primeiros seis meses "os esforços concentraram-se, em especial, na adequação da gestão do ministério às diretrizes do governo e na implementação de medidas essenciais à promoção da eqüidade" (BRASIL, 2003d, p. 1). Muita energia institucional foi gasta para superar a fragmentação das ações e implantar a nova organização do ministério. Mereceram destaques pelos gestores federais a criação da câmara de regulação do mercado de medicamentos (MP $\mathrm{n}^{\circ}$ 123) e o processo participativo para a construção no Plano Plurianual 2004-2007, envolvendo os trabalhadores, colegiados e fóruns do ministério, inclusive as instâncias de controle social, como o Conselho Nacional de Saúde (BRASIL, 2003).

Assim, a tentativa de reverter o modelo de desatenção vigente a partir de projetos que priorizam o acolhimento e a humanização, assegurando direitos dos usuários do SUS, pode ser considerada um "marcador" dessa vontade política do Ministério da Saúde. Do mesmo modo, o reforço à atenção básica com expansão do PSF e da ampliação dos recursos do PAB, inclusive para municípios com mais de 100.000 habitantes, articulado a maiores repasses para atenção especializada em hospitais públicos, propostas de expansão dos CAPS (Centro de Atendimento Psicossocial) e dos serviços de urgência e emergência (resgate), ampliação de credenciamentos para UTI e apoio aos hospitais universitários federais, sugere uma concepção integral de sistema de serviços de saúde.

Os fatos acima mencionados sinalizam para redefinições relevantes na política de saúde, apesar da falta de indicações de como enfrentar a segmentação do sistema de saúde brasileiro no sentido de melhorar o acesso, a eqüidade e a qualidade da atenção à saúde. Embora a limitação de recursos orçamentários não permita examinar a suficiência de muitas dessas medidas em relação às necessidades insatisfeitas acumuladas, elas apontam certa direcionalidade da política. Nesse sentido, a redefinição do modelo de atenção e a busca de acesso universal e integral aos serviços de saúde 
poderão ser concretizadas mediante a reorganização da atenção básica articulada à atenção especializada, o desenvolvimento da estratégia da saúde da família e a adoção, em ampla escala, da proposta de vigilância da saúde.

Presentemente, os artifícios efetuados na elaboração dos orçamentos e no contingenciamento de recursos constrangem o financiamento público da saúde, enquanto as vitórias das operadoras de planos de saúde junto ao Judiciário ameaçam, ainda mais, o acesso e a qualidade da atenção à saúde. Apesar deste conjunto de problemas, não se pode reduzir a relevância do arcabouço legal já disponível nem negligenciar os avanços e conquistas obtidos, mesmo diante de conjunturas e forças adversas.

Cabe lembrar que a Constituição reconhece a saúde como direito de todos e dever do Estado. Conseqüentemente, a saúde não é apenas questão de governo ou do Poder Executivo. Como questão de Estado, é obrigação do poder Executivo, Legislativo e Judiciário assegurar este direito, propiciando os meios para a sua concretização. Portanto, todas as ações e omissões dos três poderes constituem, também, políticas de saúde, cabendo à sociedade analisar e acompanhar este processo para influir na sua condução, sob pena de amargar suas conseqüências mais nefastas.

\section{Esboço de proposição de alternativas políticas para atenção à saúde}

A implantação do SUS em período tão difícil (crise fiscal, políticas de ajuste macroeconômico e reforma do Estado), respeitando o federalismo brasileiro desenhado pela Constituição de 1988, convivendo com o modelo médico-assistencial privatista e interagindo construtivamente com a cultura política e interesses partidários, impõe um elenco de desafios postos para a atenção à saúde no Brasil.

Desde a realização da $11^{a}$ Conferência Nacional de Saúde, realizada no ano 2000, o Conselho Nacional de Saúde tem formulado proposições e estratégias com vistas à integralidade e à melhoria do acesso e da qualidade das ações e serviços de saúde, reunidas em 11 compromissos apresentados aos candidatos das eleições de 2002, a saber:

- Construção da eqüidade.

- Adequação da oferta de serviços de saúde às necessidades e prioridades da população. 
- Explicitar responsabilidades e atribuições na definição das necessidades da população por serviços do SUS.

- Implementação do caráter de porta de entrada dos serviços de atenção básica à saúde.

- Reordenamento organizacional e programático dos serviços de média complexidade, segundo a racionalidade do SUS.

- Realização de investimentos estratégicos e utilização da capacidade instalada.

- Reestruturação dos programas e projetos federais especiais.

- Planejamento da oferta e da remuneração dos serviços.

- Ampliação do financiamento e reestruturação do Orçamento.

- Reorientação da política de recursos humanos do SUS.

- Construção do SUS como expressão da Saúde Pública e sua responsabilidade regulatória (Conselho Nacional de Saúde, 2002: 297).

Nessa perspectiva foi também proposto o fortalecimento de um sistema de vigilância em saúde, com articulação entre centros de epidemiologia e de vigilância sanitária, e reestruturação do sistema de ciência e tecnologia da pesquisa, desenvolvimento e difusão de inovações em saúde, orientado por uma agenda de prioridades (CEBES-ABRASCO, 2002).

Assim, a complexidade do sistema de saúde brasileiro (BRASIL, 2003c) composto por vários mercados que atravessam diferentes prestadores e, muitas vezes, competem mediante remunerações distintas por serviços de um mesmo hospital - exige a coleta sistemática de dados e a realização de investigações para o acompanhamento e a avaliação das políticas de saúde. A atenção à saúde, nesse contexto, torna-se um objeto privilegiado de pesquisa e, como tal, passível de ser incluído na agenda das políticas científicas e tecnológicas em saúde.

Um passo preliminar para a construção desta agenda consiste em identificar problemas do estado de saúde da população, que compõem o perfil epidemiológico e problemas relacionados à atenção à saúde, que envolvem o cuidado, as práticas, os serviços, as instituições e os sistemas de saúde. Muitos desses problemas podem ser descritos e explicados no momento da análise da situação de saúde contida em plano nacional, estadual e municipal. Uma parte deles requer a formulação de proposições para equacioná-los, ainda que não necessariamente mediante investigação científica. Nesse caso, além da decisão políitica e técnica de incluir na agenda um determinado problema, de intervir na 
situação e de mobilizar recursos e vontades para a sua superação, cabe selecionar tecnologias efetivas e aceitáveis (VIEIRA DA SILVA, 2000).

Na própria formulação de um plano de saúde, podem-se levantar, para cada problema (do estado de saúde ou dos serviços de saúde), as tecnologias e saberes disponíveis para a sua solução, os conhecimentos que podem ser obtidos mediante "síntese de pesquisas" e as lacunas a exigir produção de novos conhecimentos. A institucionalização da planificação em saúde, nessa perspectiva, corresponderia a uma das vias de definição de prioridades em pesquisa na medida em que apontaria para as instituições de C\&T um elenco de demandas relevantes para a solução de problemas atuais e potenciais. Outra via poderia recorrer a estratégias de aproximação entre gestores e pesquisadores contemplando a constituição de um comitê misto, a definição de agenda preliminar, a discussão de questões formuladas pelos gestores referentes às pré-noções e a "experiência primeira", a indicação de síntese de pesquisas e a recomendação de investigação original (VIEIRA DA SILVA, 2003).

Tendo em vista os principais problemas do sistema de saúde na conjuntura destacados no período posterior à promulgação da Constituição de 1988, pode-se considerar a seguinte pauta de pesquisa:

- Análise de situações de saúde segundo condições, estilos e modos de vida;

- Características e desenvolvimento do setor privado - relações público x privado;

- Dimensão e significado do processo de municipalização;

- Desenvolvimento e avaliação de propostas inovadoras de modelos assistenciais;

- Avaliação de práticas, programas e sistemas de saúde: eficácia, efetividade, eficiência, qualidade, satisfação/percepção dos usuários, acessibilidade, eqüidade, cobertura e análise de implantação de programas (VIEIRA DA SILVA, 2000, p. 860).

A expansão do PSF, o desenvolvimento da vigilância da saúde e a formulação de políticas intersetoriais representam novas oportunidades de investigação sobre acessibilidade, qualidade, eqüidade e efetividade do sistema de serviços de saúde. Nesse particular, cabe aprimorar os sistemas de informação do país no sentido de produzir indicadores desagregados de saúde e de utilização de serviços segundo estratos sociais, condições de vida e diferenças 
raciais, tal como tem sido realizado em países desenvolvidos há quase um século. As desigualdades raciais verificadas no BRASIL requerem mais investigações concretas no sentido de melhor orientar os formuladores de políticas públicas de saúde (HERINGER, 2002). Portanto, "enquanto as estatísticas oficiais produzirem dados que homogeneízam artificialmente a realidade, a descrição da situação atual e da evolução das desigualdades se constituem em produção de conhecimento relevante" (VIEIRA DA SILVA, 2003, p. 5).

Além da análise permanente dos dados secundários produzidos pelos sistemas de informação disponíveis, particularmente vinculados às bases de dados do SUS e do IBGE, cabe discutir a oportunidade e relevância da realização de inquéritos populacionais sobre acesso e utilização de serviços de saúde, como se tem verificado em diversos países. O conhecimento produzido poderá contribuir para a regulação pública por parte do SUS e de suas agências (ANS e Anvisa, no caso do Ministério da Saúde) e para a "construção de mecanismos capazes de criar maior solidariedade na contribuição financeira necessária à manutenção de um sistema universal, no qual o consumo seja orientado pelas necessidades e não pela capacidade de compra dos indivíduos" (TRAVASSOS et al., 2000, p. 148).

A produção de metodologias e de indicadores para monitorar as desigualdades de saúde e de condições de vida representa, por conseguinte, uma das tarefas das universidades, centros de pesquisa e sistemas de vigilância da saúde no sentido de orientar a formulação e implementação de políticas públicas que reduzam as iniqüidades (MELLO-JORGE et al. , 2001 ; TRAVASSOS et al. ; NUNES et al., 2001; DUARTE et al., 2001). Quanto à qualidade da atenção, merece pesquisas especiais, tanto no que se refere à sua dimensão técnica e ética quanto no que diz respeito ao acolhimento e à satisfação das pessoas.

Nessa perspectiva, algumas perguntas poderão balizar grandes linhas de proposições para as políticas e sistemas de serviços de saúde: Como formular políticas específicas de saúde contemplando a integralidade (MATTOS, 2003)? Como incorporar tecnologia efetiva sem propiciar aumentos exponenciais dos custos? Como utilizar o poder de regulação do SUS para aquisição de insumos, avaliação e vigilância tecnológica de procedimentos e equipamentos, bem como a prestação de serviços? Como assegurar qualidade e efetividade da atenção à saúde, mesmo em situações de restrição de gastos públicos? Como regular com eficácia a qualidade e a integralidade da atenção à saúde proporcionada pelo SAMS? 
Independentemente das políticas racionalizadoras que poderão contribuir para a melhor utilização dos recursos existentes, o Brasil necessita de investimentos para instalação de equipes e de unidades de saúde, seja em certas áreas dos grandes centros urbanos, seja nos pequenos e médios municípios, particularmente nas áreas rurais.

\section{Comentários finais}

Se considerarmos as desigualdades em saúde como um dos principais macro problemas da atualidade para as políticas públicas de saúde no Brasil, um expressivo esforço teórico-conceitual deve ser empreendido, tanto no sentido de separar este problema de outros objetos préconstruídos - disparidade, iniqüidade, diferença, distinção etc. (VIEIRA DA SILVA, 2003) - quanto na perspectiva de sua decomposição em outros mais precisos para fins de investigação e intervenção concretas. Nesse percurso, algumas proposições preliminares podem ser destacadas:

- Reforçar o estudo da distribuição espacial de problemas de saúde no sentido de identificar grupos mais vulneráveis para a adoção de políticas públicas. Tais investigações sobre desigualdades em saúde podem recuperar os estudos ecológicos da epidemiologia de modo a revelar o caráter desigual da distribuição espacial de determinados eventos, possibilitando compor "mapas do risco" e uma maior atenção para as respectivas populações vulneráveis com a formulação de políticas públicas específicas. O cadastro amplo dos indivíduos e famílias para o cartão SUS, a organização de distritos sanitários em cidades, o uso do geoprocessamento e de técnicas de análise espacial (NAJAR \& MARQUES, 1998) são ações técnicas que facilitam a atenção à saúde e, simultaneamente, requerem pesquisa científica para o seu reforço.

- Testar modelos de atenção, epidemiologicamente orientados ou referenciados pela concepção contemporânea de promoção da saúde (BRASIL, 2002b), a exemplo da oferta organizada, das ações programáticas e da vigilância da saúde, contemplando determinantes estruturais socioambientais, riscos e danos. Esses modelos são compatíveis com a ação intersetorial sobre o território e privilegiam a intervenção, sob a forma de operações, nos problemas de saúde que requerem atenção e acompanhamento contínuos. No caso da proposta referente às 
cidades saudáveis pode potencializar o PSF em face da sua compatibilidade com a vigilância da saúde (PAIM, 2003b).

- Pesquisar a segmentação do sistema de saúde brasileiro tendo em vista o preceito constitucional segundo o qual a saúde é livre à iniciativa privada e, também, as restrições financeiras impostas à expansão do setor público de saúde. Nesse particular, cabe analisar as possibilidades de regulação da atenção à saúde do setor privado mediante regulamentação da Lei Orgânica da Saúde e da Lei n 9.656/98 e promover estudos para a elaboração de projeto de lei no sentido de regular o mercado das modalidades assistenciais não-SUS (PAIM, 2003b).

- Avançar nas investigações sobre avaliação de práticas, serviços, instituições e sistemas de saúde, enfatizando a dimensão qualidade e a articulação entre epidemiologia e planejamento (PAIM, 2003a).

Enfim, pode-se vislumbrar um conjunto de pesquisas no campo da Saúde Coletiva cujos conhecimentos produzidos (teóricos, metodológicos, operativos e tecnológicos) contribuam para: formulação, implementação e avaliação de políticas de saúde; compreensão do funcionamento do mercado em saúde; explicação das relações entre Estado, organizações, mercado e sociedade; desenho de sistemas de serviços de saúde, organizações e modelos de atenção que contemplem a integralidade, a descentralização, a regionalização, a participação e eqüidade e a intersetorialidade; identificação de pautas culturais e representações sociais de segmentos da população (adolescentes, idosos, negros, índios etc.) relacionados ao complexo promoção-saúde-doença-cuidado, seja em relação à utilização de serviços ou à comunicação em saúde; e desenho, inovação e experimentação de formas alternativas de gestão.

As proposições acima podem facilitar a construção de uma agenda comum entre gestores, pesquisadores e cidadãos, criando as condições para que, de forma permanente, o sistema de saúde aproxime-se mais dos indivíduos, torne-se mais humano, solidário e, sobretudo, mais resolutivo. Princípios como territorialidade, vínculo, continuidade, planejamento local, promoção à saúde estão cada vez mais presentes nas pautas e agendas não só dos técnicos, como também dos movimentos sociais ligados ao setor (CAMPOS, 2003, p. 570). 


\section{Notas}

${ }^{2} \mathrm{O}$ cuidado à saúde, como um serviço, tem a particularidade de realizar o consumo no momento da produção, isto é, não ocorre circulação como no caso de mercadorias ou bens (AROUCA, 1975).

${ }^{3}$ Os sistemas de serviços de saúde em diversos países apresentam um espectro de combinações com mais Estado ou mais mercado (SOUZA et al. , 2000). Mesmo nas situações especiais em que o Estado é simultaneamente financiador e prestador, interage ativamente com o mercado na aquisição de insumos essenciais para a atenção à saúde.

${ }^{4}$ A gestão da atenção à saúde reveste-se de grande complexidade, pois contempla a aquisição e suprimento de milhares de itens de produtos utilizados na prestação de serviços, passa pela adesão, compromisso, qualificação e dedicação ao cuidado dos agentes das práticas de saúde, até alcançar relações especiais com o mercado, os cidadãos, políticos, partidos e o Estado nas suas diferentes instâncias governamentais, jurídicas e legislativas. No caso brasileiro, trata-se de um sistema bastante complexo em que o Estado é financiador e prestador no âmbito municipal, estadual e federal; é comprador de serviços do setor privado contratado pelo SUS e de insumos no mercado; e é regulador da assistência médica suplementar e dos bens, serviços e ambientes que afetam a saúde.

${ }^{5}$ Essas reformas podem ser analisadas tendo em conta pelo menos doze eixos temáticos: marco jurídico, direito aos cuidados de saúde, aumento da cobertura, função reitora do Ministério da Saúde, descentralização, participação e controle social, oferta de serviços, separação de funções, modelo de gestão, recursos humanos e qualidade e avaliação de tecnologias. Na avaliação dos seus resultados têm-se tomado como atributos a eqüidade, eficiência, efetividade, sustentabilidade, qualidade, participação e controle social (INFANTE et al., 2000). Alguns desses eixos e atributos serão contemplados no presente texto na medida em que se aproximam da questão da atenção à saúde a exemplo da oferta (modelo de atenção e acesso), eqüidade e qualidade. 


\section{Referências}

ALMEIDA, C. Reforma de sistemas de servicios de salud y equidad en América Latina y el Caribe: algunas lecciones de los años 80 y 90. Cad. Saúde Pública, Rio de Janeiro, 18(4), p.905-925, 2002.

ALMEIDA, P. F. de; GIOVANELA, L.; MATTOS, M. Sistema de Saúde Brasileiro: dilemas da universalização. Saúde em debate, Rio de Janeiro, 26(61), p. 137-154, 2002.

AROUCA, A. S. O dilema preventivista: contribuição para a compreensão e crítica da Medicina Preventiva. Tese. (Doutorado) - Faculdade de Ciências Médicas da Universidade Estadual de Campinas, Campinas, 1975.

BAHIA, L. Mudanças e padrões das relações público-privado: seguros e planos de saúde no Brasil. Tese (Doutorado em Saúde Pública). São Paulo: ENSP/FIOCRUZ, 1999.

BAHIA, L. Planos privados de saúde: luzes e sombras no debate setorial dos anos 90. Ciência \& Saúde Coletiva, Rio de Janeiro, 6(2), p. 329-339, 2001.

BELMARTINO, S. Los valores vinculados a equidad en la reforma de la atención médica en Argentina. Cad. Saúde Pública, Rio de Janeiro, 18(4), p.1067-1076, 2002.

BRAGA, J. C. \& GOES DE PAULA, S. Saúde e Previdência: estudos de política social. Rio de Janeiro/São Paulo: CEBES/HUCITEC,1978.

BRASIL. Conselho Nacional de Secretários de Saúde. Legislação do SUS. Brasília: CONASS, 2003a.

BRASIL. Conselho Nacional de Secretários de Saúde. A saúde na opinião dos brasileiros. Brasília: CONASS, 2003b.

BRASIL. Conselho Nacional de Secretários de Saúde. Para entender a gestão do SUS. Brasília: CONASS, 2003c. 246p.

BRASIL. Ministério da Previdência e Assistência Social. Sistema Nacional de Saúde. Braślia, 5-8/agosto/1975.

BRASIL. Ministério da Saúde. Secretaria de Assistência à Saúde. Reduzindo as desigualdades e ampliando o acesso à assistência à saúde no Brasil, 1998-2002. Brasília: Ministério da Saúde, 2002a.

BRASIL. Ministério da Saúde. Secretaria de Políticas de Saúde. Política Nacional de Promoção da Saúde (documento para discussão). Brasília, 2002.

BRASIL. Ministério da Saúde. 1 Semestre de 2003. Balanço das Ações. Brasília, 2003d.

CAMARGO JR., K.R. de. As muitas vozes da integralidade. In: PINHEIRO, R. \& MATTOS, R. A. de. (Org.). Os sentidos da integralidade na atenção e no cuidado à saúde. Rio de Janeiro: UERJ, IMS, ABRASCO, 2001.

CAMPOS, C. E. A. O desafio da integralidade segundo as perspectivas da vigilância da saúde e da saúde da família. Ciência \& Saúde Coletiva, Rio de Janeiro, 8(2), p.569-584, 2003.

CAZELLI, C. M; BRITO, J. da S.; SÁ, P. K. de; ORMELLI, C. B. Análise das desigualdades regionais na oferta de serviços de saúde: pesquisa da assistência médico-sanitária, 1992 a 1999. Saúde em Debate, Rio de Janeiro, 26(61), p. 198-209, 2002.

CEBES-ABRASCO. Em defesa da saúde dos brasileiros. Saúde em Debate, Rio de Janeiro, 26(62), p.290-294, 2002. 
CECÍlIO, L. C. de O. As necessidades de saúde como conceito estruturante na luta pela integralidade e eqüidade na atenção em saúde. In: PINHEIRO, R. \& MATTOS, R. A. de. (Org.). Os sentidos da integralidade na atenção e no cuidado à saúde. Rio de Janeiro: UERJ, IMS, ABRASCO, 2001.

CLARK, D. W. A Vocabulary for Preventive Medicine. In: Clark, D. W. \& MacMahon, B. Preventive Medicine. Boston, USA: Little, Brown and Company, 1967.

CONFERÊNCIA NACIONAL DE SAÚDE, Brasília, 1986. Anais da $8^{a}$ Conferência Nacional de Saúde. Brasília, Centro de Documentação do Ministério da Saúde, 1987.

CONSELHO NACIONAL DE SAÚDE. Desenvolvimento do Sistema Único de Saúde no Brasil: avanços, desafios e reafirmação de Princípios e Diretrizes. Saúde em Debate, Rio de Janeiro, 26(62), p.295-312, 2002.

COSTA, N. R. Política social e ajuste macroeconômico. Cad. Saúde Pública, Rio de Janeiro, 18(Suplemento), p. 13-21, 2002.

CORDEIRO, H. As empresas médicas: as transformações capitalistas da prática médica, Rio de Janeiro: Graal, 1984.

CORDEIRO, H. Descentralização, universalidade e eqüidade nas reformas da saúde. Ciência \& Saúde Coletiva, Rio de Janeiro, 6(2), p.319-328, 2001.

CZERESNIA, D. \& FREITAS, C. M. de (Org.) Promoção da saúde: conceitos, reflexões, tendências. Rio de Janeiro: Editora Fiocruz, 2003.

DONNÂNGELO, M. C. F. Saúde e sociedade. São Paulo: Duas Cidades, 1976.

DONNÂNGELO, M. C. F. A pesquisa na área da Saúde Coletiva no Brasil - A década de 70. In: ABRASCO. Ensino da Saúde Pública, Medicina Preventiva e Social no Brasil, 2. PEC/ENSP, Rio de Janeiro, 1983.

DUARTE, E.C.; SCHNEIDER, M.C.; PAES-SOUSA, R.; RAMALHO, W. M.; SARDINHA, L. M. V.; SILVA JÚNIOR, J. B. da; CASTILLO-SALGADO, C. Epidemiologia das desigualdades em saúde no Brasil. Um estudo exploratório. Brasília: Organização Pan-Americana da Saúde, 2002.

FREITAS, C. M. de. A Vigilância da Saúde para a Promoção da Saúde. In: CZERESNIA, D. \& FREITAS, C.M. de (Org.). Promoção da saúde: conceitos, reflexões, tendências. Rio de Janeiro: Editora Fiocruz, 2003.

GIOVANELA, L.; LOBATO, L. de V.C.; CARVALHO, A. I. de; CONIL, E. M.; CUNHA, E. M. da. Sistemas municipais de saúde e a diretriz da integralidade da atenção: critérios para avaliação. Saúde em Debate, Rio de Janeiro, 26(60), p.37-61, 2002.

HERINGER, R. Desigualdades raciais no Brasil: síntese de indicadores e desafios no campo das políticas públicas. Cad. Saúde Pública, Rio de Janeiro, 18(Suplemento), p.57-65, 2002.

HERNÁNDEZ, M. Reforma sanitaria, equidad y derecho a la salud en Colombia. Cad. Saúde Pública, Rio de Janeiro, 18(4), p.991-1001, 2002.

HILLEBOE, H. E. \& LARIMORE, G. W. Medicina Preventiva. Princípios de prevenção aplicáveis à ocorrência e à evolução das doenças. São Paulo: SERPEL, 1965.

INFANTE, A.; MATA, I. de la; LÓPEZ-ACUÑA, D. Reforma de los sistemas de salud en América Latina y el Caribe: situación y tendencias. Rev. Panam. Salud Pública/Pan Am.

44 J. Public Health, Washington, 8(1/2), p. 13-20, 2000. 
JUNQUEIRA, V.; PESSOTO, U. C.; KAYANO, J.; NASCIMENTO, P. R.; CASTRO, I. E. do N.; ROCHA, J. L. da; TERENCE, M. F.; BOARETTO, R. C.; IBANHES, L. C.; CORTIZO, C. T.; HEIMANN, L. S. Equidad en la salud: evaluación de políticas públicas en Belo Horizonte, Minas Gerais, Brasil, 1993-1997. Cad. Saúde Pública, Rio de Janeiro, 18(4), p.1087-1101, 2002.

LABRA, M. E. La reinvención neoliberal de la inequidad en Chile. El caso de la salud. Cad. Saúde Pública, Rio de Janeiro, 18(4), p. 1041 -1052, 2002.

LEAVELL, H. \& CLARK, L. E. G. Medicina Preventiva. Rio de Janeiro: Mcgraw-Hill do Brasil, Ltda./MEC., 1976.

LIMA, J. de C.; AZOURY, E. B; BASTOS, L. H. de C. V.; COUTINHO, M. de M.; PEREIRA, N. do N.; FERREIRA, S. C. da C. Desigualdades no acesso e utilização de serviços de saúde no Brasil. Saúde em debate, Rio de Janeiro, 26(60), p.62-70, 2002.

MATTOS, R. A. de. Os sentidos da integralidade: algumas reflexões acerca de valores que merecem ser definidos. In: PINHEIRO, R. \& MATTOS, R. A. de. (Org.). Os sentidos da integralidade na atenção e no cuidado à saúde. Rio de Janeiro: UERJ, IMS, ABRASCO, 2001.

MATTOS, R. A. de. Integralidade e a Formulação de Políticas de Saúde. In: Pinheiro, R. \& Mattos, R. A. de. (Org.). Construção da Integralidade: cotidiano, saberes e práticas em saúde. Rio de Janeiro: UERJ, IMS, ABRASCO, 2003.

MENDES, E. V. As políticas de saúde no Brasil nos anos 80: a conformação da reforma sanitária e a construção da hegemonia no projeto neoliberal. In: MENDES, E. V. (Org.). Distrito Sanitário: o processo social de mudança das práticas sanitárias do Sistema Único de Saúde. São Paulo/Rio de Janeiro: Hucitec-Abrasco, 1993.

MENDES, E. V. Uma agenda para a saúde. São Paulo: HUCITEC, 1996.

MELLO JORGE, M. H. P. de; GOTLIEB, S. L. D; LAURENTI, R. A saúde no Brasil: análise do período 1996 a 1999. Brasília: Organização Pan-Americana da Saúde. 2001.

MELLO, C. G. Saúde e assistência médica no Brasil. São Paulo: CEBES/HUCITEC, 1977.

MITJAVILA, M.; FERNÁNDEZ, J.; MOREIRA, C. Propuestas de reforma en salud y equidad en Uruguay: Redefinición del Welfare State? Cad. Saúde Pública, Rio de Janeiro, 18(4), p. $1103-1120,2002$.

MONTONE, J. O impacto da regulamentação no setor de saúde suplementar/ Ministério da Saúde, Agência Nacional de Saúde Suplementar. Rio de Janeiro: ANS, 2001. (Série ANS; n. 1)

MONTONE, J. Evolução e desafios da regulação no setor de saúde suplementar/ Ministério da Saúde, Agência Nacional de Saúde Suplementar. Rio de Janeiro: ANS, 2003. (Série ANS; n. 4)

NAJAR, A. L. \& MARQUES, E. C. (Org.). Saúde e espaço: Estudos metodológicos e técnicas de análise. Rio de Janeiro: Editora Fiocruz, 1998.

NEGRI, B. A política de saúde no Brasil nos anos 1990: avanços e limites. In: NEGRI, B. \& D'ÁVILA, A. L. (Org.). O Sistema Único de Saúde em dez anos de desafios. São Paulo: Sobravime; Cealag, 2002. 
NERI, M. \& SOARES, W. Desigualdade social e saúde no Brasil. Cad. Saúde Pública, Rio de Janeiro, 18(Suplemento), p.77-87, 2002.

NOGUEIRA, R. P. Perspectivas da qualidade em saúde. Rio de Janeiro: Qualitymark, 1994.

NORONHA, J. C. de \& SOARES, L. T. A política de saúde no Brasil nos anos 90. Ciência \& Saúde Coletiva, Rio de Janeiro, 6(2), p.445-450, 2001.

NUNES, A.; SANTOS, J. R. S.; BARATA, R. B.; VIANNA, S. M. Medindo as desigualdades em saúde no Brasil. Uma proposta de monitoramento. Brasília: Organização PanAmericana de Saúde, Instituto de Pesquisa Econômica Aplicada, 2001.

OLIVEIRA, J. A. A. \& TEIXEIRA, S. M. F. Medicina de grupo: a medicina e a fábrica. In: GUIMARÃES, R. (Org.). Saúde e medicina no Brasil: contribuição para um debate. Rio de Janeiro: Graal, 1978.

PAIM, J. S. Saúde, crises e reformas. Salvador: Centro Editorial e Didático da UFBA, 1986.

PAIM, J. S. A reorganização das práticas de saúde em distritos sanitários. In: MENDES, E. V. (Org.). Distrito Sanitário: o processo social de mudança das práticas sanitárias do Sistema Único de Saúde. São Paulo/Rio de Janeiro: Hucitec-Abrasco, 1993.

PAIM, J. S. Bases conceituais da reforma sanitária brasileira. In: FLEURY, S. (Org.). A Luta do Cebes. São Paulo: Lemos Editorial, 1997.

PAIM, J. S. Saúde, Política e Reforma Sanitária. Salvador: CEPS-ISC, 2002.

PAIM, J. S. Epidemiologia e planejamento: a recomposição das práticas epidemiológicas na gestão do SUS. Ciência \& Saúde Coletiva, Rio de Janeiro, 8(2), p.557-567, 2003.

PAIM, J. S. Gestão da atenção básica nas cidades. In: NETO, E.R. \& BÓGUS, C.M. Saúde nos aglomerados urbanos: uma visão integrada. Brasília: Organização Pan-Americana da Saúde, 2003. (Série Técnica Projeto de Desenvolvimento de Serviços de saúde, 3).

PAIM, J. S. Políticas de Saúde no Brasil. In: ROUQUAYROL, M.Z. \& ALMEIDA FILHO, N. Epidemiologia \& Saúde. 6 ed. Rio de Janeiro: Medsi. 2003.

PAIM, J. S. Modelos de Atenção e Vigilância da Saúde. In: ROUQUAYROL, M.Z. \& ALMEIDA FILHO, N. Epidemiologia \& Saúde. 6 ed. Rio de Janeiro: Medsi, 2003.

PAIM, J. S. Vigilância da Saúde: dos modelos assistenciais para a promoção da saúde. In: CZERESNIA, D. \& FREITAS, C.M. de (Org.). Promoção da Saúde: conceitos, reflexões, tendências. Rio de Janeiro: Editora Fiocruz, 2003.

PAIM, J. S., TEIXEIRA, M. G. L. C. Reorganização do sistema de vigilância epidemiológica na perspectiva do Sistema Único de Saúde (SUS). Informe Epidemiológico do SUS, Brasília, 5:27-57, 1992.

PINHEIRO, R. \& MATTOS, R. A. de. (Org.). Os sentidos da integralidade na atenção e no cuidado à saúde. Rio de Janeiro: UERJ, IMS, ABRASCO, 2001.

PEGO, R. A. \& ALMEIDA, C. Teoría y práctica de las reformas en los sistemas de salud. Los casos de Brasil y México. Cad. Saúde Pública, Rio de Janeiro, 18(4), p.971-989, 2002.

PORTO, S. Equidad y distribución geográfica de recursos financieros en los sistemas de salud. Cad. Saúde Pública, Rio de Janeiro, 18(4), p.939-957, 2002. 
REIS, C. O. O. Desigualdades no acesso aos serviços de saúde. In: NEGRI, B. \& DI GIOVANNI, G. (Org.). Brasil: radiografia da saúde. Campinas: UNICAMP.IE, 2001.

SALA, A. A avaliação de programas de saúde. In: SCHRAIBER, L.B. (Org). Programação em saúde hoje. São Paulo: HUCITEC, 1993.

SAMPAIO, L. F. R. Integralidade da atenção à saúde: análise crítica da programação da atenção básica - PPI/AB, 2001/2002. Dissertação (Mestrado em Saúde Coletiva) - Instituto de Saúde Coletiva, Universidade Federal da Bahia, Salvador, 2002.

SERAPIONI, M. Avaliação da qualidade em saúde: a contribuição da sociologia da saúde para a superação da polarização entre a visão dos usuários e a perspectiva dos profissionais de saúde. Saúde em debate, Rio de Janeiro, 23(53), p.81-92, 1999.

SCHRAIBER, L. B. Medicina tecnológica e prática profissional contemporânea: novos desafios, outros dilemas. Tese (Livre-Docência) - Faculdade de Medicina, Universidade de São Paulo, São Paulo, 1997.

SOUZA, L. E. de; SHARDONOFSKY, S.; BROUSSELLE, A.; CONTANDRIOPOULOS, A. P.; CHAMPAGNE, F.; MORALES, C.; ARREDONDO, A.; REINHARZ, D. Comparación del desempeño de los diferentes sistemas de salud de los países de la OCDE y de Al. In: CONTANDRIOPOULOS, A. P.; MORALES, C; SOUZA, L. E. de; SHARDONOFSKY, S. Entendiendo las transformaciones de los sistemas de salud. Una perspectiva canadiense. Montreal: Université de Montréal, 2002.

SZWARCWALD, C. L.; BATOS, F. I.; ANDRADE, C. L. T. de. Medidas de desigualdad en salud: la discusión de algunos aspectos metodológicos con una aplicación para la mortalidad neonatal en el Municipio de Rio de Janeiro, 2000. Cad. Saúde Pública, Rio de Janeiro, 18(4), p.959-970, 2002.

TEIXEIRA, C. F. (Org.). Promoção e Vigilância da Saúde. Salvador: CEPS-ISC, 2002.

TEIXEIRA, C. F.; PAIM, J. S; VILASBÔAS, A. L. Q. Promoção e Vigilância da Saúde. Salvador: CEPS-ISC, 2002.

UCHIMURA, K. Y. \& BOSI, M. L. M. Qualidade e subjetividade na avaliação de programas e serviços em saúde. Cad. Saúde Pública, Rio de Janeiro, 18(6), p.1561-1569, 2002.

TRAVASSOS, C.; VIACAVA, F.; FERNANDES, C.; ALMEIDA, C. M. Desigualdades geográficas e sociais na utilização de serviços de saúde no Brasil. Ciência \& Saúde Coletiva, Rio de Janeiro, 5(1), p. 133-149, 2000.

VIANA, A. L. d'A.; HEIMANN, L. S.; LIMA, L. D. de; OLIVEIRA, R. G. de; RODRIGUES, S. da H. Mudanças significativas no processo de descentralização do sistema de saúde no Brasil. Cad. Saúde Pública, Rio de Janeiro, 18(Suplemento), p. 139-151, 2002.

VIEIRA DA SILVA, L. M. Uma agenda para investigação em políticas e sistemas de saúde no Nordeste. Cad. Saúde Pública, Rio de Janeiro, 16(3), p.857-861 , 2000.

VIEIRA DA SILVA, L. M. Prioridades para a pesquisa em saúde coletiva. Congresso Brasileiro de Saúde Coletiva, VII, Brasília, 29 de julho a 2 de agosto de 2003 (não publicado). 



\section{Gestão da atenção básica nas cidades ${ }^{1}$}

Este capítulo apresenta uma breve revisão sobre as noções de atenção primária de saúde (APS) e de atenção básica de saúde (ABS), tendo como referência as políticas de saúde implementadas no Brasil nas últimas décadas. Seu objetivo é discutir algumas questões referentes à gestão da atenção básica de saúde (ABS) nas cidades e certas proposições para a sua consolidação no Sistema Único de Saúde (SUS).

As reflexões elaboradas não derivam da experiência de um gestor nem de um estudo de caso de uma cidade cuja gestão da atenção básica fosse considerada exemplar ou problemática. Não se trata, portanto, da visão de um técnico municipal ou de um urbanista com um enfoque integral sobre o espaço urbano. A abordagem desenvolvida, a partir do campo disciplinar da Política de Saúde, busca contemplar o encontro de dois eixos: um vertical, que corresponde à formulação e implementação de políticas públicas de caráter nacional onde a condução do Sistema Único de Saúde (SUS) adquire proeminência para todo o país em função da Constituição de 1988 e da legislação federal (CONASEMS, 1990), ainda que mediada pelos pactos construídos com instrumentos normativos (BRASIL, 1993; 1996; 2001 ; 2002b); e um eixo horizontal, voltado para a análise da situação de saúde das cidades e possíveis intervenções, considerando a heterogeneidade do espaço urbano e a diversidade das condições de vida dos seus habitantes.

Nessa perspectiva, as intervenções referentes à promoção, proteção, recuperação e reabilitação da saúde das populações
1 Texto originalmente publicado em: OPAS/ OMS. Saúde nos aglomerados urbanos: uma visão integrada. Elias Rassi

Neto \& Cláudia MariaBorgus (Orgs.) Brasília: Organização Pan-Americana da Saúde, 2003, p. 183-212. (Série Técnica Projeto de Desenvolvimento de Sistemas e Serviços de Saúde, 3). 
que ocupam distintos territórios são pensadas na confluência desses dois eixos. $O$ encontro pode ser representado por modelos de atenção compatíveis com a integração desses eixos (política nacional de saúde e análise da situação de saúde nas cidades) e disponíveis para a gestão da atenção básica, a exemplo das propostas de vigilância da saúde, saúde da família e cidades saudáveis. Procura-se, desse modo, "articular a dimensão política com as instâncias de decisão sobre a produção, distribuição e organização assistencial, no espaço onde tais políticas se concretizam: os serviços locais de saúde" (BODSTEIN, 1993, p. 9).

\section{Aspectos conceituais}

A partir da difusão do corpo doutrinário da atenção primária à saúde (APS) três distintas concepções têm fundamentado as políticas e práticas de saúde no Brasil: a) APS enquanto programa de medicina simplificada ou "atenção primitiva de saúde" (TESTA, 1992); b) APS enquanto nível de atenção - primeiro nível, atendimento de primeira linha ou "atenção primeira e básica" (SCHRAIBER \& MENDES-GONÇALVES, 1996); c) APS enquanto componente estratégico da proposta de Saúde para todos no ano 2000 (OPS, 1990).

A APS tem sido, também, reconhecida como espaço tático-operacional de reorientação de sistemas de serviços de saúde mediante a implantação de distritos sanitários (distritalização) e como oportunidade de experimentação de modelos assistenciais alternativos congruentes com as necessidades de saúde e com o perfil epidemiológico da população (MENDES, 1990). Para Tejada de Rivero (1992), importa destacar o que não é atenção primária de saúde:

1. Não é uma forma primitiva, empírica e elementar de atenção-cuidado de segunda ou terceira categoria para os pobres - nem se sustenta somente em tecnologias que não incorporam os maiores avanços do desenvolvimento científico;

2. Não é uma ação exclusiva dos serviços de saúde ou de algumas instituições desse setor, nem é um programa independente e paralelo às demais atividades de saúde;

3. Não é um nível de atenção dentro de um sistema de serviços de saúde nem se reduz ao que poderia considerar-se como o nível mais periférico; 
4. Não se reduz à utilização de pessoal não profissional, nem pode circunscrever-se a membros da comunidade treinados para prestar uma atenção elementar (TEJADA DE RIVERO, 1992, p. 174).

Ao conceber a APS como estratégia, esse autor destaca seus princípios fundamentais (participação, descentralização, ação multisetorial e tecnologia apropriada), rejeitando a idéia de "uma cortina de fumaça paliativa e tendente a postergar reivindicações sociais em sociedade onde existem grandes desigualdades e injustiças" (TEJADA DE RIVERO, 1992, p. 174).

No entanto, no âmbito internacional, a atenção primária tem sido definida como "aquele nível de um sistema de serviço de saúde que oferece a entrada no sistema para todas as novas necessidades e problemas" (STARFIELD, 2002, p. 28).

Recusando, também, a concepção de APS como assistência simplificada e de baixo custo para problemas simples de gente pobre, autores brasileiros enfatizam que as demandas neste nível "exigem, para sua adequada compreensão e efetiva transformação, sofisticada síntese de saberes e complexa integração de ações individuais e coletivas, curativas e preventivas, assistenciais e educativas" (SCHRAIBER \& MENDES-GONÇALVES, 1996, p. 36).

No Brasil, o Ministério da Saúde tem utilizado a expressão atenção básica talvez para evitar a confusão com a concepção de APS correspondente à "atenção primitiva de saúde". Desse modo, a atenção básica de saúde (ABS) tem sido definida no âmbito oficial, como "um conjunto de ações, de caráter individual ou coletivo, situadas no primeiro nível de atenção dos sistemas de saúde, voltadas para a promoção da saúde, prevenção de agravos, tratamento e reabilitação" (BRASIL, 1998b, p. 11). Admite que "a ampliação desse conceito se torna necessária para avançar na direção de um sistema de saúde centrado na qualidade de vida das pessoas e do seu meio ambiente" (BRASIL, 1998b, p. 11).

Constata-se, assim, um movimento em defesa da ABS, simultaneamente, como primeiro nível de atenção e como estratégia de reorientação do sistema de saúde. Pode-se concluir que a opção política expressa no discurso institucional reconhece a atenção básica como algo fundamental, primeiro ou primordial e não no sentido de elementar, simples ou reduzido, tal como o senso comum refere-se à "cesta básica" de alimentos.

Isto significa que a gestão da atenção básica ao tempo em que administra esse primeiro nível do sistema de serviços de saúde, deve conduzir a estratégia 
de reorientação de todo o sistema buscando uma atuação intersetorial. Tratase, portanto, de uma administração estratégica requerendo o desenho de instrumentos que permitam identificar todos os conjuntos sociais e os problemas de saúde, a atenção à toda a população que vive em sua área de intervenção, a gerência de todos os recursos que se encontrem nessa área, além da capacidade técnica, poder decisório, democratização e participação social ampliada no nível local (OPS, 1992).

A gestão da atenção básica, nessa perspectiva, pode ser entendida como uma forma de relacionar os problemas e necessidades em saúde dos conjuntos sociais que vivem em espaços geográficos delimitados com os conhecimentos e recursos, institucionais e comunitários, de tal modo que seja possível definir prioridades, considerar alternativas reais de ação, alocar recursos e conduzir o processo até a resolução ou controle do problema (OPS, 1992, p. 48).

A gestão da atenção básica nas cidades, por sua vez, implica analisar o espaço urbano utilizando como categoria de análise não o território em si, mas o território-processo ou o território utilizado (SANTOS \& SILVEIRA, 2001). Como chamam atenção esses autores, "quando quisermos definir qualquer pedaço do território, deveremos levar em conta a interdependência e a inseparabilidade entre a materialidade, que inclui a natureza, e o seu uso, que inclui a ação humana, isto é, o trabalho e a política" (SANTOS \& SILVEIRA, 2001 , p. 247). Portanto, o caráter histórico desse espaço torna-o um "território vivo" onde se expressam interesses, divisão do trabalho, localização de capitais, movimentos sociais, residências de pessoas, lazer, cultura e poderes diversos. E o caráter estratégico da gestão da saúde no nível local procura levar em conta a ação humana, enquanto trabalho e política, voltada para o êxito, mas também a ação comunicativa, orientada para o entendimento e para a intersubjetividade (RIVERA, 1995; GALLO, 1995).

Nessa perspectiva, oficinas de territorialização que permitam recuperar fragmentos da história e da cultura de grupos sociais que ocupam diferentes lugares do espaço urbano (VILASBÔAS, 1998) e oficinas de trabalho que possibilitem realizar análises de situação de saúde, formular proposições (BAHIA, 1987) e elaborar um orçamento participativo, constituem, além de tecnologias de gestão, momentos de sociabilidade e de invenção de novos modos de pensar e agir em saúde.

Entre as características da urbanização brasileira destaca-se a criação da pobreza (SANTOS, 1993). Pensar as cidades em tempos de globalização impli-

52 ca reconhecer os novos pobres no meio da nova riqueza. Assim,amplia-se 
a variedade de tipos econômicos, culturais, religiosos e lingüísticos, multiplicamse os modelos produtivos, de circulação e de consumo, segundo qualificações e quantidades, e também aumenta a variedade de situações territoriais [...]. Nessas condições, a metrópole está sempre se refazendo: na forma, na função, no dinamismo e no sentido. Essa riqueza do inesperado constitui a possibilidade de construção de novos futuros (SANTOS \& SILVEIRA, 2001, p. 287).

\section{Contextualização}

A atenção primária de saúde (APS) passou a ter mais visibilidade política no Brasil a partir da VII Conferência Nacional de Saúde (VII CNS), realizada em 1980. Antes desse evento, a APS restringia-se às experiências da medicina comunitária e dos programas de extensão de cobertura (PECS) das décadas de 1960 e 1970 (PAIM, 2002).

A VII CNS, cujo tema central foi "Extensão das Ações de Saúde através dos Serviços Básicos" (CNS, 1980), representou um momento privilegiado para a discussão das propostas da Conferência de Alma-Ata sobre os Cuidados Primários de Saúde (BRASIL, 2001 b). Contou, inclusive, com a presença do Diretor-Geral da Organização Mundial da Saúde (OMS) que, repetindo questões levantadas em Alma-Ata, indagou aos participantes se estavam "dispostos a introduzir, se necessário, mudanças radicais no atual sistema de prestação de serviços de saúde para que sirva de base adequada à atenção primária de saúde como principal prioridade?" (MAHLER, 1980, p. 14). Na oportunidade, o governo federal anunciou a criação do Programa Nacional de Serviços Básicos de Saúde (PREV-SAÚDE) no sentido de integrar os Ministérios da Saúde e da Previdência Social na prestação de serviços, juntamente com as secretarias estaduais e municipais de saúde.

Apesar de o PREV-SAÚDE não ter sido implantado, parte do corpo doutrinário da APS continuou inspirando, no Brasil, certas políticas de saúde a exemplo dos programas especiais do Ministério da Saúde e das tentativas de descentralização dos serviços de saúde na década de 1980, com destaque para as Ações Integradas de Saúde (AIS). Diante das limitações dessas iniciativas, a atenção básica não foi enfatizada nas proposições elaboradas durante a 8 Conferência Nacional de Saúde em 1986 (PAIM, 2002).

Com a implantação do Programa de Agentes Comunitários de Saúde (PACS) no início da década de 1990 (BRASIL, 1993b), a APS retornou a agenda política. O PACS, um programa especial nascido no Governo Collor, tinha 
como finalidade estender a cobertura de ações de saúde às populações rurais e às periferias urbanas voltando-se, especialmente, para o grupo maternoinfantil (BRASIL, 1994a). Foi criticado na época por traduzir uma política de focalização prescrita por organismos internacionais, além de ir na contramão da construção de um SUS universal, igualitário e integral.

A partir de 1993, o programa ampliou seus objetivos para que o agente comunitário fosse capaz de articular os serviços de saúde e a comunidade, incluindo entre suas atribuições, o desenvolvimento de ações básicas de saúde e atividades de caráter educativo nos níveis individual e coletivo (BRASIL, 1994b).

Na segunda metade da década de 1990, o PACS foi acoplado ao Programa Saúde da Família (PSF), enquanto o governo federal lançava o documento "1997: o ano da saúde no Brasil" destacando a prevenção, com ênfase no atendimento básico, e apresentando a saúde da família como o novo modelo assistencial do SUS (BRASIL, 1997). A implantação da Norma Operacional Básica (NOB-SUS 01/96) e a adoção do Piso da Atenção Básica (PAB) ${ }^{2}$ possibilitaram um reforço da atenção básica e a expansão do PSF (BRASIL, 1998a). A NOB-96 previa duas formas para a habilitação dos municípios junto ao SUS: gestão plena da atenção básica e gestão plena do sistema municipal (BRASIL, 1998a).

No caso do Programa de Saúde da Família (PSF), foi dirigido para a atenção básica e implantado mediante equipes voltadas para uma população adscrita de 600 a 1000 famílias e compostas por médico, enfermeiro, auxiliares e agentes comunitários, podendo ser acrescidas de odontólogos, assistentes sociais, psicólogos etc. (BRASIL, 1998b).

A partir da NOAS-01, as principais responsabilidades da atenção básica a serem executadas pelas equipes de saúde da família (ESF) são: ações de saúde da criança e da mulher; controle de hipertensão, diabetes e tuberculose; eliminação da hanseníase; e ações de saúde bucal (BRASIL, 2001c).

\section{Atenção básica nas políticas de saúde do Ministério da Saúde}

A discussão sobre gestão da atenção básica e modelos de atenção vem assumindo, progressivamente, certa relevância na formulação de políticas de saúde no Brasil. Assim, a NOB-96 concebia para o SUS "um modelo de atenção centrado na qualidade de vida das pessoas e do seu meio ambiente, bem como na relação da equipe de saúde com a comunidade, especialmente com os seus núcleos sociais primários - as famílias" (BRASIL, 1998a, p. 12). 
Além de propugnar por ações intersetoriais, essa norma defendia "a transformação na relação entre o usuário e os agentes do sistema de saúde (restabelecendo o vínculo entre quem presta o serviço e quem o recebe) e, de outro, a intervenção ambiental, para que sejam modificados fatores determinantes da situação de saúde" (BRASIL, 1998a, p. 13).

Depois de implantado o PAB, contendo um valor fixo e uma parte variável destinada ao incentivo de intervenções como Ações Básicas de Vigilância Sanitária, PACS/PSF, Programa de Combate às Carências Nutricionais, vigilância epidemiológica etc., o Ministério da Saúde (MS) estabeleceu as orientações para a organização da atenção básica, através da Portaria n ${ }^{\circ} 3.925 /$ GM de 13 de novembro de 1998 (BRASIL, 1998a).

O PSF tem sido visto como estratégia para a reorientação do modelo de atenção, além de constituir-se em porta de entrada do sistema municipal de saúde. Prevê a participação da comunidade em parceria com as equipes na discussão dos problemas de saúde, na definição de prioridades, no acompanhamento e na avaliação. Considera um erro ser imaginado como serviço paralelo, com equipes responsáveis apenas pelas visitas domiciliares e atividades coletivas ou individuais de prevenção de doenças, "enquanto a assistência curativa continua sob a responsabilidade de outros profissionais do modelo anterior" (BRASIL, 2001 a, p. 60).

Na avaliação da implantação e funcionamento do PSF, constatou-se que $71 \%$ dos coordenadores estaduais consideram o programa como uma estratégia de reorganização da atenção básica, embora apresentando as seguintes limitações: falta de entendimento dos gestores, alta rotatividade dos secretários municipais e estaduais de saúde, infra-estrutura precária das Unidades de Saúde da Família, dupla militância de médicos, condições de trabalho e vínculos empregatícios precários, insuficiência de profissionais, formação inadequada e dificuldade institucional de absorver o novo modelo (BRASIL, 2000b).

Presentemente, encontram-se em atividade 16.000 equipes de saúde da família, abrangendo mais de 55 milhões de brasileiros (Saúde, BRASIL, 2003). A análise da implementação do PSF, enquanto política pública, durante a década de 1990 aponta para perspectivas promissoras, a despeito das dificuldades verificadas tendo em vista restrições do financiamento e ambigüidades dos diferentes governos. Apesar da precariedade das relações de trabalho, alguns estudos apontam para um comprometimento dos profissionais com o PSF, "associado a sentimentos de satisfação social, apego, envolvimento 
ligado a razões morais, quando consideram seu trabalho uma atividade de responsabilidade social, um dever a ser cumprido" (SCALDAFERRI, 2000).

Outros reconhecem o PSF enquanto "proposta contra-hegemônica em maturação", apresentando fragilidades (SILVA, 2002). A autora realiza uma análise da natureza das atividades das equipes do PSF, seja no planejamento e gestão, seja na promoção, proteção, assistência e reabilitação da saúde. Em outras palavras, a pesquisa indica os avanços alcançados pelo PSF, no caso concreto investigado de Vitória da Conquista (BA), no que se refere à realização de atividades voltadas para o controle de riscos e de danos e à insuficiência das ações de controle das causas dos problemas de saúde. Portanto, os acúmulos sócio-políticos e a "pedagogia do exemplo" desta iniciativa, não obstante os seus percalços, parecem contribuir, via ação política, para a reorientação do sistema e redefinição das práticas de saúde (GOULART, 2002).

\section{Gestão da atenção básica}

A gestão da atenção básica tem utilizado um conjunto de ferramentas resultantes de normas técnicas e administrativas emanadas da direção nacional do SUS e pactuadas, na maioria das vezes, com as instâncias estadual e municipal através da Comissão Inter-gestora Tripartite (CIT). A partir dessas iniciativas, alguns instrumentos e procedimentos têm sido propostos, tais como cadastro e implantação do Cartão SUS, adscrição de clientela, referência para assistência de média e alta complexidade, acompanhamento, avaliação e "estratégia de saúde da família" (BRASIL, 2000a).

De acordo com a NOB-96, os municípios teriam responsabilidades na gestão da atenção básica, tais como: desenvolvimento de métodos e instrumentos de planejamento e gestão, incluídos os mecanismos de referência e contra-referência de pacientes; coordenação e operacionalização do sistema municipal de saúde; desenvolvimento de mecanismos de controle e avaliação; desenvolvimento de ações básicas de vigilância sanitária; administração e desenvolvimento de recursos humanos para atenção básica; e fortalecimento do controle social no município (BRASIL, 2000a).

A NOAS-SUS 01/2001, atualizou as condições de gestão do NOB-96, definiu prerrogativas dos gestores municipais e estaduais, propôs a formula-

56 ção de plano diretor de regionalização e a qualificação das microrregiões 
na assistência à saúde, além de recomendar a organização dos serviços de média e alta complexidade. A NOAS-02 manteve as duas modalidades de habilitação previstas pela NOAS-01 para a gestão dos municípios: Gestão Plena da Atenção Básica Ampliada - GPABA e Gestão Plena do Sistema Municipal - GPSM (BRASIL, 2001 c; 2002b).

Além dessas normas, existe o Pacto da Atenção Básica que permite, desde 1999, a realização de uma espécie de "contrato de gestão", pautado em indicadores selecionados e em negociação de metas, bem como o estabelecimento de processos sistemáticos de acompanhamento e de avaliação. Desse modo, o Pacto de Indicadores da Atenção Básica "inaugura no cotidiano da gestão do SUS uma nova prática que vincula a organização de ações e serviços de saúde à análise do desempenho de indicadores de saúde selecionados" (BRASIL, 2000a, p. 2) no sentido de melhorar a qualidade da atenção à saúde.

Ao definir as responsabilidades de cada uma das instâncias gestoras, - Pacto da Atenção Básica integra-se à Programação Pactuada Integrada $(\mathrm{PPI})^{3}$, que pretende "estabelecer de forma coerente e articulada uma nova maneira de conduzir a gestão do SUS" (BRASIL, 2002b, p. 18). Este Pacto, com seus respectivos indicadores, tem sido renovado a cada ano mediante portarias (Portaria n 779 de 14/7/2000). Além disso, tem sido discutida com estados e municípios a Agenda Nacional de Saúde.

$O$ desenvolvimento dessas ferramentas parece constituir passos relevantes para a gestão da ABS (SAMPAIO, 2003). Entretanto, a utilização de todas as potencialidades dessas tecnologias de gestão fica, em parte, na dependência da capacitação técnica das equipes municipais e do compromisso político dos dirigentes em relação ao SUS.

\section{Análise da situação atual da gestão da atenção básica nas cidades}

Não obstante os esforços mencionados no tópico anterior, a gestão da atenção básica encerra um conjunto de problemas a exigir análise e encaminhamento. ${ }^{5} \bigcirc$ fato de a assistência hospitalar/urgência/emergência ter ganho maior proeminência, face à visibilidade que adquire na mídia em função de pacientes graves sem acesso ao sistema, não deve obscurecer os desafios postos para a gestão da atenção básica. 
Nesse particular, merecem ser mencionados os desafios referentes à complexidade do perfil epidemiológico, recursos humanos (relações de trabalho, qualificação, compromisso, remuneração etc.), gestão participativa, financiamento, intersetorialidade, equidade, eficiência, entre outros. Apesar da relevância desses desafios, três problemas serão destacados para discussão na situação brasileira: o desprestígio da análise da situação de saúde, o viés do planejamento agregado e normativo, e a segmentação do sistema de saúde. Ainda que tais problemas não apresentem a mesma estatura daqueles desafios têm, no entanto, a possibilidade de diálogo com os mesmos, e assim possíveis soluções levantadas para algumas partes poderiam influenciar o todo.

\section{a) Desprestígio da análise da situação de saúde}

A análise da situação de saúde corresponde ao momento explicativo do processo de planificação/gestão. A partir desse momento, podem ser identificados os problemas de saúde (riscos e danos), examinado o perfil demográfico e suas tendências, realizado o balanço entre demanda e oferta de serviços de saúde e discutidas as necessidades na situação atual. A explicação dos problemas e a busca dos determinantes das necessidades de saúde conferem maior racionalidade na análise da situação, oferecem elementos para a configuração de prognósticos ou cenários (KNOX, 1981) e permitem vislumbrar certas oportunidades para a ação. Apesar de alguns esforços esparsos de institucionalização do planejamento como ferramenta de gestão (PAIM, 2002) e não obstante a exigência legal de elaboração de planos municipais de saúde, constata-se um progressivo desprestígio da análise da situação de saúde.

Assim, as necessidades de saúde que requerem ações individuais e coletivas visando à prevenção e ao controle de doenças e agravos, bem como as de proteção e promoção da saúde, não têm sido dimensionadas para melhor planejar e organizar a atenção básica. Os problemas de saúde que constituem a demanda por serviços de ambulatório, apoio diagnóstico e terapêutico, urgência/emergência e assistência hospitalar têm sido pouco investigados para orientar a oferta. Desse modo, as doenças e agravos que se distribuem na população nem sempre são consideradas para o estabelecimento de prioridades ou mesmo para fundamentar as intervenções. A utilização da epidemiologia na planificação da atenção à saúde (KNOX, 1981) passa a ser supérflua, cumprindo apenas o ritual de apresentar certos indicadores no capítulo diagnóstico dos planos de saúde. As recentes propostas de elaboração de agendas de saúde (nacional, estadual e municipal) ainda não modificaram tal situação. 
A ausência de um sistema de informação que forneça indicadores de necessidades e cobertura/utilização de serviços de saúde restringe a análise dos problemas. A inexistência de indicadores que apontem tais necessidades ou mesmo as demandas real e potencial, considerando a população residente nos diversos lugares da cidade e o fluxo adicional de pessoas de outros municípios ou estados que buscam serviços de saúde de grandes centros urbanos, compromete o processo decisório referente à condução dos sistema de saúde e, em particular, a gestão da atenção básica.

Até o sistema de informações ambulatoriais do SUS (SIA-SUS), montado sob uma lógica inampsiana vinculada a procedimentos e produtividade, tem sido pouco utilizado para fins de planejamento. Este sistema encontra-se atualmente em declínio, pois a implantação do $P A B$, viabilizando repasses financeiros globais em vez de pagamentos por procedimentos, teve como efeito colateral o abandono do SIA-SUS por parte de certos gestores municipais (SAMPAIO, 2003).

O Sistema de Informação da Atenção Básica (SIAB), inicialmente concebido para o acompanhamento do PACS/PSF, inclui diversos indicadores (demográficos, sociais, cobertura do PACS e PSF, morbidade, mortalidade, difusão de práticas preventivas e de utilização de serviços), além de contemplar as dimensões de território, micro-localização de problemas e responsabilidade sanitária. Abrange diversos níveis agregação - micro-área em que residem 150 a 250 famílias cobertas por agentes comunitários, território com 600 a 1000 famílias vinculadas à equipe de saúde da família (ESF), segmento, estado, regiões e país. Este sistema tem sido objeto de propostas de reformulação no sentido de contemplar todas as unidades básicas de saúde e não apenas aquelas de saúde da família, podendo contribuir para "identificação de desigualdades nas condições de saúde da população através da espacialização das necessidades e respostas sociais" (BRASIL, 2000a, p. 22).

Apesar da sua importância e dos indicadores que produz, esses sistemas de informação não são suficientes para uma análise da situação de saúde que contemple tanto os problemas do estado de saúde da população quanto os problemas dos serviços de saúde. Portanto, o planejamento presentemente realizado por intermédio da PPI, embora tenha alcançado indiscutível progresso, ainda mostra-se deficiente para aferir necessidades e demandas, restando para muitos gestores apenas uma impressão geral sobre a insuficiência na oferta da atenção básica. 


\section{b) Viés do planejamento agregado e normativo}

Além da insuficiência de informações, o próprio enfoque do planejamento utilizado compromete a racionalização da oferta da ABS, pois, normalmente, toma como "objetos" uma população supostamente homogênea da cidade e uma rede de serviços aparentemente comungando os mesmos objetivos e interesses. Este viés do planejamento agregado e normativo negligencia a heterogeneidade estrutural que segmenta a população em classes sociais com distintos poderes econômico, político, cultural e simbólico, bem como a apropriação e a ocupação diferenciadas do espaço urbano (SILVA et al., 1999), de um lado, e a distribuição desigual dos poderes técnico, administrativo e político (TESTA, 1992) nos serviços de saúde, de outro.

As desigualdades sociais que resultam desses determinantes estruturais produzem perfis epidemiológicos diversos segundo as condições de vida dos diferentes segmentos sociais (PAIM, 2000), assim como padrões de consumo de bens e serviços de saúde bastante diferenciados. Se o planejamento ignora as desigualdades em saúde, enquanto expressão de desigualdades sociais, deixa de considerar os diferentes danos e riscos a que estão sujeitos distintamente os subgrupos da população que ocupam o espaço urbano, perdendo, conseqüentemente, a sua relevância. Propostas alternativas como as cidades saudáveis, promoção e vigilância da saúde (TEIXEIRA, 2002), apesar de mencionadas em documentos técnicos e oficiais (BRASIL, 1996; RADIS, 2000; BRASIL, 2002a) e desenvolvidas em alguns municípios, não chegaram a constituir políticas para o conjunto das cidades brasileiras.

Do mesmo modo, o planejamento encontra obstáculos para a racionalização pretendida no que tange à organização de redes regionalizadas e hierarquizadas de serviços de saúde com mecanismos formais e eficientes de referência e contra-referência ${ }^{7}$, quando negligencia os diagnósticos estratégico e ideológico no âmbito do setor e não desenvolve um pensamento estratégico que apreenda as contradições e estabeleça cursos de ação para contornar os impasses, seja na oferta, seja na demanda.

Do lado da oferta, os hospitais integrantes dos SUS funcionam de modo autárquico $^{8}$, pouco se preocupando com o que ocorre na rede básica, na maioria das vezes com serviços redundantes nos seus ambulatórios a ponto de hospitais universitários atenderem casos simples de infeção respiratória aguda, diarréia e escabiose. Se esta inserção não solidária no sistema de serviços se saúde já se fazia na época do SUDS e das AIS (CARDOSO, 1988), a situação agravou-se com a lógica de produtividade inoculada pelas 
AlH e demais mecanismos de remuneração dos hospitais públicos, semelhantes aos dos serviços privados contratados pelo SUS.

Do lado da demanda, evidências reforçam o pressuposto de que "o acesso real não ocorre em função de uma hierarquização formal idealizada, mas, pelo contrário, da utilização de diversas estratégias que a população utiliza, em face dos constrangimentos impostos pela precariedade da oferta" (BODSTEIN, 1993, p. 12).

\section{c) Segmentação do sistema de saúde brasileiro}

Ainda que seja possível enfrentar os problemas relativos à análise da situação de saúde e ao planejamento de grandes agregados nos níveis técnicoadministrativo e técnico-operacional do SUS, mediante a incorporação de propostas alternativas de atenção e da planificação estratégica e situacional (TEIXEIRA, 2002), o mesmo não ocorre com o problema da segmentação do sistema de saúde brasileiro. Nesse caso tem-se uma questão política bastante complexa, social e historicamente determinada. Assim, cabe reconhecer as diferentes modalidades assistenciais que mantêm paralelismo de ações e relações competitivas, parasitas ou predatórias com o SUS. Trata-se de modalidades assistenciais vinculadas ao "sistema de assistência médica supletiva" (SAMS), tais como a medicina de grupo, o seguro-saúde e outros "planos de saúde", e aquelas vinculadas ao desembolso direto (medicina liberal e certas empresas médicas).

Apesar da denominação Sistema Único de Saúde, podem ser constatados nas grandes cidades brasileiras três "sistemas": o SUS (público), o SAMS (prépagamento) e o da chamada "medicina liberal" (desembolso direto). Alguns autores chamam a atenção para a "perversidade que a manutenção dos três sistemas separados induz pela existência de subsídios cruzados entre eles e pela sustentação, ainda que parcial, dos sistemas privados com base em renúncias fiscais e contributivas" (MENDES, 1998, p. 42).

A mera existência dessas modalidades assistenciais do setor privado em saúde produz efeitos simbólicos ao insinuar maior qualidade, amenidade, agilidade e conforto aos pacientes, em contraposição aos serviços públicos. Esse sistema, voltado para subespecialidades médicas, compromete a eqüidade já que "os recursos necessários para a atenção altamente técnica orientada para a enfermidade competem com aqueles exigidos para oferecer serviços básicos, especialmente para as pessoas que não podem pagar por eles" (STARFIELD, 2002, p. 21). Além disso, a oferta desordenada de assistência 
médica ambulatorial desse setor privado dificulta a realização do planejamento e da programação local em saúde e favorece a concentração de atendimentos a uns indivíduos em detrimento de outros.

Apesar de a lei 8080/90 estabelecer a regulação em saúde para todo o sistema de saúde e não apenas para o subsistema público (SUS), a sua regulamentação, mediante normas operacionais e assistenciais, não contemplou as modalidades assistenciais supostamente autônomas por referência ao SUS (SAMS ou serviços não-SUS). Os planos municipais e estaduais de saúde e a vigilância sanitária que poderiam orientar, pelo menos, a instalação e funcionamento de estabelecimentos de saúde (hospitais, laboratórios, consultórios, clínicas, ambulatórios etc.) não têm prestado atenção para o pleno cumprimento da lei. Esqueceram-se do preceito constitucional segundo o qual os serviços de saúde são de relevância pública, apesar de serem livres à iniciativa privada.

Até mesmo a Lei dos Planos de Saúde e a própria criação da Agência Nacional de Saúde (BRASIL, 2002c), nascidas sob o modismo da regulação, não regularam adequadamente a oferta de serviços de saúde e, em particular, a ABS nessas modalidades assistenciais não-SUS.

Esses fatos tornam a gestão da atenção básica muito complexa, sobretudo por não poder se descolar dos outros níveis do sistema do mesmo modo que os municípios não conseguem prescindir das instâncias de gestão estadual e nacional do SUS. Assim, ao lado da engenharia política necessária à implementação da descentralização da gestão em saúde face às características do federalismo brasileiro, o gestor da atenção básica participa de negociações penosas para compra de serviços no setor privado contratado pelo SUS e tem fora de sua governabilidade a assistência médica supletiva. Resolver essa equação, composta por elementos extremamente contraditórios representa uma das questões centrais da gestão da atenção básica nas grandes cidades brasileiras.

\section{Questões para a gestão da atenção básica}

Pensar a atenção básica nas grandes cidades brasileiras, portanto, requer levar em consideração duas questões que continuam a produzir fatos negativos para $A B S$ em situações concretas: o aprofundamento das desigualdades sociais entre os

62 diferentes segmentos populacionais que ocupam distintamente o espaço 
urbano; e a segmentação do sistema de saúde brasileiro com superposição de consumo entre diversas modalidades assistenciais para as classes alta e média e dificuldades de acesso ou exclusão para os mais pobres.

No primeiro caso, caberia examinar os diferenciais intra-urbanos da mortalidade, morbidade e riscos enquanto expressão das desigualdades de saúde. Estas representam a face fenomênica das iniqüidades sociais a serem investigadas pela economia política da cidade (SANTOS, 1994). Na realidade, as iniqüidades sociais constituem a essência das formas de produção e reprodução social nas cidades sob o capitalismo, tal como revelam diversos estudos sobre saúde e condições de vida. A própria constituição do espaço urbano, por sua vez, indica certos determinantes históricos e estruturais que conformam a distribuição espacial das populações, segundo condições de vida, e ajuda a analisar a situação de saúde e a explicar as desigualdades em saúde (PAIM, 1995). O estudo desse espaço, território utilizado ao longo da história, com seus sistemas de objetos e sistemas de ações, seus fixos e fluxos, "aponta para a necessidade de um esforço destinado a analisar sistematicamente a constituição do território" (SANTOS \& SILVEIRA, 2001, 20).

A segmentação do sistema de saúde brasileiro, instalada a despeito do SUS, reproduz as mesmas desigualdades observadas nas condições de saúde, dessa vez em relação ao acesso e qualidade da atenção. Propostas de regionalização e hierarquização da atenção à saúde, tal como as contidas nas NOAS (2001 e 2002), e o fortalecimento da "estratégia de saúde da família", apesar de inteligíveis pelo seu caráter racionalizador, estão longe de responder à segmentação dos sistema, sobretudo sem os investimentos necessários à expansão da rede pública e à remuneração adequada dos seus recursos humanos.

Este apartheid sanitário representa, portanto, o enigma a ser decifrado para a gestão da atenção básica, especialmente nas grandes cidades. Assim, a pergunta central é como fortalecer processos de reorganização da atenção básica, mantendo o padrão de desigualdades e a segmentação do sistema de saúde por tempo indeterminado? Evidentemente que questões como esta, ao permanecerem sem políticas públicas consistentes voltadas para a sua equação, configuram constrangimentos para o desenvolvimento da $A B S$ na perspectiva da equidade, qualidade, efetividade e humanização. 


\section{Proposições preliminares}

As proposições e estratégias expostas a seguir constituem uma sistematização preliminar, sem proceder, por conseguinte, a análises de coerência, factibilidade e de viabilidade. Seu propósito é estimular uma reflexão capaz de propiciar debates e encaminhamentos políticos que favoreçam a consolidação da ABS nas grandes cidades. O Brasil já dispõe de um acúmulo de experiências inovadoras nas últimas décadas (ALMEIDA, 1989; SCHRAIBER, 1990; CECÍLIO, 1994; CAPISTRANO FILHO, 1995; TEIXEIRA \& MELO, 1995; SCHRAIBER et al., 1996; MERHY \& ONOCKO, 1997; MENDES, 1998; Silva Jr, 1998; TEIXEIRA, 2002) que precisam ser valorizadas e difundidas no sentido de contribuir para a qualificação da gestão da atenção básica.

No que diz respeito à análise da situação de saúde, cabe reforçar o estudo da distribuição espacial de problemas de saúde com o objetivo de identificar grupos mais vulneráveis para a adoção de políticas públicas. Desde a constatação de uma distribuição extremamente desigual da mortalidade infantil entre diferentes distritos ou bairros em cidades como São Paulo, Porto Alegre e Salvador na década de 1980 aponta-se para a pertinência da utilização dessa abordagem na planificação e gestão. Tais investigações sobre desigualdades em saúde recuperaram os estudos ecológicos da epidemiologia para a planificação em saúde e possibilitaram a sua utilização pela mídia, organizações da sociedade civil e secretarias de saúde. Na Bahia, verificou-se o aproveitamento dos resultados dessas pesquisas pela Secretaria Municipal de Saúde de Salvador no desenvolvimento dos seus programas entre 1993 e 1996 e na elaboração do Plano Municipal de Saúde (1997-2001) e pela Secretaria do Estado no caso do Plano Estadual de Saúde (1996-1999). Tais estudos (PAIM et al., 1999; PAIM, 2000) revelam o caráter desigual da distribuição espacial das violências possibilitando compor "mapas do risco" de homicídios (NORONHA et al., 1997). Desse modo, tornou-se possível "microlocalizar" o risco de morrer por essa causa e identificar os diferenciais intraurbanos de mortalidade. O mapeamento das áreas de maior risco permite, portanto, uma maior atenção para as populações vulneráveis e a formulação de políticas públicas tendo em conta os espaços de ocorrência das violências e de residência das vítimas.

Portanto, a análise de informações desagregadas no espaço urbano pode ensejar, também, um planejamento desagregado e a organização da saúde 64 no nível local (MENDES, 1998). No caso da gestão, caberia assegurar 
a universalização da atenção básica ampliada, iniciando pelas áreas com piores condições de vida e saúde, enquanto se racionaliza a oferta dos níveis secundário e terciário (média e alta complexidade) e se valoriza os mecanismos formais referência e contra-referência mediante um desenho estratégico.

O caminho a ser acionado seria o cadastro amplo dos indivíduos e famílias para o cartão SUS, por intermédio da distritalização. As iniciativas de organização de distritos sanitários em cidades como Salvador, Maceió, Natal, Fortaleza, Curitiba e São Paulo, entre outras (TEIXEIRA \& MELO, 1995; SILVA JR, 1998), apesar de negligenciadas até recentemente pelo Ministério da Saúde, poderão ser recuperadas por processos inovadores de gestão da atenção básica. A metodologia a ser adotada seria semelhante à usada pelo IBGE nas pesquisas censitárias. Isto facilitaria procedimentos posteriores de geoprocessamento dos dados bem como a utilização de técnicas de análise espacial (Najar \& Marques, 1998).

Diversas experiências têm sido acumuladas no Brasil com sistemas de informação geográfica (SIG) para a área de saúde (TASCA et al., 1993; 1995; KADT \& TASCA, 1993; FERREIRA \& AZEVEDO, 1998; RIPSA, 2000) e precisam ser utilizadas mais amplamente como ferramenta de gestão da atenção básica. Entretanto, o alto custo e complexidade tecnológica de alguns desses empreendimentos não devem inibir a análise da distribuição espacial dos eventos de interesse para a saúde. Desde os estudos clássicos do jovem Engels sobre a situação da classe trabalhadora em Londres no início do século XIX podem ser constatadas as desigualdades em saúde e suas relações com as condições de vida, (PAIM, 1995), mesmo sem a utilização do computador...

No que concerne a uma alternativa ao planejamento de agregados e normativo, a distritalização pode ser considerada uma tática de reorientação de sistemas de saúde que considera a heterogeneidade do espaço urbano e a diversidade da situação de saúde segundo as condições de vida das populações inseridas nos distintos territórios. Requer no seu desenho estratégico o teste de modelos de atenção, epidemiologicamente orientados com ênfase na atenção básica, a exemplo da oferta organizada, das ações programáticas e, especialmente, a vigilância da saúde. O distrito sanitário não se restringe, portanto, a uma concepção topográfica e burocrática (MENDES, 1996). Ao contrário, quando a distritalização é acompanhada de propostas alternativas de modelos de atenção, verificam-se novas perspectivas para a gestão da atenção básica.

No caso da vigilância da saúde, trata-se de uma proposta reconhecida como uma via de reorganização da atenção básica (BRASIL, 2000a) na medi- 
da em que orienta uma intervenção integral sobre distintos momentos do processo saúde-doença: os determinantes estruturais socioambientais, riscos e danos (PAIM, 1999). Assim, contempla a promoção da saúde, a prevenção de doenças e outros agravos e a atenção curativa e reabilitadora.

A proposta de vigilância da saúde transcende à idéia de análise de situações de saúde (monitoramento e vigilância da situação de saúde através da "inteligência epidemiológica") ou a mera integração institucional das vigilâncias sanitária e epidemiológica. Ao contrário, apóia-se na ação intersetorial sobre o território e privilegia a intervenção, sob a forma de operações, nos problemas de saúde que requerem atenção e acompanhamento contínuos. A sua operacionalização se realiza mediante a microlocalização dos problemas de saúde, a apropriação de informações sobre território-processo por intermédio de "oficinas de territorialização" e utilização da Geografia Crítica e do planejamento e programação local de saúde (TEIXEIRA et al., 1998).

Se a perspectiva da gestão corresponde à da vigilância da saúde e não à primazia da assistência médica-hospitalar, pouco importaria se as pessoas com melhores condições de vida informassem que não pretendem "usar" o SUS $^{10}$. Na realidade, elas poderão utilizar o SUS na urgência/emergência, nos procedimentos de alta complexidade, ou mesmo no atendimento domiciliar para idosos, pacientes com transtornos mentais e doenças crônicas. E ainda que não utilizem tais serviços, estarão sujeitas a surtos e epidemias a exigir ação coletiva (que também é SUS) bem como a ações de proteção a riscos, prevenção de danos e de promoção da saúde.

No caso da proposta referente às cidades saudáveis contempla uma gestão governamental que inclui a promoção da cidadania e o envolvimento criativo de organizações 'comunitárias' no planejamento e execução de ações intersetoriais dirigidas à melhoria das condições de vida e saúde, principalmente em áreas territoriais das grandes cidades onde se concentra a população exposta a uma concentração de riscos vinculados à precariedade das condições de vida, incluindo fatores econômicos, ambientais e culturais (TEIXEIRA, 2002, p. 90-1).

Essa proposta, apoiada pela OMS a partir da década de 1980 vem sendo reconhecida como geradora de políticas públicas saudáveis com impacto positivo sobre a qualidade de vida nas cidades (FERRAZ, 1993). Alguns setores do Ministério da Saúde vêm estimulando o desenvolvimento da Promoção da Saúde e apoiando a estratégia do Município Saudável (RADIS, 2000; BRA66 SIL, 2002a)". De acordo com o Ministério, "um município começa a se 
tornar saudável quando suas organizações locais e seus cidadãos adquirem o compromisso e iniciam o processo de melhorar continuamente as condições

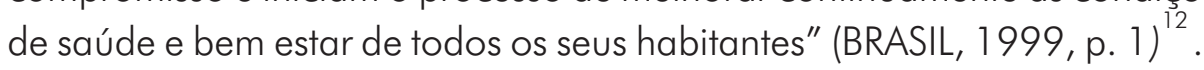

O movimento das cidades saudáveis pode potencializar a ampliação progressiva do PSF. ${ }^{13}$ Assim o cadastro amplo sugerido no início deste tópico deveria distinguir os segmentos da população totalmente usuários do SUS e aqueles apenas parcialmente usuários, qualificando os vários graus e níveis. O PSF seria mantido como a estratégia fundamental para tal proposição em face de sua compatibilidade com a vigilância da saúde e com a proposta das cidades saudáveis. No entanto, deveriam ser cogitadas algumas alternativas para os "sem família", ou seja, os moradores de rua, crianças e adolescentes em situação de risco e até mesmo certos grupos de residentes em áreas sob o domínio do narcotráfico e demais organizações criminosas. Nesses casos, os procedimentos utilizados pelo PSF e pela vigilância da saúde teriam de ajustar-se, com criatividade e respeito à cidadania, às especificidades de cada contexto.

Num segundo momento poder-se-ia cruzar informações do cadastro para - Cartão SUS com as obtidas pelo IBGE nas pesquisas da assistência médica e sanitária e PNAD-saúde dimensionando necessidades, cobertura e utilização da ABS por diferentes segmentos sociais, e considerando as variáveis renda, educação e ocupação. Finalmente, seriam utilizados os dados produzidos pelo cadastro e pelo SIAB (Sistema de Informação da Atenção Básica), adotados pelo PACS/PSF (decorrentes da sua ampliação ou quase universalização) na perspectiva da distritalização e da vigilância da saúde.

Já que o SIAB e as equipes de saúde da família não cobrem toda a população, poderiam ser adotados certos parâmetros utilizados no aplicativo da PPI ${ }^{14}$ (SAMPAIO, 2003) e modificados, progressivamente, considerando a experiência de implantação do SUS e do próprio SIAB. Este procedimento poderia, mediante aproximações sucessivas, calcular os investimentos necessários à ampliação da oferta da atenção básica, estimando as possibilidades de uso dos serviços da SAMS e da medicina liberal por certos segmentos da população.

As informações obtidas por tais mecanismos orientariam a implantação de novas equipes de saúde da família (ESF), a instalação de unidades de saúde da família (USF), de ambulatórios e de serviços de apoio diagnóstico e terapêutico que assegurassem a atenção básica ampliada (ABA). Daí a relevância do PSF: enquanto se montam serviços estruturados, podem ser criadas equipes de saúde da família (ESF) voltadas para necessidades e demandas. 
A partir delas seriam estruturados serviços com outras lógicas, inclusive da oferta pública da atenção especializada. Esses elementos deveriam, necessariamente, compor o plano diretor de investimentos, articulado ao plano municipal de saúde, tendo em conta as experiências do orçamento participativo (OP).

Se o acesso e cobertura representam variáveis importantes para a ABS, torna-se imprescindível desagregar, o máximo possível, a produção de dados e informações no espaço urbano. Assim, a espacialização dessas informações entre distritos sanitários, bairros, zonas de informação, setores censitários e logradouros é fundamental para analisar a situação de saúde segundo as condições de vida da população e, sobretudo, para planejar a melhoria do acesso à ABS na malha urbana, considerando os fixos e os fluxos (SANTOS, 1997), tais como unidades de saúde, acesso físico, vias de transportes etc. Portanto, a ênfase no planejamento e programação local em saúde (TEIXEIRA, 1993) corresponde a uma via para o alcance de maior racionalização na oferta da $\mathrm{ABS}$ e, conseqüentemente, uma utilização mais razoável dos níveis secundário e terciário da atenção ${ }^{16}$. A experiência de Vitória da Conquista (BA) demonstra como a gestão da atenção básica, apoiada na distritalização, vigilância da saúde e saúde da família, pode reorganizar o sistema de saúde e assegurar o atendimento nos níveis secundário e terciário, incluindo central de marcação de consultas e procedimentos especializados com terminais funcionando em rede (BRIGHAM \& RODRIGUES, 2000; GOULART, 2002).

Finalmente, cabe enfrentar a questão da segmentação do sistema de saúde brasileiro, tendo em vista o preceito constitucional segundo o qual a saúde é livre à iniciativa privada e, também, as restrições financeiras impostas à expansão do setor público de saúde.

Seria útil refletir, do ponto de vista jurídico, sobre as possibilidades de regulação da $A B S$ do setor privado mediante regulamentação da Lei Orgânica da Saúde (CONASEMS, 1990) e da Lei n 5536/98 (BRASIL, 2002c), seja por decreto presidencial ou portaria ministerial. Em caso positivo, seria estimulada a elaboração de projetos de lei nos níveis estadual e municipal sobre a matéria, além de pactuar novas normas, portarias e decretos a serem estabelecidos pelo nível federal que pudessem respaldar tais iniciativas. No que diz respeito ao desenho estratégico, essa regulamentação poderia ser realizada por etapas, iniciando com a ABS e concomitante à expansão do PSF nos centros urbanos. Em caso negativo, caberia elaborar projeto de lei no sentido de 68 regular o mercado nessas modalidades assistenciais não-SUS, assim como 
a oferta de serviços públicos de saúde (ABS, média e alta complexidade), inclusive no que diz respeito à importação, localização e instalação de equipamentos médico-hospitalares.

\section{Comentários Finais}

As proposições acima formuladas no sentido de contribuir nos debates para superar o desprestígio da análise da situação, o viés do planejamento agregado e normativo, bem como a segmentação do sistema de saúde que incidem sobre a reprodução do apartheid sanitário brasileiro requerem, além de análise crítica e fundamentação técnica, a mobilização de vontades para a construção da sua viabilidade.

A gestão da atenção básica, portanto, não está imune aos grandes desafios postos para o desenvolvimento do sistema de saúde brasileiro. As dicotomias historicamente postas entre saúde pública e medicina, desde o século XIX, têm sido objeto de reflexão e de intervenção pelo campo da Saúde Coletiva no Brasil. E a chamada rede básica de serviços de saúde atraiu para si distintos projetos tecno-assistenciais que competiram na condução das políticas de saúde nas diferentes conjunturas da República: posições conservadoras em que a assistência médica é vista sob a lógica do mercado e a saúde pública é destinada aos necessitados ou excluídos, mediante campanhas, programas especiais e educação sanitária em postos e centros de saúde; posições reformadoras que preservam a dicotomia assistência médica e saúde pública e apenas propõem uma rede básica como "porta de entrada" do sistema público de saúde; e as posições transformadoras, originárias do movimento sanitário e da $8^{a} \mathrm{CNS}$, ao postularem que a rede básica teria de ser não só a porta de entrada de um sistema de saúde, mas o lugar essencial a realizar a integralidade das ações individuais e coletivas de saúde, ao mesmo tempo em que fosse a linha de contato entre as práticas de saúde e o conjunto das práticas sociais que determinam a qualidade de vida, provocando a mudança no sentido das práticas (MERHY, 1997, p. 224).

A Constituição de 1988 ao reconhecer a saúde como direito de todos e dever do Estado, garantido mediante políticas sociais e econômicas, eleva-a como expressão da qualidade de vida. Desse modo, ou a questão saúde configura-se como questão de Estado e não apenas de governo, ou haverá grandes obstáculos para a superação dos seus impasses. Essas reflexões apontam para a tese segundo a qual a questão saúde no Brasil não pode ser enfrenta- 
da exclusivamente por políticas setoriais. Enquanto qualidade de vida, a saúde deve mobilizar todas as pessoas, individualmente, e a sociedade, organizada ou não.

Na medida em que a atenção básica de saúde (ABS) não fique confinada aos antigos "pobres da cidade" (MONTANO, 1983) nem a gente pobre criada pelas grandes cidades junto ao desmantelamento do estado de bem-estar (SANTOS \& SILVEIRA, 2001, p. 287), a gestão da ABS terá de interagir com todo o sistema de saúde e com arranjos intersetoriais para garantir efetividade, qualidade, equidade e integralidade das intervenções. Assim, alguns autores têm mostrado a necessidade de "novas missões e papéis para esta rede básica, que se traduzem pela construção de um modelo de atenção que permita, junto ao conjunto dos usuários, realizar práticas que acolham, vinculem e resolvam, no sentido de promover e proteger a saúde, no plano coletivo" (MERHY, 1997, p. 198).

Algumas das reflexões e proposições esboçadas nos tópicos anteriores tiveram a preocupação de examinar certas vias para o cumprimento dessas "novas missões" da gestão básica, embora sem a pretensão de apresentá-las como uma norma dura capaz de ser adotada em todas as situações. Ao contrário, o recurso ao enfoque estratégico-situacional no planejamento participativo das ações de saúde, locais e intersetoriais, para a promoção da saúde e qualidade de vida, talvez seja um dos caminhos a explorar (TEIXEIRA \& PAIM, 2000). Nessa perspectiva, a produção de conhecimentos e a cooperação técnica em políticas públicas, planificação e gestão podem fazer diferença no processo de formulação e de implementação de políticas de saúde e na mudança das práticas sanitárias em conjunturas que contem com governos democráticos, efetivamente comprometidos com a transformação social.

\section{Notas}

2 PAB corresponde a um valor per capita, que somado às transferências estaduais e aos recursos próprios dos municípios, deveria financiar a atenção básica da saúde (BRASIL, 1998).

${ }^{3}$ Entre os objetivos da PPI, destacam-se: a) garantir a eqüidade do acesso; b) explicitar os recursos federais, estaduais e municipais, que compõem o montante de recursos do SUS; c) consolidar o papel das secretarias estaduais de saúde na coordenação da política estadual de saúde e na regulação geral do sistema estadual de saúde; d) estabelecer processos e métodos que assegurem a condução única do sistema de saúde em cada esfera de governo; e) consubstanciar 
as diretrizes de regionalização da assistência à saúde; f) explicitar a programação dos recursos estaduais e municipais, respeitada a autonomia dos vários níveis de gestão e realidades locais (BRASIL, 2000a).

${ }^{4}$ A Agenda estabelece os seguintes eixos prioritários de intervenção: a) redução da mortalidade infantil e materna; b) controle de doenças e agravos prioritários; c) reorientação do modelo assistencial e descentralização; d) melhoria da gestão, do acesso e da qualidade das ações e serviços de saúde; e) desenvolvimento de recursos humanos do setor saúde (BRASIL, 2001d).

${ }^{5}$ Nesse particular, não se pode esquecer a grande variedade das cidades brasileiras. $\bigcirc$ país possui cerca de 5.500 municípios com grande diversidade de extensão, de população e de condições socioeconômicas. Se forem consideradas apenas as cidades com mais de 100.000 habitantes, elas passaram de $12 \mathrm{em}$ 1940 para 101 em 1980 e 175 em 1996 (SANTOS \& SILVEIRA, 2001, p. 205).

${ }^{6}$ Existe, no entanto, um conjunto de indicadores para o acompanhamento da atenção básica nos municípios habilitados pelas normas em vigor tendo em conta os seguintes bancos de dados nacionais: a) Sistema de Informação sobre Mortalidade - SIM; b) Sistema de Informações sobre Nascidos Vivos - SINASC; c) Sistema de Vigilância Alimentar e Nutricional - SISVAN; d) Sistema de Informações sobre Agravos de Notificação - SINAN (BRASIL, 1998b).

Observou-se em São Paulo que "as unidades básicas atendiam a população e faziam seu encaminhamento, sem entrar no mérito de ter esta assistência se transformado ou não em 'encaminhoterapia'; quando o paciente chegava aos serviços de referência, ou não recebia atendimento, ou, se atendido, os diagnósticos e tratamento preconizados nas unidades básicas não eram considerados" (HEIMANN et al., 1992, p. 151). Resultados semelhantes foram constatados na Bahia (CARDO$\mathrm{SO}, 1988)$.

" "É na assistência médica especializada que a força do corporativismo se faz decisiva e os critérios de acesso mais 'obscuros'. Trata-se de uma clientela construída pela própria prática médica. Destarte é nos hospitais especializados que sobressai o intercâmbio informal entre médicos, sobrepondo-se ao sistema de referência e contra-referência, formando verdadeiras clientelas cativas dentro do serviço público" (VELLOZO \& SOUZA, 1993, p. 109).

${ }^{9}$ Estudo realizado em uma área de planejamento do Rio de Janeiro no início da implantação do SUS indicava uma "proporção de praticamente 50\% entre o número de hospitais e de unidades ambulatoriais e, conseqüentemente, um enorme déficit de unidades básicas na área" (CARVALHO, 1993, p. 126).

${ }^{10} \mathrm{O}$ ex-secretário de Atenção à Saúde do Ministério da Saúde, Dr. Jorge Solla, lembrou que "o senso comum diz que o usuário do SUS está na população de baixa condição socioecnonômica, enquanto sabemos que, hoje, o SUS é utilizado por toda a população. $\bigcirc$ que difere é o quanto você precisa utilizar e o que você precisa utilizar" (RADIS, 2003, p. 31).

${ }^{11}$ Entre as principais características desses municípios destacam-se: iniciativa local com forte compromisso político; mobilização e participação comunitária; estrutura organizada e ações intersetoriais; diagnóstico de problemas e necessidades; liderança local reconhecida. 
Essa estratégia teria as vantagens de apoiar processos de descentralização, fortalecer a participação social e o processo democrático, influir nas políticas públicas locais, incorporar a promoção da saúde na agenda de desenvolvimento local e de coadjuvar na reorientação dos serviços de saúde (BRASIL, 1999).

13

O secretário de Atenção à Saúde informou, recentemente, o propósito da expansão e qualificação da atenção básica, com investimentos apoiados pelo Banco Mundial para os próximos cinco anos e meio. No que se refere ao PSF, a meta seria implantar mais 4000 equipes em 2003 (Saúde, Brasil, 2003) e dobrar a população coberta em quatro anos (100 milhões de pessoas). Assim, pretende-se "requalificar a Atenção Básica, criando condições de maior resolutividade para o PSF, articulando o acesso de pacientes que precisarem da Atenção Especializada, melhorando e investindo em ações de qualificação de recursos humanos visando superar a precarização do trabalho na área da Saúde" (RADIS, 2003, p. 29).

${ }^{14}$ A partir de maio de 2001, a primeira versão eletrônica de um instrumento de programação elaborado pelo Ministério da Saúde foi colocada à disposição dos estados para subsidiar a elaboração da PPI juntamente com os municípios. "Este instrumento buscou relacionar e explicitar compromissos que iam desde a agenda nacional e agendas estaduais e municipais de saúde, o pacto da atenção básica, até a programação das ações propriamente ditas e relatórios de cunho gerencial. A programação iniciava-se pela atenção básica, seguindo para média e alta complexidade, programação hospitalar, do tratamento fora do domicílio TFD, das órteses e próteses, enfim de todos os grupos que compõem as ações financiadas pelo SUS nos três níveis de governo" (SAMPAIO, 2003, p. 11-2).

${ }^{15}$ Uma das desvantagens atuais desse aplicativo da PPI reside no planejamento de agregados e normativo. Assim, o objeto de programação é a população do município e não os residentes de unidades menores como regiões administrativas, distritos sanitários ou bairros, tal como trabalha o planejamento e programação local da vigilância à saúde. No entanto, ao nível local, este aplicativo poderia ser complementado com os instrumentos elaborados por Silva (2002). Nesse estudo, a autora indica os avanços alcançados pelo PSF, no que se refere à realização de atividades voltadas para o controle de riscos e de danos, porém com insuficiência das ações de controle das causas. Os seis instrumentos elaborados servem ao planejamento e gestão do trabalho em Saúde da Família e, especialmente, para a supervisão das equipes e dos agentes das práticas de saúde. Mesmo reconhecendo a pertinência de considerar o trabalho vivo em ato e, portanto, as tecnologias leves como propõe Merhy (1997), que permitiriam a criatividade e a adequação às singularidades do real, não creio ser dispensável certo grau de padronização de condutas técnicas tendo em vista a meta de mais de 30.000 equipes de saúde da família no Brasil. Conseqüentemente, as atividades relacionadas nos seis instrumentos poderiam representar um embrião para o estabelecimento de normas técnicas para o trabalho das equipes e, como tal, balizamentos para a formação das equipes e para a educação permanente dos seus agentes. Nessa perspectiva, as universidades e serviços de saúde que integram os Pólos de Capacitação em Saúde da Família teriam muito o que contribuir para o salto de qualidade que requer o PSF tendo em conta a sua expansão no Sistema Único de Saúde. 
${ }^{16}$ A partir do instrumento desenvolvido para a PPI foi possível proceder a estimativas e simulações, com parâmetros flexíveis para o cálculo automático das ações, inclusive de exames complementares para o cumprimento de protocolos de prénatal, hipertensão e diabetes. Desse modo, torna-se possível calcular déficit de coberturas, além de programar diversas áreas. Na PPI/AB-2002 foram acrescidas às 12 telas existentes mais duas: saúde do trabalhador e outras atividades (promoção e vigilância à saúde). A partir do diagrama de vigilância da saúde (PAIM, 1999) foi observado em 2001 que 60\% das ações eram destinadas ao "controle de danos", 38\% ao "controle de riscos" e apenas $2 \%$ para o "controle de causas". Este em 2002, representou a mudança mais expressiva, pois passou para 10\% (SAMPAIO, 2003). 


\section{Referências}

ALMEIDA C. M. de. Os atalhos da mudança na saúde do Brasil. Serviços em Nível Local: 9 Estudos de Caso. Uma análise comparativa. Rio de Janeiro: OPAS/OMS; 1989. (Série Desenvolvimento de Serviços de Saúde, n. 10).

BAHIA. Secretaria Estadual de Saúde. Plano Estadual de Saúde (1988-1991). Salvador: SESAB/Assessoria de Planejamento; 1987.

BODSTEIN, R. (Org.) Serviços Locais de Saúde: construção de atores e políticas. Rio de Janeiro: Relume-Dumará; 1993.

BRASIL. Ministério da Saúde. Norma Operacional Básica SUS - 01/1993. Inf. Epid. SUS, Brasília, n. 49-73 (Número Especial), 1993a.

BRASIL. Ministério da Saúde. Programa de Agentes Comunitários de Saúde. Brasília: Fundação Nacional de Saúde, 1993b.

BRASIL. Ministério da Saúde. Avaliação Qualitativa do PACS. Brasília: Fundação Nacional de Saúde, 1994a.

BRASIL. Ministério da Saúde. PACS. Normas e Diretrizes. Brasília: Fundação Nacional de Saúde, 1994b.

BRASIL. Ministério da Saúde. Norma Operacional Básica do SUS - NOB-SUS 01/96. DOU, Brasília, v. 2, n. 70, set 1996.

BRASIL. Ministério da Saúde. 1997, o ano da saúde do Brasil: ações e metas prioritárias. Brasília: MS, 1997.

BRASIL. Ministério da Saúde. Secretaria de Assistência à Saúde. Saúde da Família: uma estratégia para a reorientação do modelo assistencial. 2 ed. Brasília: Coordenação de Saúde da Comunidade, 1998a.

BRASIL. Ministério da Saúde. Manual para a Organização da Atenção Básica. Brasília: MS, 1998b.

BRASIL. Ministério da Saúde. Programas e Projetos: Promoção da Saúde e Município Saudável. Disponível em: www.saude.gov.br. Acesso em: 20 set. 1999.

BRASIL. Ministério da Saúde. SPS/DAB/CGPLAN. Termo de Referência da Oficina de Avaliação da Atenção Básica. 2000, Salvador. Anais do 6o Congresso Brasileiro de Saúde Coletiva, Brasília, 2000a.

BRASIL. Ministério da Saúde. Secretaria de Assistência à Saúde. Avaliação da implantação e funcionamento do Programa de Saúde da Família - PSF. Brasília: Ministério da Saúde, 2000b.

BRASIL. Ministério da Saúde. Departamento de Atenção Básica. Guia prático do programa de Saúde da Família. Brasília: Ministério da Saúde, 2001 a.

BRASIL. Ministério da Saúde. Declaração de Alma-Ata. In: . Promoção da Saúde: Declaração de Alma Ata, Carta de Otawa, Declaração de Adelaide, Declaração de Sundsvall, Declaração de Santafé de Bogotá, Declaração de Jacarta, Rede de Megapaíses, Declaração do México. Brasília: MS/Projeto Promoção da Saúde, 2001 b.

BRASIL. Ministério da Saúde. Secretaria de Assistência à Saúde. Regionalização da assistência à saúde: aprofundando a descentralização com equidade no acesso. NOAS - 
SUS 01/01 Brasília: Ministério da Saúde, 2001c. (Série A. Normas e Manuais Técnicos). BRASIL. Ministério da Saúde. Gabinete do Ministro. Portaria n 393 de 29 de março de 2001. DOU 2001 Mar 30(63), 2001d.

BRASIL. Ministério da Saúde. Secretaria de Políticas de Saúde. Política Nacional de Promoção de Saúde: documento de discussão. Brasília: Ministério da Saúde, 2002a.

BRASIL. Ministério da Saúde. Secretaria de Assistência à Saúde. Regionalização da assistência à saúde: aprofundando a descentralização com equidade no acesso. NOAS SUS 01/02. 2 ed. rev. e atual. Brasília: Ministério da Saúde; 2002b. (Série A. Normas e Manuais Técnicos).

BRASIL. Ministério da Saúde. Agência Nacional de Saúde Suplementar. Regulação \& Saúde: estrutura, evolução, e perspectivas da assistência médica suplementar. Rio de Janeiro: ANS, 2002c.

BRASIL C,; RODRIGUES, A. Vitória da Conquista: a estratégia está no nome. Rev. Bras. de Saúde da Fam., Brasília, v. 1, n. 2. p. 12-9, 2000.

CAPISTRANO FILHO, D. Da saúde e das cidades. São Paulo: Hucitec, 1995.

CARDOSO DE ARAÚJO, E. A referência e contra-referência e a reorganização dos serviços: da atenção primária a um novo modelo de cuidado à saúde. $210 \mathrm{fl}$. Dissertação [Mestrado em Saúde Coletiva] - Instituto de Saúde Coletiva, Universidade Federal da Bahia, Salvador, 1988.

CARVALHO, M. R. de. Modelos assistenciais de unidades básicas e o conceito de integralidade. In: BODSTEIN R. (Org.). Serviços Locais de Saúde: construção de atores e políticas. Rio de Janeiro: Relume-Dumará, 1993.

CECÍLIO, L. C. de O (Org.). Inventando a mudança na saúde. São Paulo: Hucitec, 1994.

CONASEMS. Sistema Único de Saúde (Constituição Federal - Seção Il; Lei Orgânica da Saúde n 8080; Lei 8142; Decreto n 99.438; Carta de Fortaleza). Porto Alegre: CONASEMS, 1990. (Publicações Técnicas, 2).

CONFERÊNCIA NACIONAL DE SAÚDE, 7, Anais. Brasília: Centro de Documentação do Ministério da Saúde, 1980.

FERRAZ, S. T. A pertinência da adoção da filosofia de cidades saudáveis no Brasil. Saúde em Debate, Londrina, n. 41, p. 45-9, dez. 1993.

FERREIRA, S. M. G.; AZEVEDO, P. C. V. de. Sistema de Informação para Tomada de Decisões em Saúde - SINTOMAS. Sistema de Informação Geográfico para Sistemas Locais de Saúde. In: MENDES, E. V. A organização da saúde no nível local. São Paulo: Hucitec, 1998.

GALLO, E. (Org). Razão e Planejamento. Reflexões sobre Política, Estratégia e Liberdade. São Paulo/Rio de Janeiro: HUCITEC/ABRASCO, 1995.

GOULART, F. A. de A. Experiências em Saúde da família: cada caso é um caso? Tese Doutorado em Saúde Pública - Escola Nacional de Saúde Pública/Fiocruz, Rio de Janeiro, 2002.

HEIMANN L. S.; CARVALHEIRO, J. R.; DONATO, A. F.; IBANHES, L. C.; LOBO, E. F.; PESSOTO, U. C. O município e a saúde. São Paulo: Hucitec, 1992. 
KADT, E. de; TASCA, R. Promovendo a eqüidade: um novo enfoque com base no setor da saúde. São Paulo: Hucitec-Cooperação Italiana em Saúde, 1993.

KNOX, E. G. La epidemiologia en la planificación de la atención a la salud. Mexico: Siglo XXI, 1981.

MAHLER, H. Discurso de Halfdan T. Mahler, Diretor-Geral da Organização Mundial da Saúde. Anais 7a Conferência Nacional de Saúde; 1980, Brasília: Centro de Documentação do Ministério da Saúde, 1980.

MENDES, E. V. Importancia de los sistemas locales de salud en la transformacion de los sistemas nacionales de salud. In: PAGANINI JM, CAPOTE MIR, R. Los sistemas locales de salud. Conceptos, Métodos, Experiencias. Washington D.C.: OPS, 1990. (Publicación Científica, 519).

MENDES, E. V. Uma agenda para a saúde. São Paulo: Hucitec, 1996.

MENDES, E. V. A organização da saúde no nível local. São Paulo: Hucitec, 1998.

MERHY, E. E. A rede básica como uma construção da saúde pública e seus dilemas. In: MERHY, E. E.; ONOCKO, R. Agir em saúde: um desafio para o público. São Paulo/ Buenos Aires: Hucitec/Lugar Editorial, 1997.

MERHY, E. E.; ONOCKO, R. Agir em saúde: um desafio para o público. São Paulo/ Buenos Aires: Hucitec/Lugar Editorial, 1997.

MONTANO, J. Los pobres de la ciudad en los asentamientos espontáneos: poder y política. 4 ed. México: Editora, 1983.

NAJAR, A. L.; MARQUES, E. C. (Org.). Saúde e espaço: estudos metodológicos e técnicas de análise. Rio de Janeiro: Fiocruz, 1998.

NORONHA, C. V.; ALMEIDA, L. M. A. de; PAIM, J. S.; LANIADO, R. N. Mapa de risco da violência: cidade de Salvador. São Paulo: CEDEC, 1997.

OPS/OMS. Desarrollo y fortalecimiento de los sistemas locales de salud. La administración estrategica. Washington: OPS/OMS, 1992.

OPS. Desarrollo y fortalecimiento de los sistemas locales de salud en la transformacion de los sistemas nacionales de salud. (Documento CD33/14, Resolução XV - XXXIII del Comité Directivo. Washington, D.C., 30 de sptiembre de 1988). In: PAGANINI, J. M.; CAPOTE MIR, R. Los Sistemas Locales de Salud. Conceptos, Métodos, Experiencias. Washington, D.C.: OPS, 1990. (Publicación_Científica, 519).

PAIM, J. S. Abordagens teórico-conceituais em estudos de condições de vida e saúde: notas para reflexão e ação. In: BARATA, R. B. (Org.). Condições de vida e situação de saúde. Rio de Janeiro: Abrasco, 1995.

PAIM, J. S. A reforma sanitária e os modelos assistenciais. In: ROUQUAYROL, M. Z.; ALMEIDA FILHO, N. (Orgs.). Epidemiologia \& Saúde. 5 ed. Rio de Janeiro: Medsi, 1999.

PAIM, J. S. A epidemiologia e a superação de desigualdades em saúde. Acta Paul Enf, São Paulo, v. 13, n. 2943, 2000 (Número Especial).

PAIM, J. S. Saúde, Política e Reforma Sanitária. Salvador: CEPS-ISC, 2002.

PAIM, J. S.; COSTA, M. C. N.; MASCARENHAS, J. C. S.; VIEIRA DA SILVA, L. M. Distribuição espacial da violência: mortalidade por causas externas em Salvador (Bahia), 
Brasil. Rev. Panamericana de Salud Pública/ Pan Am J Public Health, Washington, v. 5, n. 321-332, 1999.

RADIS (TEMAS). Cidades Saudáveis. Radis Comunicação em Saúde, Rio de Janeiro, v. 19, n. 30, maio 2000.

RADIS. Entrevista: Jorge Solla. Radis Comunicação em Saúde, Rio de Janeiro, v. 8, n. 29-31, abr. 2003.

RIPSA (Rede Interagencial de Informações para a Saúde). Conceitos básicos de sistemas de informação geográfica e cartografia aplicada à saúde. Brasília: Organização Panamericana da Saúde/Ministério da Saúde, 2000.

RIVERA, F. J. U. Agir comunicativo e planejamento social: uma crítica ao enfoque estratégico. Rio de Janeiro: FIOCRUZ, 1995.

SAMPAIO, L. F. R. Integralidade da atenção à saúde: análise crítica da programação da atenção básica - PPI/AB, 2001/2002. Dissertação [Mestrado em Saúde Coletiva] - Instituto de Saúde Coletiva, Universidade Federal da Bahia, Salvador, 2003.

SANTOS, M. A urbanização brasileira. São Paulo: Hucitec, 1993.

SANTOS, M. Por uma economia política da cidade. São Paulo: Hucitec, 1994.

SANTOS, M. A natureza do espaço: técnica e tempo, razão emoção. 2 ed. São Paulo: Hucitec, 1997.

SANTOS, M.; SILVEIRA, M. L. O Brasil: território e sociedade no início do século XXI. Rio de Janeiro: Record, 2001.

SAÚDE BRASIL. Medidas reforçam atenção básica. Saúde, Brasil, Basília, v. 84, n. 4-5, 2003.

SCALDAFERRI, M. C. O profissional faz acontecer. Comprometimento no trabalho: avaliando uma dimensão do Programa de Saúde da Família. 133 fl. Dissertação [Mestrado em Saúde Coletiva] - Instituto de Saúde Coletiva, Universidade Federal da Bahia, Salvador, 2000.

SILVA, A. da P. A prática da equipe do Programa de Saúde da Família. 100fl. Dissertação de Mestrado em Saúde Coletiva - Instituto de Saúde Coletiva, Universidade Federal da Bahia, Salvador, 2002.

SILVA, L. M. V.; PAIM, J. S.; COSTA, M. C. N. Desigualdades na mortalidade, espaço e estratos sociais. Rev. Saúde Pública, São Paulo, v. 33, n. 2, p. 187-97, 1999.

SILVA, J. R. A. G. da. Modelos tecnoassistenciais em saúde. O debate no campo da Saúde Coletiva. São Paulo: Hucitec, 1998.

SCHRAIBER, L. B. (Org.). Programação em saúde, hoje. São Paulo: HUCITEC, 1990.

SCHRAIBER, L. B.; MENDES-GONÇALVES, R. B. Necessidade de saúde e atenção primária. In: SCHRAIBER, L. B.; NEMES, M. I. B.; MENDES-GONÇALVES R. B. (Org.) Saúde do adulto. Programas e ações da Unidade Básica. São Paulo: Hucitec, 1996.

SCHRAIBER, L. B. ; NEMES, M. I. B.; MENDES-GONÇALVES, R. C. (Org.) Saúde do Adulto. Programas e Ações da Unidade Básica. São Paulo: Hucitec, 1996.

STARFIELD, B. Atenção primária: equilíbrio entre necessidades de saúde, serviços e tecnologia. Brasília: UNESCO/Ministério da Saúde, 2002. 
TASCA, R.; GREGO, C.; VILLAROSA, F. N. di. Sistemas de informação em saúde para distritos sanitários. In: MENDES, E. V. (Org.) Distrito Sanitário: o processo social de mudança das práticas sanitárias do Sistema Único de Saúde. São Paulo/Rio de Janeiro: Hucitec/ABRASCO, 1993.

TASCA, R. VILLAROSA, F. N. di; GREGO, C. A construção de um sistema de informação territorializado nos distritos de saúde de Campo Limpo e de Itaquera, SP. In: TEIXEIRA, C. F.; MELO, C. Construindo Distritos Sanitários. A experiência da Cooperação Italiana no Município de São Paulo. São Paulo/Salvador: Hucitec/Cooperação Italiana em Saúde, 1995.

TEIXEIRA, C. F. Planejamento e programação situacional em distritos sanitários: metodologia e organização. In: MENDES, E. V. (Org.). Distrito Sanitário: o processo social de mudança das práticas sanitárias do Sistema Unico de Saúde. São Paulo/Rio de Janeiro: Hucitec/ABRASCO, 1993.

TEIXEIRA, C. F.; MELO, C. Construindo distritos sanitários. A experiência da Cooperação Italiana no Município de São Paulo. São Paulo/Salvador: Hucitec/Cooperação Italiana em Saúde, 1995.

TEIXEIRA, C. F. Promoção e Vigilância da Saúde. Salvador: CEPS-ISC, 2002.

TEIXEIRA, C. F.; PAIM, J. S.; VILASBOAS, A. L. SUS, modelos assistenciais e vigilância da Saúde. Inf. Epidem. SUS, Brasília, v. 7, n. 2, p. 7-28, 1998.

TEIXEIRA, C. F.; PAIM, J. S. Planejamento e programação de ações intersetoriais para a promoção da saúde e qualidade de vida. RAP, Rio de Janeiro, v. 34, n. 6, p. 63-80, 2000.

TEJADA DE RIVERO, D. Salud Pública y atención primária de Salud: una evaluación crítica. In: OPS. La crisis de la salud pública: reflexiones para el debate. Washington, DC: OPS, 1992. (Publicación Científica, 540).

TESTA, M. Pensar em saúde. Porto Alegre: Artes Médicas/ABRASCO, 1992.

VELLOZO, V. R. O.; SOUZA, R. G. de. Acesso e hierarquização: um caminho (re)construído. In: BODSTEIN R. (Org.) Serviços locais de Saúde: construção de atores e políticas. Rio de Janeiro: Relume-Dumará, 1993.

VILASBOAS A. L. Vigilância à saúde e distritalização: a experiência de Pau da Lima. 114 fl. Dissertação [Mestrado em Saúde Coletiva] - Instituto de Saúde Coletiva, Universidade Federal da Bahia, Salvador, 1998. 


\section{Epidemiologia e planejamento: a recomposição das práticas epidemiológicas na gestão do SUS ${ }^{1}$}

\section{Introdução}

Há quase meio século tem-se apontado para os usos da epidemiologia na descrição da doença na comunidade, na identificação de grupos vulneráveis e na avaliação de serviços e programas de saúde (MORRIS, 1975). No entanto, a constituição da epidemiologia enquanto disciplina científica e a reflexão epistemológica sobre a mesma seguiram, por algum tempo, os

Texto originalmente publicado em: Ciencia \& Saúde Coletiva, 8(2), p.557$567,2003$. seus próprios caminhos, sem um vínculo mais consistente com a organização social dos serviços de saúde, dada a relativa autonomia dos campos científicos.

A ênfase nos estudos etiológicos, no desenvolvimento metodológico e mesmo na formalização da disciplina (BARATA, 1998) distanciava, de certo modo, muitos dos epidemiologistas de um pensamento e de uma ação sobre os serviços de saúde. A hegemonia das universidades norte-americanas e dos centros de epidemiologia dos Estados Unidos, a exemplo do Centers for Disease Control and Prevention (CDC, 1992), na formação de epidemiologistas do mundo inteiro e, particularmente, dos países dependentes, reforçava tal situação. Os serviços de saúde, por sua vez, muito mais orientados pela lógica do mercado do que pelas necessidades de saúde pareciam não ver a epidemiologia como uma ferramenta necessária para o seu desenvolvimento.

Evidentemente que muitos países do "socialismo real" e aqueles capitalistas que realizaram profundas modificações na organização dos serviços de saúde - como o Reino Unido, com a implantação do National Health Services a partir de 1948, 
e o Canadá, desde o Relatório Lalonde em 1974 - exploraram de forma mais ampla as potencialidades científicas e tecnológicas da epidemiologia na gestão de sistemas de serviços de saúde (PAIM, 2002).

A identificação desse gap entre as possibilidades das práticas epidemiológicas e a sua utilização pelos serviços da saúde para além do controle de doenças transmissíveis ou da vigilância epidemiológica, estimulou a Organização Pan-americana da Saúde e a Organização Mundial da Saúde (OPS/OMS) a apoiarem um conjunto de iniciativas visando à incorporação e à utilização desse saber no âmbito dos sistemas de saúde (OPS, 1984; 1988; 1991).

O presente capítulo tem como objetivo sistematizar os esforços visando à utilização da epidemiologia pelos serviços de saúde na América Latina nas últimas décadas, descrever algumas das propostas construídas no Brasil e discutir certos obstáculos e possibilidades de recomposição das práticas epidemiológicas na gestão do Sistema Único de Saúde (SUS).

\section{O papel da epidemiologia nos serviços e sistemas de saúde}

Nas duas últimas décadas a Organização Panamericana de Saúde tem demonstrado preocupação com processos de mudança nos procedimentos técnicos de prestação dos serviços, no uso das tecnologias disponíveis, na integração dos conhecimentos, nas formas de utilização dos recursos e nos modos de concretizar a participação social (OPS, 1984; 1988; 1991; TIGRE et al, 1990).

Ao propugnar por ações integradas de saúde, este organismo internacional ratificava o princípio da integralidade adotado pelo movimento sanitário brasileiro desde a 8 Conferência Nacional de Saúde e inclú́do como diretriz no capítulo Saúde da Constituição de 1988. Recomendava, assim, um enfoque global das ações agrupadas de acordo com o conjunto de problemas da população, sendo executadas de forma integral, evitando-se os agrupamentos por patologias e programas isolados. Ademais, defendia um serviço de saúde organizado para produzir mudança no perfil epidemiológico com relação aos problemas de saúde (riscos e danos), coletivos e individuais.

Parte dessa discussão se expressou no desenvolvimento da proposta de Sistemas Locais de Saúde (SILOS) e na reflexão e crítica aos modelos de prestação de serviços de saúde ou modelos de atenção, possibilitadas pela 
concepção e implantação dos distritos sanitários, enquanto modos de reorganização das práticas de saúde (PAIM, 1993).

Ao se discutir o uso da epidemiologia nos sistemas e serviços de saúde, é comum ressaltar o papel da disciplina na produção de conhecimentos para a tomada de decisões no que se refere à formulação de políticas de saúde, à organização do sistema e às intervenções destinadas a dar solução a problemas específicos (TIGRE et al., 1990). Nesse particular, identificam-se os seguintes campos de ação para a disciplina no âmbito dos serviços de saúde: a) estudos da situação de saúde em diferentes grupos da população, seus determinantes e tendências; b) vigilância epidemiológica de doenças e de outros problemas de saúde; c) investigação causal e explicativa sobre problemas prioritários de saúde; d) avaliação do impacto em saúde dos serviços, de tecnologias e de outras ações.

Refletindo sobre os processos de tomada de decisões em saúde e, particularmente, sobre a aproximação entre epidemiologia e gestão, Dussault (1995) enumera as seguintes possibilidades de utilização: a) nas políticas públicas de saúde, apoiando a definição de prioridades, objetivos e estratégias; b) na configuração dos serviços, especialmente na descentralização e integração dos serviços nos programas; c) nas práticas dos profissionais, sobretudo na avaliação da eficiência e eficácia; d) nas práticas de gestão; e) nas prioridades de investigação.

Após extensa revisão da literatura sobre limites e possibilidades do "enfoque epidemiológico", Teixeira (1996) destaca o grande dinamismo da produção científica da área no Brasil e a contribuição da epidemiologia ao desenvolvimento teórico-metodológico do planejamento de saúde. Considera que a reorientação da gestão, do financiamento, da organização e do modelo assistencial do sistema de serviços de saúde constitui processos que "não podem prescindir da epidemiologia, enquanto saber científico e prática instrumental que confere especificidade aos objetos de conhecimento e de intervenção no âmbito da saúde em sua dimensão populacional, isto é coletiva" (TEIXEIRA, 1999, p. 288). Nesse particular, enumera os seguintes usos da epidemiologia: a) no processo de formulação de políticas; b) na definição de critérios para a repartição de recursos; c) na elaboração de diagnósticos e análises de situação de saúde; d) na elaboração de planos e programas; e) na organização de ações e serviços; f) na avaliação de sistemas, políticas, programas e serviços de saúde. Ao discutir os limites e as possibilidades de desenvolvimento do "enfoque epidemiológico" no processo de reorientação 
da gestão e da organização social das práticas de saúde, a autora dedica uma reflexão especial para o papel da epidemiologia na própria definição do objeto do planejamento de saúde.

\section{Redefinições no estudo da gestão em saúde e tendências contemporâneas da epidemiologia}

Para a discussão deste tópico faz-se necessário refletir sobre questões referentes à gestão de sistemas e serviços de saúde e, visitar, ainda que brevemente, alguns elementos da chamada "crise da epidemiologia" e certas propostas de superação.

\section{Redefinições da gestão}

Embora sem uma consistente elaboração teórica, consubstanciada em investigações concretas, é freqüente vincular a epidemiologia à gestão como se fora algo natural e racional. Assim, prescrevem-se recomendações para a sua utilização no processo decisório como se a incorporação tecnológica pudesse ser efetivada num campo neutro ou inteiramente receptivo face à racionalidade e aos benefícios desse saber.

No entanto, a gestão em saúde pode ser reconhecida como a direção ou condução de processos político-institucionais relacionados ao sistema de saúde, eminentemente conflituosos ou contraditórios, ainda que nos níveis técnicoadministrativo e técnico-operacional desenvolva ações de planejamento, organização, gerenciamento, controle e avaliação dos recursos humanos, financeiros e materiais empregados na produção de serviços de saúde. Nessa perspectiva, a noção de gestão se aproxima da proposta de administração estratégica (OPS/OMS, 1992), na qual podem ser valorizados os componentes vinculados à distribuição dos diferentes tipos de poder em saúde e à construção de viabilidade das intervenções desenhadas.

Uma via de aproximação a essa temática desenvolvida no Brasil tem sido o recurso ao conceito de práticas de saúde, elaborado pioneiramente por Cecília Donnângelo e Ricardo Bruno Mendes-Gonçalves (DONNÂNGELO, 1976; MENDES-GONÇALVES, 1994). Esta via tende a produzir reflexões e análises sobre planificação e gestão que não se limitam a pensar objetosmeio (recursos financeiros, materiais, "informacionais", de poder etc.), isoladamente, mas suas articulações com objetos-fim (intervenção, assistência,

82 acolhimento, cuidado etc.) em uma totalidade social. 
Desse modo, a formulação da teoria do processo de trabalho em saúde possibilitou uma reflexão sobre o objeto, os meios de trabalho, as atividades e os agentes (agentes-sujeitos ou sujeitos/agentes). Além disso, ao investigar as relações técnicas e sociais sob as quais se realiza o trabalho em saúde, o método histórico-estrutural permite o estudo das organizações, da distribuição do poder nas instituições e do processo decisório para a implementação de políticas (PAIM, 2002). Essa linha de estudos tem realizado, recentemente, abordagens mais processuais das organizações, trazendo a interatividade e a comunicação dos sujeitos como objetos de reflexão, deslocando a ênfase da administração das coisas para a condução de processos político-institucionais e de trabalho em saúde. Converge, desse modo, com a gestão estratégica na qual a "administração da incerteza" centra-se na condução de processos coletivos de trabalho (MOTA, 1992), valorizando a construção de consensos.

Assim, a gestão não se reduz à ação instrumental sobre o mundo objetivo (RIVERA, 1995). Pode ser considerada analiticamente em uma dupla dimensão de ação social: ação estratégica dirigida a fins, com a criação de consenso ativo entre dirigentes e dirigidos, e ação comunicativa voltada para o entendimento e para as trocas intersubjetivas na constituição de novos sujeitos das práticas institucionais de saúde. Nesse caso, cabe ressaltar a natureza ético-política da gestão em saúde, enquanto resposta a necessidades humanas e, simultaneamente, formas de sociabilidade (PAIM, 1999). Ao se examinarem os sujeitos em ação e em comunicação nas organizações, é possível analisar a interação social, identificar as racionalidades presentes na gestão e valorizar a intersubjetividade na explicitação de conflitos e na busca de entendimento. O saber epidemiológico, nessa perspectiva, comporia parte da racionalidade técnico-sanitária presente na explicação da situação de saúde (TEIXEIRA, 1999) e compete, no processo decisório das instituições de saúde, com outras racionalidades igualmente importantes: política, médicoassistencial, econômica e burocrática (PAIM, 2002).

É possível que o recurso aos conceitos de tecnologias leves, leves-duras e duras (MERHY, 1997) e a análise dessas racionalidades ajudem a compreender a incorporação da epidemiologia no planejamento e gestão em saúde. Assim, a partir de uma concepção de modelos assistenciais ou modos estruturados de intervenção em saúde que signifiquem combinações de tecnologias orientadas para o atendimento de necessidades, poder-se-ia investigar o uso da epidemiologia para a apreensão da dimensão coletiva dos problemas de saúde. 
Essas indicações fazem supor a pertinência de estudos de incorporação tecnológica e de inovação ou desenvolvimento institucional para examinar a epidemiologia nos serviços de saúde. Ou seja, não basta o acúmulo de um saber, a existência de uma tecnologia nem o reconhecimento de uma necessidade social para que a epidemiologia seja utilizada por uma organização. Agentes capacitados, recurso ao planejamento, influência na gestão, liderança etc. podem ser variáveis a serem examinadas na análise das possibilidades de incorporação. Conceitos outros, compondo quadros teóricos distintos, poderiam apontar outras variáveis a serem contempladas em investigações sobre políticas, instituições e práticas de saúde (PAIM, 2002).

Ao se analisar possíveis relações entre epidemiologia, planejamento e gestão caberia examinar modos de articular as dimensões política com a técnicocientífica nas intervenções em saúde, tal como se propõe na discussão dos modelos assistenciais (PAIM, 1993; 2002). Além de uma "tecnologia de poder" ou de uma técnica que ajuda a dispor, arranjar e processar outras técnicas, bem como organizar e dirigir processos de trabalho, o planejamento pode ser um meio de auxiliar a interação entre os sujeitos no sentido de viabilizar um dado projeto ético-político para a saúde (PAIM, 1999).

\section{Tendências da epidemiologia}

No que se refere à Epidemiologia faz-se necessário concebê-la, para fins de análise da sua utilização na gestão, como disciplina científica e enquanto meio de trabalho.

Na primeira acepção trata-se de pensar o saber científico e os paradigmas em que se insere a Ciência Epidemiológica, o que remete para um trabalho teórico e para uma reflexão epistemológica. Assim, caberia problematizar a crise do paradigma dominante, a capacidade de formulação teórica, a ruptura dos compromissos históricos, a relação com a práxis e a capacidade explicativa (BARRETO, 1998). Segundo esse autor, a "crise da epidemiologia" no que diz respeito ao desgaste da sua capacidade explicativa se expressa nas seguintes situações: a) as propostas de prevenção fator a fator são de difícil implementação e apresentam uma "eficiência" limitada; b) a avaliação de tecnologias não oferece um quadro completo dos efeitos previstos e imprevistos quando são utilizadas como parte de programas complexos de intervenção em saúde; c) a capacidade de previsão dos efeitos dos programas e ações geralmente é baixa, independentemente das boas intenções e da consistência

84 dos conhecimentos disponíveis; d) parecem esgotadas as possibilidades de 
gerar novos conhecimentos acerca de fatores de risco com forças associativas elevadas ou com alto grau de especificidade em relação aos seus efeitos.

Conseqüentemente, mesmo epidemiologistas comprometidos com a meIhoria dos serviços de saúde como o referido autor, ainda são reticentes quanto às possibilidades da disciplina no interior do sistema de serviços de saúde. Todavia, a pujança dos vários congressos brasileiros de Epidemiologia e de Saúde Coletiva no Brasil parece indicar o contrário, quando se destacam as contribuições no estudo das desigualdades, na planificação, gestão e avaliação das intervenções em saúde (TEIXEIRA, 1996).

Pensar a epidemiologia como meio de trabalho significa concebê-la como tecnologia, ou seja, ferramenta de gestão. Assim, a epidemiologia, enquanto saber tecnológico, pode ser investigada na sua aplicação como instrumento para a formulação de políticas, para a planificação e para avaliação em saúde (SCHRAIBER et al, 1999). Nessa perspectiva, poder-se-ia examinar a sua utilização na análise da situação de saúde (investigando o modo e as condições de vida dos grupos sociais que se inserem e se movimentam no espaço urbano), no desenvolvimento de tecnologias, na elaboração e teste de modelos assistenciais. O saber epidemiológico, enquanto tecnologia não material, poderia ser utilizada na organização de processos de trabalho, de serviços e de sistemas de saúde, bem como na planificação, gestão, vigilância e avaliação em saúde (PAIM, 1999).

\section{Epidemiologia e gestão: alguns desafios}

Na perspectiva da Saúde Coletiva, entre os desafios da epidemiologia destacam-se: o estudo das desigualdades em saúde; o desenvolvimento de um pensamento sobre ambiente, qualidade de vida, conceito e medidas de saúde; a pesquisa sobre avaliação, seleção de tecnologias e intervenções em saúde (BARRETO, 1998).

No âmbito do planejamento e da gestão, caberia retomar propostas de diagnósticos administrativo, estratégico e ideológico (TESTA, 1992), assumindo o poder como categoria central de análise e identificando como seus objetos os serviços, organizações e sistemas, além de necessidades/problemas de saúde (TEIXEIRA, 1999). Esse objeto de trabalho poderia ser delimitado, então, como a relação entre os problemas de saúde e as respostas sociais aos mesmos (SÁ, 1993), o que significa pensar o planejamento e a gestão na sua articulação com as instâncias política, econômica e ideológica que compõem a estrutura social. Eis, portanto, um dos grandes desafios para o planejamento e a gestão em saúde: 
Articular em seu interior como prática social, tanto a explicação dos problemas de saúde dos distintos grupos populacionais na perspectiva apontada pela 'epidemiologia crítica', enfatizando as relações entre os problemas de saúde, as condições de vida e seus determinantes histórico-estruturais, quanto a compreensão das representações sociais acerca da saúde-doença e atenção à saúde dos diversos grupos, o que indica a necessidade de um planejamento participativo, em que os especialistas e população sejam atores e autores das respostas sociais aos problemas (TEIXEIRA, 1999, p. 297).

\section{A epidemiologia no Sistema Único de Saúde (SUS)}

A preocupação com a melhoria dos serviços do SUS e com a efetividade das intervenções sobre a situação de saúde tem motivado alguns autores a indagar sobre a incorporação da epidemiologia nas organizações de saúde em diferentes níveis do sistema de serviços de saúde e, especialmente, a sua utilização nas práticas de saúde (SCHRAIBER, 1990; PAIM, 1993; TEIXEIRA, 1999; DRUMMOND, 2001).

Ainda que a Constituição da República e a Lei Orgânica da Saúde (8080/ 90), complementada pela Lei $8142 / 4$, indicassem muitos caminhos para a incorporação da epidemiologia no planejamento e gestão do SUS, elementos de inércia burocrática da saúde pública institucionalizada juntamente com a lógica inampsiana que dirigia o modelo médico assistencial privatista dificultavam o desenvolvimento das práticas epidemiológicas.

\section{A epidemiologia na implantação do SUS}

No início da década de 1990, a epidemiologia era confinada, no nível federal, à Fundação Nacional de Saúde (FUNASA), instituída nos primeiros dias do Governo Collor, reunindo a Superintendência de Campanhas de Saúde Pública (SUCAM) e a Fundação Serviço Especial de Saúde Pública (FSESP). A criação do Centro Nacional de Epidemiologia (CENEPI), apesar de saudada por muitos epidemiologistas brasileiros e não obstante certos esforços dos seus primeiros dirigentes para disseminar o saber epidemiológico entre as instituições de saúde (TEIXEIRA, 1999), não reduziu a perspectiva de confinamento. No nível estadual, concentrava-se, por sua vez, nas ações de vigilância epidemiológica, sobretudo mediante os programas de imunização e controle de doenças, implementados pelas estruturas próprias das secretarias 
de saúde, reforçando a dicotomia com as Coordenações Regionais da FUNASA. E, no âmbito municipal, a epidemiologia tendia a ser residual, graças à própria insignificância que a Lei 6259/75 reservava para o município no então Sistema Nacional de Vigilância Epidemiológica, além da fragilidade institucional das secretarias municipais de saúde. Portanto, os esforços para o uso da epidemiologia no planejamento e na gestão naquele período limitavam-se às proposições dos Planos Diretores de Epidemiologia (DRUMOND $J R, 2001$ ) e às tentativas locais de desenvolvimento de modelos assistenciais alternativos, com o apoio de universidades e de organismos de cooperação técnica (TEIXEIRA, 2002).

Mesmo assim, em seminário realizado pelo CENEPI, baseado em documento propondo a reorganização do Sistema de Vigilância Epidemiológica na perspectiva do SUS (PAIM \& TEIXEIRA, 1992), considerou-se que era "necessário romper a dicotomia tradicional entre vigilância e assistência, possível a partir do aprofundamento da discussão das propostas de Vigilância à Saúde e pela incorporação das ações de vigilância em todas as unidades de atenção à saúde, inclusive hospitais" (SEMINÁRIO NACIONAL DE VIGILÂNCIA EPIDEMIOLÓGICA, 1992, p. 11).

Alguns elementos dessa mudança sobre os procedimentos técnicos, o uso de tecnologias e a integração de conhecimentos, configuram, no caso brasileiro, o debate em torno dos modelos assistenciais iniciado nos anos $1980 \mathrm{e}$ disseminado na década seguinte. Já as mudanças nas formas de utilização dos recursos e de participação social tiveram proeminência com a edição da Lei 81 42/90 e, especialmente, com a vigência das NOB 93 e NOB 96 (BRA$\mathrm{SIL}, 1993 ;$ 1996). Ao se examinar o contexto nacional, podem ser identificados componentes do arcabouço legal e normativo do SUS permeáveis à utilização da epidemiologia bem como certas relações desse saber com o planejamento e com os chamados modelos tecno-assistenciais.

\section{Epidemiologia e descentralização}

A NOB 93, apesar de contribuir para o avanço da municipalização das ações e serviços de saúde, praticamente não contou com a participação das instâncias responsáveis pela epidemiologia no SUS, de modo que as suas orientações tecnico-administrativas deixam grandes vazios para o uso do saber epidemiológico como ferramenta de gestão. A adoção simultânea de políticas econômicas de ajuste estrutural, a implantação de propostas de "Reforma do Estado", a restrição de recursos financeiros para o setor saúde e a opção por 
mecanismos de financiamento que privilegiam a lógica do mercado, transformavam o setor público em prestador de serviços e o planejamento em mero instrumento de captação de recursos. A gestão tendia a se concentrar em aspectos administrativos, reproduzindo um estilo que privilegia "a gerência contábil e o atendimento à demanda por serviços médico-ambulatoriais e hospitalares em detrimento das ações promocionais e de prevenção de agravos e danos à saúde coletiva, reforçando a iniqüidade no acesso aos serviços e desigualdades das condições de vida e saúde da população" (TEIXEIRA, 1999, p. 290).

Assim, mesmo municípios geridos sob a forma de gestão plena do sistema de saúde apresentaram resultados modestos no que se refere ao uso da epidemiologia e à reorganização das práticas de saúde (HEIMANN et al., 1998), seja em relação à redefinição do objeto, dos meios de trabalho, do trabalho propriamente dito ou das relações técnicas e sociais sob as quais é realizado o trabalho.

Contudo, as possibilidades abertas com a implantação do SUS para a experimentação de modelos assistenciais; a produção teórica, epistemológica e metodológica sobre a Epidemiologia na América Latina; o conjunto de proposições políticas e técnicas contidas nos Planos Diretores para o Desenvolvimento da Epidemiologia no Brasil I (1990-1994), II (1995-1999) e III (20002004) elaborados pela Associação Brasileira de Saúde Coletiva (ABRASCO); e a implementação das políticas de municipalização das ações e serviços de saúde na última década, compuseram um contexto que poderia favorecer a construção de uma "epidemiologia em serviços de saúde" (DRUMOND JR, 2001). Nesse particular, as promessas do CENEPI mediante o VIGISUS (BRASIL, 1998) chegaram a mobilizar secretarias de saúde interessadas em implementar o modelo da Vigilância da Saúde (TEIXEIRA, 2002).

Ao "levantar as formas predominantes dos instrumentos e modos de fazer epidemiologia que têm sido utilizados nos serviços de saúde no Brasil" (DRUMOND JR., 2001, p. 45) o autor revelou usos criativos e inovadores da epidemiologia em serviços de saúde do SUS fornecendo indicações que já permitem vislumbrar certa reorganização das práticas sanitárias. Assim, os projetos Nascer em Curitiba, Risco Evolutivo e Mãe Curitibana são bons exemplos dos modelos assistenciais correspondentes à oferta organizada (incluindo busca ativa), ao trabalho programático (ações programáticas de saúde) e à vigilância da saúde, implementados de forma complementar. Se-

88 gundo o mencionado autor, "os modelos de planejamento, tecnoassistenciais 
e de organização dos serviços propostos no país, apesar de muitas identidades, têm visões diferenciadas sobre a ênfase e o uso da epidemiologia nos serviços de saúde" (DRUMOND JR., 2001, p. 36). Por conseguinte, uma das grandes contribuições desse estudo foi ressaltar as possibilidades e a criatividade de novos enfoques e temas, realizando reflexões muito apropriadas sobre inovação institucional e incorporação tecnológica. Nessa oportunidade, o autor critica o diagnóstico normativo em saúde pelo seu caráter ritualista, formalista e irresponsável em relação à gestão e à reorientação dos modos de intervenção em saúde. Assinala que a pretensa onipotência da epidemiologia em definir necessidades e prioridades em saúde deve ser questionada e relativizada, ainda que possa ser considerada uma ferramenta de grande utilidade, inclusive no diagnóstico estratégico de análise de situação de saúde. E assim o autor anuncia uma "epidemiologia do cotidiano e do atrevimento" (DRUMOND JR., 2001, p. 170).

\section{Agenda de saúde e avaliação: uns passos adiante}

A partir da NOB-96 e, especialmente, com a expansão dos Programas de Agentes Comunitários de Saúde e de Saúde da Família (PACS/PSF), favorecida pela adoção do Piso Assistencial Básico (PAB) em 1998, o Ministério da Saúde, através da Secretaria de Política de Saúde (SPS), vem introduzindo, progressivamente, certos dispositivos que tendem a valorizar a incorporação de práticas epidemiológicas na gestão do SUS, incluindo o apoio a estudos sobre avaliação de políticas e programas (VIEIRA DA SILVA et al, 2002).

Nessa perspectiva, a aprovação pelo Conselho Nacional de Saúde dos Eixos Prioritários de Intervenção para o Ano 2001 ilustra um passo importante para o envolvimento de estados e municípios na Agenda Nacional de Saúde (BRASIL, 2001). Entre as intervenções propostas destacam-se a redução da mortalidade infantil e materna e o controle de doenças e agravos prioritários onde se incluem as "doenças da pobreza" (imunopreveníveis, transmitidas por vetores, diarréias, tuberculose, hanseníase etc.), as doenças crônicodegenerativas (câncer, diabetes e hipertensão) e os chamados "novos desafios" (AIDS e morbi-mortalidade por causas externas). As demais intervenções 1) reorientação do modelo assistencial e descentralização; 2) melhoria da gestão, do acesso e da qualidade das ações e serviços de saúde; 3) desenvolvimento de recursos humanos do setor saúde; e 4) qualificação do controle social - representam, também, espaços para o desenvolvimento de práticas epidemiológicas. 


\section{Conjuntura pós-XI Conferência Nacional de Saúde: os tortuosos caminhos do SUS}

No caso da recente da Norma Operacional de Assistência à Saúde (BRASIL, 2001), em que pese a ausência no debate público da XI Conferência Nacional de Saúde, os riscos de recentralização da política setorial, o privilégio da hierarquização da assistencia médico-hospitalar sob a denominação de "regionalização da assistência à saúde", bem como a ênfase na noção de economia de escala e a visão restrita de integralidade da atenção (centrada na demanda espontânea e reduzida à idéia de continuidade da assistência médica), caberia aproveitar a oportunidade da sua implementação para introduzir o saber epidemiológico nos processos de gestão (TEIXEIRA, 2002).

Assim, a criação de "módulos assistenciais" e de "sistemas microregionais de saúde" poderá ensejar um debate que "venha a incorporar e articular práticas de promoção da saúde e prevenção de riscos e agravos, bem como a reorientação da assistência individual e coletiva" (TEIXEIRA, 2002, p. 107). Enfim, a incorporação da proposta de Vigilância da Saúde ao planejamento municipal e regional poderá constituir "uma alternativa de superação do viés economicista da Programação Pactuada Integrada - PPI, basicamente um instrumento de racionalização da oferta de serviços pelas unidades de saúde, que não problematiza o conteúdo das práticas que são realizadas nem a sua adequação às necessidades e problemas de saúde da população" (TEIXEIRA, 2002, p. 116). A partir das propostas da autora, poderiam ser destacadas a redefinição das ações programáticas de saúde no âmbito das unidades básicas, a reestruturação dos estabelecimentos de saúde para assegurar a oferta organizada e programada das ações e serviços e a formulação de políticas públicas que tomem como referências básicas a promoção e a proteção da saúde (cidades saudáveis, vigilância sanitária em defesa da saúde, ação intersetorial em saúde, empowerment etc.).

A conjuntura em que a XI Conferência Nacional de Saúde defende o compromisso dos governos com políticas públicas integradas, com articulação intersetorial, capazes de assegurar as condições necessárias à produção, promoção e preservação da saúde é a mesma em que o Conselho Nacional de Saúde aprova a Política Nacional de Redução da Morbmortalidade por Acidentes e Violências e o Ministério da Saúde implementa o Programa Nacional de Controle do Tabagismo (BARROS, 2002), avança no Programa de Saúde da Família (PSF) - um dos espaços institucionais que emprega a prática epidemiológica - e busca, atualmente, formular uma Política de Promoção da

90 Saúde e uma Política Nacional de Ciência \& Tecnologia em Saúde. 


\section{O agenciamento da epidemiologia: muitos passos atrás}

As iniciativas mencionadas, ao lado da formulação e implementação da NOAS, ocorrem "em um contexto marcado pela multiplicidade de eventos de caráter político-institucional que configuram uma trama complexa de decisões acerca do processo de construção do SUS, nem sempre coerentes e articuladas" (TEIXEIRA, 2002, p. 107). A autora se refere, nesse caso, à proposta de criação da Agência Federal de Prevenção e Controle de Doenças (APEC), autarquia vinculada ao Ministério da Saúde, enquanto "agência executiva", subsidiária da chamada "Reforma do Estado".

Na realidade, sob o manto aparente de Reforma do Estado e de modernização da burocracia sanitária toma corpo um processo de desmantelamento do organismo capaz de reduzir o paralelismo dos serviços e ações de saúde, ou seja, o Ministério da Saúde, responsável pela gestão nacional do SUS (PAIM, 2001). Este "esquartejamento" do SUS se inicia com a promulgação da Constituição quando assegurou que a saúde é livre à iniciativa privada. Mas avançou em 1998, com a criação da Agência Nacional de Vigilância Sanitária (ANVISA), após uma avalanche de denúncias de falsificação de medicamentos envolvendo empresas farmacêuticas multinacionais de renome. No ano seguinte, tem continuidade com o estabelecimento da Agência Nacional de Saúde Suplementar, depois de um conjunto de denúncias sobre os chamados "planos de saúde", vinculados ao Sistema de Assistência Médica Supletiva (SAMS). Em 2000 já se discutia uma "agência de vigilância epidemiológica", cuja proposta de Medida Provisória foi encaminhada pelo ministro da Saúde em julho do ano seguinte. No entanto, como das outras vezes, foi necessária a existência de mais denúncias na mídia - no caso vinculadas à incompetência dos governos diante da epidemia de dengue - para que a Presidência da República editasse mais uma Medida Provisória (MP 33, 19/2/02) visando à transformação da FUNASA em APEC (BRASIL, 2002).

Verifica-se, desse modo, que a conjuntura pós-XI Conferência Nacional de Saúde, ao lado de certos avanços, traz sérios retrocessos no que diz respeito à incorporação das práticas epidemiológicas na gestão do SUS, conforme a avaliação da ABRASCO:

Esta MP ressuscita a Lei 6259/75, que instituiu o Sistema Nacional de Vigilância Epidemiológica, ignorando o papel do município [...]. Do mesmo modo atenta contra o princípio constitucional da integralidade da atenção. Ao dispor sobre o Sistema Nacional de Epidemiologia confina o saber epidemiológico e a Epidemiologia, como disciplina científica, a um 
"sistema" paralelo, subordinado a uma agência para a execução das ações de prevenção e controle, justamente quando o país tenta avançar na adoção de modelos assistenciais mais integrais [...]. Apresenta proposições mais truculentas e retrógradas que as desenvolvidas pela polícia sanitária do Brasil no início do século XX [...] A partir de uma vaga e indefinida "situação de risco", atenta contra os direitos dos indivíduos e comunidades colocando-os no mesmo nível dos animais! (ABRASCO, 2002, p. 2-3).

Sob o ponto de vista da gestão das secretarias estaduais e municipais de saúde, a pulverização do comando federal sobre o SUS, além de configurar o risco de fragmentação das orientações políticas, principalmente por separar o que se havia tentado unir, isto é, a assistência médica (antigo INAMPS), a vigilância epidemiológica e sanitária (antigo MS), representa um acréscimo de complexidade nas relações intergovernamentais com o nível federal (TEIXEIRA, 2002, p. 108).

Ademais, os níveis estadual e municipal do SUS podem vir a reproduzir, mecanicamente, a imagem e semelhança das estruturas federais produzindo o reconfinamento da epidemiologia em certos guetos da burocracia sanitária. Como já se alertara há uma década, "a organização sanitária brasileira já pagou um alto preço pelo mimetismo organizacional e pelo artificialismo das reformas administrativas" (PAIM \& TEIXEIRA, 1992, p. 46).

Diante desse quadro, o CNS aprovou a proposição de transformar a MP 33 em projeto de lei e o Congresso Nacional a rejeitou em 17/4/02. Lamentavelmente, o Projeto de Lei que substituiu a MP ignorou olimpicamente as críticas e sugestões apresentadas no V Congresso Brasileiro de Epidemiologia e insistiu na criação da APEC, mantendo o "estado de quarentena federal" no qual os cidadãos teriam de se reportar, periodicamente, à "autoridade de epidemiologia" (ABRASCO, 2002).

Assim, a "Reforma do Estado" que o Governo tem implementado no setor saúde nos últimos anos, longe de atender aos pressupostos modernizantes e democratizantes anunciados (PEREIRA \& GRAU, 1999), caracteriza-se pela criação de agências como parte das reações espasmódicas diante da crise sanitária e das denúncias da mídia. Nesse contexto, a racionalidade técnicosanitária que a Epidemiologia poderia proporcionar à gestão do sistema de serviços de saúde praticamente desaparece no processo decisório, predominando um conjunto de interesses menores da burocracia associados aos das 92 classes hegemônicas. 


\section{Comentários finais}

Diante dos fatos acima examinados e ao se discutir certas possibilidades de as práticas epidemiológicas serem recuperadas para a gestão do SUS, é pertinente indagar qual epidemiologia está no horizonte das propostas? A epidemiologia solidária à efetivação do SUS, através do acesso, qualidade e humanização na atenção à saúde, com controle social, ou aquela que constrange os cidadãos, submetendo-os à "autoridade da epidemiologia" que pode ser um ministro da Saúde, um presidente de Agência, um secretário de Saúde, um tecno-burocrata ou um inspetor de quarteirão? (ABRASCO, 2002). A epidemiologia que gera informação relevante para os que sofrem os processos destrutivos da organização das cidades e, em última análise, da lógica capitalista ou a epidemiologia que mascara a realidade, domestica e controla as populações de acordo com os interesses de tecno-burocratas e em função dos projetos políitico-ideológicos das classes dirigentes? Uma epidemiologia dos "de cima" para reproduzir seus privilégios e exclusão social ou dos "de baixo" para produzir informação e poder em busca da eqüidade e da efetividade?

Portanto, a epidemiologia, como disciplina científica ou como ferramenta de gestão, não é inocente, neutra, nem paira sobre os interesses de classes e os respectivos projetos políticos e ideológicos. Enquanto prática social, não se encontra livre das determinações que a estrutura social faz incidir sobre as práticas de saúde. Diante da crise da disciplina, distintas propostas têm sido formuladas por epidemiologistas e pensadores da Medicina Social e da Saúde Coletiva latino-americana tais como: a) recuperar as experiências relevantes acumuladas na história da epidemiologia e de outras disciplinas que estudam a saúde e seus determinantes; b) redirecionar o desenvolvimento teórico, metodológico e operacional da disciplina; c) deslocar o atual modus operandi da prática científica da epidemiologia para temas de prevenção e para o desenvolvimento de novas bases éticas, coerentes com seus compromissos sociais e históricos (BARRETO, 1998); d) proceder uma análise crítico-epistemológica de categorias centrais como "causalidade", "determinação", "risco", "exposição"; e) promover uma discussão ampla sobre metodologia (BREILH, 2002).

Se a epidemiologia for pensada para além da sua dimensão técnica, outros desafios apresentar-se-ão diante da práxis. Teria de ser uma testemunha crítica dos processos destrutivos para a vida que se realizam na sociedade, uma ferramenta de monitoramento da qualidade de vida e da saúde, um instrumento de "empoderamento" da população e uma arma de planificação estratégica e participativa (BREILH, 1998). 
Portanto, revisar criticamente o paradigma científico dominante pode ser uma via de analisar certas possibilidades de transição paradigmática no campo da Saúde Coletiva, diante da complexidade do objeto da epidemiologia. Nesse caso, caberia "aproximar a ciência da sociedade e seus problemas ampliando sua capacidade de produzir conhecimento crítico e propositivo. Conhecimento ético, emancipador, solidário e democrático" (DRUMMOND, 2001 , p. 8). Evidentemente que numa estrutura social que nega tais valores, a epidemiologia defronta-se com sérias contradições: "na sua tensão entre disciplina científica e campo profissional, a epidemiologia traz à tona, para os seus praticantes, independentemente de onde estejam situados, os desafios da dialética entre o sonhar e o fazer, entre a utopia e a realidade, entre a técnica e a política" (BARRETO, 1998).

Ainda que muitas questões relevantes na atualidade sejam insuficientemente consideradas pela epidemiologia hegemônica caberia destacar certos "objetivos essenciais" de um saber que tome partido pela vida e pela emancipação dos seres humanos. Uma epidemiologia que fundamente as ações em Saúde Coletiva, inspirada nos seus compromissos democráticos desde as lutas históricas do movimento sanitário contra o autoritarismo. Uma epidemiologia que possa garantir o conhecimento do processo saúde-doença na realidade complexa e concreta; reconhecer e abordar suas relações em diferentes níveis da realidade buscando se integrar com as visões de diferentes disciplinas e profissionais para orientar intervenções; e contribuir na redução do sofrimento humano, das iniqüidades sociais detectadas e no movimento em defesa da vida (DRUMMOND JR., 2001, p. ?). Trata-se, enfim, de construir coletivamente as bases de uma epidemiologia contra-hegemônica que examine o movimento geral da sociedade e suas relações com o modo de vida dos grupos sociais e com o estilo de vida das pessoas, identificando processos críticos de exposição ou de imposição (BREILH, 2002), conforme as palavras do autor:

Hablar de praxis epidemiológica a comienzos del novo milenio no es lo mismo que hacerlo cuando fundábamos el movimiento de la salud colectiva en la década de los setenta e trabajábamos en las primeras rupturas [...]. No somos lo mismos pero somos iguales. No somos lo mismos porque nuestra praxis ha experimentado cambios y acumulaciones decisivas, nuestras propuestas se han enriquecido, nuestras ideas han crecido en amplitud y extensión. Pero somos iguales, porque seguimos siendo humanistas, en el más profundo y marxista sentido de la palabra, el sentido de forjar identidad e recrear utopía emancipadora (BREILH, 2002, p. 188). 
Uma epidemiologia que contribua na constituição de sujeitos sociais comprometidos com uma prática sanitária voltada para a generosidade, a solidariedade e a ética na luta pela saúde e qualidade de vida, representa uma aposta na planificação e gestão de um sistema de saúde que se pretende efetivo, democrático, humanizado e equânime. Mais que uma aposta, tais processos de construção contra-hegemônica implicam una articulación organizativa entre sujetos como condición previa a la transformación de las prácticas, tal como lo quería GRAMSCl, al generar un nuovo pensamiento que no sólo cuestiona los saberes tradicionales sino que pude constituirse en el liderazgo para proponer uma nueva manera de hacer las cosas (TESTA, 1997, p. 156). Portanto, a explicitação, a disseminação e a apropriação desses valores pelas classes subalternas e seus intelectuais orgânicos poderá favorecer a construção de identidades capazes de influir na mobilização de subjetividades e vontades políticas para a concretização de práticas epidemiológicas e de gestão comprometidas com os princípios e diretrizes originais do SUS. 


\section{Referências}

ABRASCO. Outra emenda pior que o soneto. APEC - Novas Ameaças ao Processo de Descentralização da Saúde (Editorial). Boletim Abrasco, Rio de Janeiro, n. 84, p. 2-3, 2002.

BRASIL. Ministério da Saúde. Norma Operacional Básica SUS-01/1993. Informe Epidemiológico do SUS, Número Especial, Brasília, p. 49-73, 1993.

BRASIL. Ministério da Saúde. 1996. Norma Operacional Básica SUS -01/96. DOU, Brasília, 6/11/96.

BRASIL. Ministério da Saúde. Cenepi. Vigisus, S. N. T. Brasília, 1998.

BRASIL. Ministério da Saúde. Portaria N. 393. DOU, Brasília, 30/03/2001.

BRASIL. Ministério da Saúde. Regionalização da assistência à saúde: aprofundando a descentralização com equidade no acesso (Norma Operacional da Assistência à Saúd. NOAS.SUS 01/01. Portaria MS/GM N. 95, de 26 de janeiro de 2001) Brasília, DF, 2001.

BRASIL. Presidência da República. Casa Civil.. Medida Provisória No. 33. DOU, Brasília, 19/2/2002.

BARATA, R. B. Epidemiologia e saber científico. Rev. Bras. Epid, São Paulo, v. 1, n. 3, p. 14-27, 1998.

BARRETO, M. L. Por uma epidemiologia da saúde coletiva. Rev. Bras. Epid, São Paulo, v. 1, n. 3, p. 104-22, 1998.

BARROS, E. Avanços e desafios para o SUS face às principais recomendações da XI Conferência Nacional de Saúde. (Texto elaborado para subsidiar o Conselho Nacional de Saúde). Brasília, 2002.

BREILH, J. La sociedad, el debate de la modernidad y la nueva epidemiologia. Rev. Bras. Epid, São Paulo, v. 1, n. 3, p. 207-33, 1998.

BREILH, J. Nueva Epidemiologia: construcción intercultural de otro paradigma de la ciencia. 226fl. Tese [Doutorado em Saúde Coletiva] - Instituto de Saúde Coletiva, Universidade Federal da Bahia, Salvador, 2002.

CDC. Proceedings of the 1992 Inernational Symposium on Public Health Surveillance. MMWR, n. 41 /Supplement, Atlanta, 1992.

DONNÂNGElO, M. C. F. Saúde e Sociedade. São Paulo: Duas Cidades, 1976.

DUSSAULT, G. La epidemiologia y la gestión de los servicios de salud.. Boletin Epidemiológico OPS, Washington, v. 16, n. 2, p. 1-5, 1995.

DRUMMOND JÚNIOR, M. Epidemiologia e Saúde Pública: reflexões sobre os usos da epidemiologia nos serviços do Sistema Único de Saúde em nível municipal. 189fl. Monografia [Pós-Graduação em Medicina Preventiva e Social] - Faculdade de Ciências Médicas, Universidade Estadual de Campinas, Campinas, 2001.

HEIMANN, L .S.; CASTRO, I. E. do N.; KAYANO, J.; ROCHA, J. L. de; RIEDEL, L. R. et al. A descentralização do sistema de saúde no Brasil - uma proposta de investigação sobre o impacto de políticas. Relatório Final. Instituto de Saúde, São Paulo, 1998.

96 MENDES-GONÇALVES, R. B. Tecnologia e organização das práticas de saúde: carac- 
terísticas tecnológicas do processo de trabalho da rede estadual de centros de saúde de São Paulo. São Paulo: HUCITEC/ABRASCO, 1994.

MERHY, E. E. Em busca do tempo perdido: a micropolítica do trabalho vivo em saúde. In: MERHY, E. E. \& ONOCKO, R. (Org.) Agir em saúde: um desafio para o público. São Paulo/Buenos Aires: HUCITEC/Lugar Editorial, 1997.

MORRIS, J. N. Uses of Epidemiology. 3 ed. Edimburgh: Churchull Livingistone, 1975.

MOTA, P. Gestão contemporânea: a ciência e a arte de ser dirigente. Rio de Janeiro: Record, 1992.

OPS. Documento del seminario sobre usos y perspectivas de la epidemiologia, Buenos Aires. Boletin Epidemiológico, Washington, v. 5, n. 1, p. 1-4, nov. 1984.

OPS. El desafio de la epidemiologia, problemas y lecturas selecionadas. Publicación Científica, Washington, n. 505, p. 881-9, 1988.

OPS. Vigilancia de la situación de salud según condiciones de vida. Boletin Epidemiológico, Washington, v. 12, n. 3, p. 7-10, 1991.

OPS/OMS. Desarrollo y fortalecimiento de los sistemas locales de salud: la administración estratégica. Washington, D.C: Organización Panamericana de la Salud, 1992.

PAIM, J. S. A reorganização das praticas de saúde em distritos sanitários. In: MENDES, E. V. (Org.). Distrito Sanitário: o processo social de mudança das práticas sanitárias do Sistema Único de Saúde. São Paulo/Rio de Janeiro: HUCITEC/ABRASCO, 1993.

PAIM, J. S. Por um planejamento das práticas de saúde. Ciência \& Saúde Coletiva, Rio de Janeiro, v. 4, n. 2, p. 243-324, 1999.

PAIM, J. S. Transición paradigmática y desarrollo curricular en Salud Pública. In: OPS. Educación en Salud Pública: nuevas perspectivas para las Américas. Washington, D.C.: OPS, 2001.

PAIM, J. S. Saúde, Política e Reforma Sanitária. Salvador: CEPS/ISC, 2002.

PAIM, J. S. \& TEIXEIRA, M. G. L. C. Reorganização do sistema de vigilância epidemiológica na perspectiva do Sistema Único de Saúde. Informe Epidemiológico do SUS, Brasília, n. 5, p. 27-57, 1992.

PEREIRA, L. C. B. \& GRAU, N. C. (Org.). O público não-estatal na Reforma do Estado. Rio de Janeiro: Editora FGV, 1999.

RIVERA, F. J. U. Agir comunicativo e planejamento social: uma crítica ao enfoque estratégico. Rio de Janeiro: FIOCRUZ, 1995

SÁ, M. C. Planejamento estratégico em saúde: problemas conceituais e metodológicos. Dissertação de Mestrado em Saúde Pública - Escola Nacional de Saúde Pública, Fundação Oswaldo Cruz, Rio de Janeiro, 1993

SCHRAIBER, L. B. (Org.). Programação em saúde, hoje. São Paulo: HUCITEC, 1990.

SCHRAIBER, L. B.; PEDUZZI, M,; SALA, A.; NEMES, M. I. B.; CASTANHERA, E. R. L.; $\mathrm{KON}, \mathrm{R}$. Planejamento, gestão, e avaliação em saúde: identificando problemas. Ciência \& Saúde Coletiva, Rio de Janeiro, v. 4 n. 2, p. 221 -242, 1999.

SEMINÁRIO NACIONAL DE VIGILÂNCIA EPIDEMIOLÓGICA. Relatório Final. Informe Epidemiológico do SUS, Brasília, n. 5 p. 5-24, 1992. 
TEIXEIRA, C. F. Epidemiologia e Planejamento em Saúde: contribuição ao estudo da prática epidemiológica no Brasil 1990-1995. 300fl. Tese de Doutorado em Saúde Coletiva - Instituto de Saúde Coletiva, Universidade Federal da Bahia, 1996.

TEIXEIRA, C. F. Epidemiologia e planejamento de saúde. Ciência \& Saúde Coletiva, Rio de Janeiro, v. 4, n. 2, p. 287-303, 1999.

TEIXEIRA, C. (Org.). Promoção e Vigilância da Saúde. Salvador: CEPS/ISC, 2002.

TESTA, M.. Pensar em Saúde. Porto Alegre: Artes Médicas/Abrasco, 1992.

TESTA, M. Saber en Salud. La construcción del conocimiento. Buenos Aires: Lugar Editorial, 1997.

TIGRE, C.; PLAUT, R.; LIBEL, M. et al. La practica epidemiológica en los sistemas de servicios de salud. Educ. Méd. Salud, Washington, v. 24, n. 3, p. 306-320, 1990.

VIEIRA DA SILVA, L. M.; HARTZ, Z. M. A.; COSTA, M. C. N.; OLIVEIRA, A. B.; BISCARDE, P.; PAZ, B. M. da. Avaliação dos efeitos da descentralização em relação às condições traçadoras da atenção à saúde. Relatório Preliminar Instituto de Saúde Coletiva /Universidade Federal da Bahia/Centro Colaborador do Ministério da Saúde, 2002. 


\section{O objeto e a prática da Saúde Coletiva: o campo demanda um novo profissional?}

\section{Introdução}

A sociologia das profissões contempla um elenco variado de questões relacionadas ao Estado, sociedade, associações e instituições, relações entre base cognitiva e mercado de trabalho, as arenas conflitivas, entre outras. Assim, diversas perguntas surgem, contemporaneamente, no âmbito dessa disciplina: quais os critérios sociológicos que definem uma profissão? $\bigcirc$ que diferencia uma profissão de uma semiprofissão? Há um processo crescente de profissionalização da sociedade? Ou vivemos a era da desprofissionalização de corporações poderosas, como a medicina, advocacia e a engenharia? (MACHADO, 1995, p. 13).

Nessa literatura sociológica, tem-se identificado dois atributos para a definição de uma profissão: a configuração de um corpo de conhecimentos e a orientação para um ideal de serviços. Portanto, a existência de uma profissão passa pela identificação de um conjunto de habilidades e conhecimentos (competências) referentes a um segmento do saber e por um elenco de valores que fornece identidade cultural para a ação de sujeitos. E entre os fatores que colaboram na emergência de um novo campo profissional podem ser destacados o avanço do conhecimento científico, o progresso tecnológico, a identificação de problemas que interferem no desenvolvimento da sociedade, os mercados de bens e serviços, as políticas públicas e a estrutura do complexo de organizações prestadoras de serviços.

No Brasil, três ofícios de nível superior serviram de base para a profissionalização universitária: a Engenharia Civil, na área das

'Texto elaborado como subsídio para a discussão de grupos no I Seminário e Oficina de Trabalho "Graduação em Saúde Coletiva: Pertinência e Possibilidades", organizado pelo Instituto de Saúde Coletiva da Universidade Federal da Bahia (ISC) UFBA) com o apoio de Ministério da Saúde. Salvador, 5 e 6 de setembro de 2002. 
ciências exatas; a Medicina na área das ciências biológicas; e a Advocacia, na área das ciências humanas. No caso da Medicina, posteriormente identificada como componente das "ciências da saúde", voltava-se efetivamente para "a ciência e a arte" de conhecer as doenças e cuidar dos doentes, individualmente, dela derivando outros cursos de graduação tais como Farmácia, Odontologia, Enfermagem etc. Tais profissões, no entanto, voltavam-se para controlar episódios de doenças nos indivíduos e por força do prestígio da profissão médica, a extensão de conceitos tradicionais centrados na relação médico/paciente foi determinante para que a gestão universitária visualizasse o estudo e as soluções para os problemas do conjunto de indivíduos como uma extensão do objeto da Medicina e suas profissões derivadas (PADILHA, 1997, p. 1).

O modelo biomédico tornou-se hegemônico no século XX, sobretudo diante das proposições do Relatório Flexner, influenciando, ainda, a partir da Johns Hopkins University, a formação de sanitaristas (Fee, 1987) como apenas uma das especializações possíveis para os graduados das "ciências da saúde". Portanto, o modelo médico hegemônico ( $\mathrm{MMH}$ ) não se desenvolveu por acaso nem devido a proposições técnicas de um determinado relatório. Resultou de escolhas políticas, orgânicas aos interesses de um complexo médico-industrial que então se formava a partir dos Estados Unidos.

Já a Saúde Coletiva, enquanto campo do saber e âmbito de práticas, teve o seu desenvolvimento histórico na América Latina durante as três últimas décadas a partir da crítica ao $\mathrm{MMH}$, aos movimentos ideológicos referentes à Higiene, Medicina Preventiva, Medicina Comunitária, Medicina da Família, bem como em relação à saúde pública institucionalizada (DONNÂNGELO, 1983; PAIM \& ALMEIDA FILHO, 2000). Encontra-se, presentemente, em condições de maturidade teórica, metodológica e operativa suficientes para enumerar competências e articular valores que permitam a constituição de novos sujeitos sociais comprometidos com a defesa da vida e a saúde do público.

Nas discussões sobre a chamada crise da saúde pública e na busca de novos paradigmas promovidas pela Organização Pan-Americana de Saúde, Organização Mundial de Saúde, Academia de Medicina dos Estados Unidos e Associação de Educação em Saúde Pública da América Latina e do Caribe (ALAESP) têm sido agregadas novas idéias e reflexões sobre este campo do saber (PAHO, 1992). Nesse particular, destaca-se o reconhecimento de que Saúde Pública e Saúde Coletiva não constituem especialidade médica (BELISÁRIO, 1995). Ainda que componham a área da saúde, suas interseções são cada vez 100 mais amplas e profundas com as ciências humanas, economia, administração, 
comunicação social e marketing, pedagogia, direito, ecologia etc. Daí a recomendação da I Conferência Pan-Americana de Educação em Saúde Pública para que as instituições formadoras desse pessoal de saúde passassem por um processo de "indepentização" das faculdades de medicina, estabelecendo redes com outras unidades acadêmicas que possibilitassem a interdisciplinaridade ou a transdisciplinaridade (ALAESP, 1994).

O objetivo do presente texto é discutir o objeto e a prática da Saúde Coletiva analisando, no contexto brasileiro, a pertinência da formação de um novo profissional no âmbito da graduação.

\section{Movimentos ideológicos contemporâneos: promoção da saúde e funções essenciais da saúde pública (FESP)}

No final

do século XX dois grandes movimentos ideológicos no campo social da saúde foram apoiados pela Organização Mundial da Saúde (OMS) e Organização Pan-Americana de Saúde (OPS): promoção da saúde e funções essenciais de saúde pública (FESP).

A promoção da saúde, inicialmente considerada um dos objetivos da saúde pública ou um dos níveis de prevenção, adquiriu proeminência quando o Ministério da Saúde do Canadá apresentou o Relatório Lalonde em 1974, baseado na noção de "campo da saúde", composto por quatro pólos: biologia humana, meio-ambiente, sistema de saúde, estilo de vida. Posteriormente, a divulgação da Carta de Ottawa (1986) estabeleceu um conceito amplo de saúde e seus determinantes, sistematizando proposições centradas na mudança dos estilos de vida e na defesa de políticas públicas saudáveis. $\bigcirc$ conceito e as estratégias da Promoção da Saúde foram endossados por organismos internacionais sendo lançado o Projeto Cidades Saudáveis em 1986 pela OMS (TEIXEIRA, 2202). ${ }^{2}$

Enquanto na Região das Américas a OPS debatia a crise da saúde pública (PAHO, 1992), a OMS promoveu a discussão de propostas internacionais em torno da "Nova Saúde Pública" e das chamadas Funções Essenciais de Saúde Pública (PAIM, 2001). Nessa perspectiva, a OPS organizou um Grupo de Trabalho sobre Reforma Setorial e Funções Essenciais de Saúde Pública: Implicações para a Educação em Saúde Pública. Este grupo reuniu-se em Washington no período 29 de junho a 1 de julho de 1998, com o propósito iniciar a identificação das implicações para a educação, investigação 
e intervenção em saúde pública que se derivam dos processos de reforma do setor saúde e da definição das funções essenciais de saúde pública. Nessa oportunidade, foram identificadas as seguintes "práticas sociais" vinculadas às FESP:

a) Construção de "entornos" saudáveis e melhoramento das condições de vida;

b) Desenvolvimento e fortalecimento de uma cultura da vida e da saúde;

c) Geração de inteligência em saúde;

d) Atenção às necessidades e demandas em saúde;

e) Garantia da segurança e qualidade de bens e serviços relacionados à saúde;

f) Intervenção sobre riscos e danos coletivos à saúde.

Desdobramentos desse trabalho ocorreram na ll Conferência Pan-Americana de Educação em Saúde Pública já em 1998 no México (OPS/OMS, 2000) e na reunião da ALAESP, em Cuba, no ano 2000 (OPS/ALAESP, 2001). No Brasil, diversos especialistas foram convidados pelo Ministério da Saúde em 2002 para a medição do desempenho das FESP, a partir da utilização de um guia elaborado pela OPS/OMS e o Center for Disease Control and Prevention (CDC). Nessa oportunidade, foram avaliadas as seguintes FESP:

a) Monitoramento, avaliação e análise da situação de saúde;

b) Vigilância de saúde pública, investigação e controle de riscos e danos em saúde pública;

c) Promoção da saúde;

d) Participação dos cidadãos em saúde;

e) Desenvolvimento de políticas e capacidade institucional de planificação e gestão em saúde pública;

f) Fortalecimento da capacidade institucional de regulamentação e fiscalização em saúde pública;

g) Avaliação e promoção do acesso eqüitativo aos serviços de saúde necessários;

h) Desenvolvimento de recursos humanos e capacitação em saúde pública;

i) Garantia e melhoria da qualidade dos serviços de saúde individuais e coletivos;

i) Pesquisa em saúde pública;

k) Redução do impacto de emergências e desastres em saúde (OPS/ 102 OMS/CDC, s/d). 
Não obstante as reservas críticas que podem ser feitas a tal movimento ideológico, à formalização dessas funções (PAIM, 2001) e ao respectivo processo de medição, a referência às FESP, no momento em que se discute a formação de um novo profissional de saúde coletiva, pode servir de contraponto em relação às competências a serem identificadas para a graduação e a pósgraduação. Essa via pode ser explorada desde que não se perca de vista todo o trabalho teórico e epistemológico desenvolvido no Brasil para a delimitação do campo da Saúde Coletiva.

\section{O objeto e a prática da saúde coletiva}

A elaboração teórica sobre práticas de saúde, como componente da prática social (DONNÂNGELO, 1976), possibilita pensar a especificidade das práticas de saúde coletiva nos seus momentos constituintes: objeto, meios de trabalho, trabalho propriamente dito, agentes e relações técnicas e sociais (MENDES-GONÇALVES, 1994).

Tomar como referência as práticas de saúde para a elaboração de um projeto educativo implica considerar essas dimensões objetivas do trabalho no âmbito da Saúde Coletiva. Este enfoque, além de propiciar uma aproximação do ensino ao mundo do trabalho e, conseqüentemente, aos serviços de saúde, propicia uma reflexão crítica sobres os modelos de atenção em distintas conjunturas a partir da análise das relações sociais que permeiam tais práticas, bem como das representações sociais dos agentes sobre a situação de saúde e sua inserção nas instituições.

A saúde pública, enquanto campo de saber e de intervenção sobre a situação de saúde, traz desde a sua emergência alguns elementos relativamente persistentes: atuação sobre o coletivo, ainda que insuficientemente conceitualizado, e aproximação ao Estado. Com base nesses dois elementos podem-se considerar tantas visões de saúde pública quantas sejam as concepções sobre o coletivo/social e sobre a natureza e os modos de intervenção do Estado em cada formação social (PAIM, 2002).

As diferentes perspectivas doutrinárias que perpassam a saúde pública são frutos da variação dessas visões, presentes em diversos movimentos de reforma em saúde, inclusive no que diz respeito ao recente movimento das Funções Essenciais de Saúde Pública (FESP). No Brasil, o convívio contraditório desses movimentos desde a década de 1970 possibilitou a redefinição da saúde pública na Saúde Coletiva, campo aberto a novos paradigmas (PAIM \& ALMEIDA FILHO, 2000). 
Este campo do saber e âmbito de práticas confronta-se com o modelo médico hegemônico. Daí o permanente questionamento sobre o campo: qual a crise da saúde pública? O que é Saúde Coletiva? Quem é o sanitarista? Qual o trabaIho do sanitarista? Qual(is) a(s) prática(s) do trabalhador em saúde coletiva? Quais as funções do sanitarista e que práticas pode exercer nos serviços de saúde e na ação intersetorial? De que habilidades, conhecimentos e valores tal profissional deve dispor diante de situações de saúde que se modificam e de organizações de serviços que se redefinem? (PAIM, 2002).

Nesse sentido, a reconceitualização do objeto das práticas de saúde coletiva e a reflexão epistemológica sobre o conceito de saúde impõem a redefinição dos meios de trabalho e das atividades, bem como a reconfiguração do agente-sujeito. Do mesmo modo, na medida em que um determinado contexto favoreça a instalação de novas relações técnicas e sociais sob as quais é realizado o trabalho desses sujeitos-agentes, cabe repensar a formação de novos sujeitos-agentes.

Admitindo-se que uma prática, enquanto processo de trabalho, é constituída por três componentes básicos - objeto, instrumentos de trabalho e atividades, pode-se analisar a prática em saúde coletiva desenvolvendo-se uma reflexão sobre a natureza e especificidade de cada um dos seus componentes (SCHRAIBER, 1990; MENDES-GONÇALVES, 1994).

Se o objeto for reconhecido como necessidades sociais de saúde, e não apenas como problemas de saúde (riscos, agravos, doenças e mortes), impõe-se uma análise dessas necessidades e seus determinantes. Para se proceder a uma aproximação a esse objeto, manipulá-lo e/ou transformá-lo são necessárias tecnologias ou meios de trabalho. Esses instrumentos de trabaIho precisam dar conta do caráter "coletivo" do objeto, tanto na sua apreensão quanto na sua transformação.

As necessidades de saúde não se esgotam na demanda, nas "necessidades sentidas", nas "necessidades médicas", nas "necessidades de serviços de saúde", ou nas doenças, carências, riscos e sofrimentos (PAIM, 1980). Contudo, mesmo se as necessidades sociais de saúde forem reduzidas a problemas de saúde em populações, o saber epidemiológico, e não a clínica, representaria o meio de trabalho fundamental para a sua apreensão e, parcialmente, para a sua explicação.

No entanto, se as necessidades sociais não forem redutíveis a problemas de saúde, mas envolverem as condições necessárias para o gozo da saúde 104 (inclusive os determinantes socioambientais), os instrumentos de trabalho para 
apreensão do objeto seriam provenientes de outros saberes: antropologia, sociologia, economia, política, ecologia etc. O caráter abrangente do objeto e, especialmente, a compreensão ampla sobre os determinantes sociais e ambientais dos problemas de saúde indicam que os serviços de saúde, entendidos também como meios de trabalho, seriam insuficientes para transformar tal objeto. As tecnologias empregadas no âmbito dos serviços para o diagnóstico, prevenção e tratamento das doenças, ainda que eventualmente eficazes no plano individual (clínica), podem ser ineficazes em relação às necessidades sociais de saúde (PAIM, 1996). Do mesmo modo, as "ferramentas" do trabaIhador em saúde coletiva devem ser orgânicas ao caráter coletivo e socialmente determinado do objeto.

A contribuição das ciências humanas, da filosofia e da arte na definição dessas necessidades permitiria trazer a idéia de projeto porquanto o trabalho humano que justifica o atendimento de uma necessidade supõe, previamente, a visualização de uma finalidade (SCHRAIBER \& MENDES-GONÇALVES, 1996). O conceito de necessidade radical (HELLER, 1986), ao tempo em que fornece elementos para uma teoria de necessidades em saúde, estimula pensar a idéia de projeto ou "ideais de saúde", sobretudo quando se buscam modelos de atenção voltados para a qualidade de vida.

Nessa perspectiva, as necessidades podem ser entendidas não apenas como carências ou problemas de saúde (doenças, agravos e riscos), mas como projetos que expressem uma necessidade radical: aquilo de que um ser precisa para permanecer sendo um ser. Ou nas palavras de Mendes-Gonçalves (1992, p. 19): "aquilo que precisa 'necessariamente' ser satisfeito para que um ser continue sendo um ser". Assim, a defesa da saúde, do ambiente, da vida e da sua qualidade, bem como o gozo estético, o produzir para viver, o lazer, a arte, enfim, passam a integrar projetos que presentemente se constroem sob rótulos diversos tais como promoção da saúde, cidades saudáveis, políticas públicas saudáveis etc.

Conseqüentemente, a reconceitualização das necessidades sociais de saúde, imposta mais pela realidade do que por uma opção de reflexão teórica, aponta para a pertinência de estruturar conhecimentos e habilidades que conformem competências profissionais organicamente vinculadas às exigências de novos tempos.

No que se refere ao trabalho propriamente dito desse agente, o fato de voltar-se para um conjunto de práticas estruturadas sobre o coletivo impele-o a exercer funções de direção do processo coletivo de trabalho (planejamen- 
to, programação, controle e avaliação) como forma de viabilizar a intervenção estruturada para atender a tais necessidades. Portanto, suas atividades envolvem uma dimensão epidemiológica e social dos meios de trabalho que incide na apreensão das necessidades de saúde e na seleção de tecnologias para atendê-las e uma dimensão organizacional/gerencial que visa à apreensão dos problemas dos serviços de saúde e das organizações, bem como a adoção de procedimentos que interferem na factibilidade e na viabilidade do trabalho coletivo em saúde. Daí o tripé da Saúde Coletiva estar assentado na Epidemiologia, na Planificação \& Gestão e nas Ciências Sociais em Saúde.

A realização dessas atividades e a utilização desses meios de trabalho conferem uma dupla-face do profissional em saúde coletiva: técnico de necessidades de saúde e gerente de processos de trabalho em saúde ou de produção de serviços. Ao tempo em que precisa identificar, descrever e explicar a ocorrência de necessidades, produzindo informações para o estabelecimento de prioridades, deve selecionar técnicas e modos de intervenção para enfrentálas e, também, gerenciar um conjunto de trabalhos cujos produtos (ou serviços) ocasionam resultados (impactos) sobre a saúde da coletividade (PAIM, 2002).

O trabalho em saúde coletiva, além das dimensões técnica, econômica, política e ideológica, envolve um componente ético essencial vinculado à emancipação dos seres humanos. Não se trata de um trabalho qualquer, mas de um conjunto de atividades eticamente comprometido com o seu objeto - as necessidades sociais de saúde. Este trabalho, portanto, é integralmente perpassado por valores de solidariedade, equidade, justiça e democracia.

Assim, para a compreensão do trabalho do profissional de saúde coletiva não basta o reconhecimento de que são distintos os processos que utilizam a clínica ou a epidemiologia e a gestão. Ao recorrer a tecnologias centradas no coletivo e ao exercer funções de direção, planejamento, supervisão e controle sobre um conjunto de práticas de saúde, esse profissional precisa dominar conhecimentos e habilidades específicas não redutíveis às ciências biológicas ou da saúde. De um modo mais simplificado e resumido, pode-se reconhecer tal profissional como um "técnico de necessidades sociais de saúde" e um "gerente de processos coletivos de trabalho em saúde", voltados para a realização de ações de vigilância, planificação, gestão, controle, avaliação, além de intervenções sociais organizadas dirigidas à promoção, proteção, comunicação e educação em saúde (PAIM, 2002). 


\section{Análise preliminar do contexto}

No caso brasileiro, a exigência de um novo profissional de saúde coletiva no momento se faz mais contundente do que a discussão de movimentos ideológicos ou de novos marcos conceituais. Desde o início da implantação da Reforma Sanitária, com a implementação do Sistema Único de Saúde (SUS), tem havido um esforço de qualificação de recursos humanos nos níveis de aperfeiçoamento, especialização e pós-graduação senso estrito em Saúde Coletiva.

A política de descentralização da saúde, impulsionada por instrumentos normativos (NOB/SUS 01/93, NOB/SUS 01/96 e NOAS/SUS 01/2001) e sustentada pela expansão do Programa de Agentes Comunitários de Saúde (PACS), do Programa de Saúde da Família (PSF) e do Programa de Interiorização do Trabalho em Saúde (PITS), vem requerendo pessoal com formação em Saúde Coletiva. Desse processo geral resulta, entre outras conseqüências, uma profunda redefinição das funções e competências dos vários níveis de governo do SUS. A implementação de novos modelo assistenciais, buscando privilegiar a intervenção sobre determinantes da situação de saúde, grupos de risco e danos específicos vinculados às condições de vida, deverá racionalizar a atenção médico-ambulatorial e hospitalar de acordo com o perfil das necessidades e demandas da população e expandir a ação intersetorial em saúde (TEIXEIRA, 2002) ${ }^{3}$.

As parcerias desenvolvidas entre as instituições formadoras, o Ministério da Saúde e as secretarias estaduais e municipais de saúde têm possibilitado a qualificação de milhares de profissionais e trabalhadores de saúde coletiva, quase em caráter de urgência, para dar contar das necessidades mais imediatas dos serviços de saúde, em curto tempo. Entretanto, mesmo os Pólos de Capacitação em Saúde da Família não têm conseguido atender toda a demanda por qualificação. Os esforços iniciais de educação a distância realizados pela Escola Nacional de Saúde Pública (ENSP), entre outras, também não têm garantido a satisfação das carências de formação de agentes para todo - país nas áreas de vigilância sanitária, saúde ambiental, vigilância epidemiológica, gestão de sistemas de serviços de saúde, planejamento, programação etc.

Enfim, estamos diante de um processo talvez único no mundo em que um país com 170 milhões de habitantes, com oito milhões e quinhentos mil $\mathrm{Km}^{2} \mathrm{e}$ cinco grandes regiões com características das mais diversas, decide implantar um sistema de saúde descentralizado, abrangendo mais de 5.500 municípios 
e que, em menos de dez anos, consegue envolver cerca de $99 \%$ desses entes federativos na gestão municipal da saúde, com a coordenação de 26 unidades da Federação.

Cabe lembrar que, no campo da saúde, o profissional que se envolve com problemas coletivos que afligem as comunidades tem sido denominado e reconhecido como sanitarista ou salubrista. Ainda que tal denominação possa ser redefinida diante da crise da saúde pública institucionalizada e da emergência de novos paradigmas a partir da construção do campo da Saúde Coletiva, algumas convergências, diálogos e identidades produzidos pelas escolas de saúde pública e institutos de saúde coletiva e assemelhados no Brasil podem apontar para um perfil geral desse profissional: seu conhecimento das doenças, agravos, riscos e determinantes se volta para os aspectos que, de forma coletiva, facilitam ou obstaculizam sua ocorrência ou seu progresso, reservando o atendimento personalizado aos doentes para os tradicionalmente graduados para atendê-los. Portanto, a sua formação prescinde, até certo ponto, dos conhecimentos clínicos e terapêuticos específicos, requeridos dos profissionais voltados para o atendimento de cada indivíduo isoladamente. Sua habilitação, entretanto, o capacita a cooperar com os demais profissionais em situações particulares, desde que devida e oportunamente treinados para a tarefa (PADILHA, 1997).

O contexto acima descrito está a exigir, portanto, uma massa crítica de profissionais com uma formação básica em saúde coletiva contemplando a epidemiologia, as ciências sociais em saúde e a planificação em gestão, além dos núcleos temáticos correspondentes à saúde ambiental e ocupacional, vigilância em saúde, educação e comunicação social em saúde, direito sanitário, economia da saúde, entre outros ${ }^{4}$.

Esta demanda tende a se apresentar de forma mais expressiva na medida em que os esforços pela mudança do modelo assistencial hegemônico se intensifiquem nos próximos anos e décadas. Nessa perspectiva, inscreve-se a expansão da estratégia de saúde da família, posto que o PSF alcançou recentemente a implantação de 15 mil equipes equivalendo a uma cobertura de 50 milhões de brasileiros. Outros modelos de atenção, progressivamente propostos e experimentados, com ênfase na promoção e proteção da saúde como a vigilância da saúde, as ações programáticas de saúde desenvolvidas no nível local, municípios saudáveis etc., exigirão recursos humanos com formação em Saúde Coletiva capazes de apoiar a implementação de estratégias voltadas para a diretriz da integralidade das ações de saúde e para o desenvolvimento de políticas públicas intersetoriais. 


\section{O processo de produção de trabalhadores em saúde coletiva}

No Brasil, a formação de recursos humanos em saúde pública teve início em 1925, através do Curso de Higiene e Saúde Pública voltado para a formação de médicos-sanitaristas. Desde então a formação e a utilização desse agente tem sofrido inflexões relacionadas com o desenvolvimento das políticas públicas e com as formas de estruturação das práticas de saúde. Desse modo, o especialista em saúde pública passa a ter uma composição multiprofissional, exibindo no desenvolvimento histórico dos modelos tecno-assistenciais, inúmeras faces: campanhista, desenvolvimentista, racionalizadora/modernizante, médico-social, generalista e gerencial (BELISÁRIO, 1995).

Com a emergência da Saúde Coletiva, a produção de especialistas foi submetida à hegemonia da pós-graduação sensu estrito, importada do modelo norte-americano de escola de saúde pública que reforça o "modo escolar", dissociando o trabalho do estudo (PAIM, 1985). O seu desenvolvimento mais recente comporta tipos menos homogêneos de formação como certos programas de residência multiprofissional, mestrados profissionalizantes e algumas experiências de cursos de atualização e de especialização desenvolvidas por instituições acadêmicas de Saúde Coletiva e apoiadas pelo Ministério da Saúde e representação da OPAS.

Novas estratégias de formação de pessoal de nível superior na área de Saúde Coletiva têm sido experimentadas buscando a aproximação com os serviços de saúde, embora insuficientes para superar o "modo escolar". Entretanto, na medida em que o "objeto de ensino" se constitua efetivamente como sujeito que trabalha, novas relações de ensino poderão ser instauradas, redefinindo o "modo escolar" de produção desses sujeitos. $\bigcirc$ seu potencial instituinte deveria, portanto, ser estimulado considerando os distintos projetos em disputa nas instituições concretas e conjunturas específicas visando a reorganização do sistema de saúde.

O desenvolvimento teórico-conceitual, metodológico e operativo da Saúde Coletiva no Brasil nos últimos trinta anos, e o florescimento das ciências sociais e humanas no campo da saúde, particularmente da Economia, da Administração, da Antropologia, da Sociologia, da Psicossociologia, ao lado da Epidemiologia e das Ciências da Informação e da Comunicação tornaram patente não apenas a independência da produção de bens e serviços de saúde com relação aos conhecimentos de base oferecidos pelas referidas 
graduações tradicionais, mas também o grave desvio de função experimentado pelos profissionais com tais graduações ao inserir-se na produção de serviços de saúde, sempre e quando as exigências se voltam para o atendimento das coletividades (PADILHA, 1997, p. 2).

Consequentemente, o espectro de atuação do profissional de saúde coletiva é o de descrever, explicar e prognosticar o comportamento das doenças nas coletividades, manejar os meios e modos para prevenção, controle, eliminação ou erradicação de doenças ou agravos e participar dos esforços para a proteção e promoção da saúde das comunidades, visando a melhoria das condições de saúde das populações. A formação de um profissional com tal perfil no nível da graduação requer a aquisição de conhecimentos e habilidades provenientes da Epidemiologia, da Política de Saúde, do Planejamento \& Gestão (incluindo gerência de sistemas, estabelecimentos, rede de unidades, linhas de produção e processos de trabalho), da Economia, da Informação, da Comunicação e da Educação, entre outras.

\section{Por que formar os agentes da saúde coletiva na graduação?}

Evidentemente, há um número incalculável de comunidades no país desatendidas no que se refere às ações possíveis de serem realizadas por um profissional com tal perfil, o que dá uma idéia da demanda não atendida e, consequentemente, da possibilidade de expansão dessas ações. Essa desatenção pode ser explicada em parte pela adesão das autoridades sanitárias do país ao modelo médico hegemônico de matriz flexneriana, cuja organização de serviços centra-se na assistência médico-hospitalar. Os esforços empreendidos por alguns dirigentes nos últimos anos com vistas à reorientação do modelo de atenção precisam ser respaldados pela formação ampliada de profissionais de saúde coletiva que operem no cotidiano dos serviços os desafios dessa transformação.

De acordo com a perspectiva de certas correntes teórico-conceituais da sociologia das profissões, um processo de profissionalização pode envolver os seguintes passos:

1) O trabalho torna-se uma ocupação de tempo integral;

2) Criam-se escolas de modo que a transmissão de conhecimentos é feita de modo sistematizado para os aspirantes, por pares experientes; 
3) Forma-se a associação profissional, quando se definem os perfis profissionais que fornecerão identidade ao grupo;

4) A profissão é regulamentada;

5) Adota-se um código de ética e estabelecem-se normas e regras profissionais. (MACHADO, 1995, p. 19)

É possível inferir que já se encontram concretizados muitos desses passos no que diz respeito ao profissional da saúde coletiva no Brasil. Apenas a formação tem-se restringido à pós-graduação e a profissão não foi regulamentada, nem tampouco estabelecido o seu código de ética. Esses passos, caso necessários, poderão ser cogitados à medida que a formação desse profissional e a sua inserção no mercado de trabalho ganhem apoios para a construção da sua viabilidade.

Por conseguinte, não é possível nem desejável que todo o contingente desses profissionais seja formado através da pós-graduação (lato e estrito senso). Então por que apostar na formação em Saúde Coletiva no nível da graduação, articulando o mundo do ensino ao mundo do trabalho?

Em primeiro lugar porque não se justifica, racionalmente, esperar seis anos de curso médico, cinco de odontologia e psicologia, quatro de enfermagem, nutrição, assistente social etc. para depois capacitar esses profissionais na área da Saúde Coletiva. Por melhor que tenha sido o ensino das disciplinas dessa área nos cursos de graduação, as competências adquiridas são limitadas além de subalternas ao modelo médico hegemônico que estrutura as práticas educativas nas instituições de ensino. A graduação em Saúde Coletiva encurta o tempo de formação profissional, pois promove uma economia substancial, dispensando um gasto extraordinário com o ensino de disciplinas que não trazem qualquer contribuição para o formato profissional desejado. Do mesmo modo, a sua articulação com o trabalho em serviço, desde o primeiro ano da graduação, poderia dispensar grande parte da carga horária consumida pelos programas de residência quando buscam o treinamento em serviço no sentido de oferecer "experiência prática" para médicos, enfermeiros, odontólogos, psicólogos e assistentes sociais que não a obtiveram nas suas respectivas graduações.

Em segundo lugar, a formação pós-graduada limitou expressivamente a produção desse especialista. Assim, a relação custo-benefício da formação de tais profissionais exclusivamente na pós-graduação é menos favorável do que a alcançada com o preparo de um profissional de saúde coletiva no 
período de três anos, com a possibilidade de uma habilitação específica em mais um ano. Nesse caso, a pós-graduação será, efetivamente, a realização de uma especialização e uma qualificação avançada e não um curso básico para a formação em massa do pessoal necessário ao desenvolvimento das práticas de saúde coletiva no SUS ou uma estratégia de correção de deficiências acumuladas na graduação.

Em terceiro lugar, porque o SUS, a descentralização e a expansão da estratégia de saúde da família, vigilância da saúde e a ação intersetorial em saúde têm pressa para reorientar o modelo assistencial dominante. Não é defensável confinar o profissional de saúde coletiva nas unidades de administração central de órgãos públicos (Ministério e Secretarias estaduais e municipais de saúde) quando a reorganização das práticas de saúde nos sistemas locais, nas unidades de saúde e até nas equipes de saúde da família requer habilidades e competências em Saúde Coletiva. Manter o desempenho do especialista na administração central ou regional (com a exceção da histórica experiência da Secretaria de Saúde do Estado de São Paulo nos anos 1970), pode resultar em um transtorno duplamente perverso: de um lado, privar os estabelecimentos de saúde desse profissional qualificado e, por outro, forçar uma relação profissional distorcida em que as ações propostas pelos especialistas do nível central passam a ser realizadas por profissionais não habilitados para a tarefa (PADILHA, 1997).

Há mais de dez anos tem-se cogitado formar o profissional da saúde coletiva no âmbito da graduação. Professores de escolas de saúde pública brasileira e de institutos e núcleos de Saúde Coletiva têm defendido essa idéia em reuniões públicas ${ }^{5}$. Do mesmo modo, a Secretaria de Políticas de Saúde (SPS) do Ministério da Saúde tem manifestado interesse em apoiar os esforços para a implementação de um projeto dessa natureza.

Portanto, já é tempo de superar o dilema de desencadear o processo de formação desse profissional: indica-se ao mercado de trabalho quais os avanços tecnológicos de que se dispõe para enfrentar os problemas associados ao desenvolvimento da sociedade ou prudentemente, mantém-se a estrutura vigente de tecnologias para atender a demanda convencional? Com a primeira opção, corre-se o risco de empregar recursos para criar um contingente de trabalhadores que o mercado não absorve; com a segunda, o risco é o de privar o mercado de avanços que favorecem a eficiência dos procedimentos e a eficácia dos serviços e bens a serem consumidos pela população (PADILHA, 112 1997). No entanto, é possível identificar, presentemente, sinais do mercado 
de trabalho apontando para a possibilidades de emprego de pessoal com tal formação. Caberia às universidades prestarem atenção para tal sinalização e prepararem pessoal para suprir o mercado de trabalho com esses recursos humanos.

Responder à situação analisada e aos desafios postos pela agenda não esgotada da Reforma Sanitária Brasileira significa formular um projeto de graduação em Saúde Coletiva adequado e consistente, sustentado por instituições formadoras reconhecidamente competentes e comprometidas com o pleno desenvolvimento do SUS democrático. Ainda no período de elaboração, deve-se atender a necessidade da conquista de uma clientela institucional, demonstrando a validade desta argumentação e a inevitabilidade de um desdobramento profissional desta natureza, em função do progresso científico e tecnológico; essa conquista é particularmente importante e deve ser dirigida a responsáveis por órgãos integrantes do Sistema Único de Saúde, inclusive porque induz a firmar convênios e acordos da Universidade com instituições públicas e privadas, vinculadas às três instâncias do SUS que propiciem financiamentos para a realização de um programa que lhes seja eventualmente proposto (PADILHA, 1997, p. 5).

A partir da constituição desses novos sujeitos da Saúde Coletiva, a sociedade brasileira poderá promover a adoção de novos modelos de atenção mais efetivos, humanizados e igualitários. $\bigcirc$ alargamento do debate ${ }^{6}$ entre docentes, técnicos, autoridades e estudiosos dos problemas do setor saúde para as instâncias de controle social do SUS, da mídia, o Congresso Nacional e da sociedade em geral, criará melhores oportunidades de promover uma mudança substancial na situação atual.

\section{Notas}

${ }^{2}$ No Brasil, a promoção da saúde cada vez mais se vincula ao campo da Saúde Coletiva, integra-se à noção de vigilância da saúde e estimula, presentemente, a formulação de políticas no interior do Ministério da Saúde, além de ampliar o âmbito de discussão nos Congressos da ABRAsco e em eventos específicos.

${ }^{3}$ Outras iniciativas, no contexto de programas estratégicos do Governo Federal nos últimos anos como Brasil em Ação e Avança Brasil, têm contemplado a problemática intersetorial da promoção da saúde, particularmente no que se refere a saneamento, desenvolvimento urbano, emprego e renda, ação social, educação e meio-ambiente. No momento [que momento?], os programas dos candidatos à Presidência da República apontam também para a ação intersetorial, 
contemplando intervenções que abrangem, simultaneamente, emprego, segurança pública, saúde, educação, cultura, entre outros.

${ }^{4} \mathrm{Se}$, na pior das hipóteses, cada município precisar de um mínimo de quatro novos profissionais com tal formação, 22.000 agentes deveriam estar formados de início para que um modelo assistencial comprometido com o princípio da integralidade da atenção, tal como estabelece a Constituição da República e as Leis Orgânicas da Saúde e reiteram as recomendações das Conferências Nacionais de Saúde, pudesse ser implantado e desenvolvido com qualidade, efetividade e humanização. Trata-se, portanto, de uma estimativa minimalista. Estudos mais consistentes poderão indicar demandas bem maiores num futuro breve que poderiam ser atendidas pelas universidades públicas, inclusive através de cursos noturnos.

${ }^{5}$ Ver, por exemplo, Paulo Buss (FIOCRUZ-ENSP), José Maria Pacheco (FSPUSP), Roberto Medronho (UFRJ), Lígia Maria Vieira da Silva (ISC-UFBA), entre outros. No caso do ISC-UFBA tal proposta vem sendo amadurecida desde a sua criação, sendo o Prof. Naomar de Almeida Filho, atual Reitor da UFBA, um dos entusiastas. Mais recentemente, a Universidade Federal do Rio de Janeiro formulou projeto nessa direção, tendo o compromisso do Reitor Prof. Carlos Lessa para a sua implantação. O Governo do Rio Grande do Sul deu início no ano passado à graduação em saúde coletiva com ênfase na gestão em saúde.

${ }^{6}$ No presente Seminário, algumas perguntas poderiam provocar tal discussão: 1) Que atributos definiriam um profissional de saúde coletiva? 2) Em que medida o trabalho em Saúde Coletiva pode configurar um campo profissional? 3) Quais razões justificariam a exclusividade da formação em Saúde Coletiva no nível de pós-graduação? 4) Que vantagens poderiam ser enumeradas para que a formação do profissional em saúde coletiva pudesse ser realizada com terminalidade na graduação, ainda que complementada pela pós-graduação (especialização, residência, mestrado e doutorado)? 5) Que competências e habilidades deveriam compor o currículo da graduação em Saúde Coletiva? 6) Que elenco de disciplinas e conteúdos programáticos mínimos deveria constituir o plano de estudos da graduação em Saúde Coletiva? 7) A formação em saúde coletiva na graduação exigiria a regulamentação de uma nova profissão no Brasil? 


\section{Referências}

ALAESP I. Conferencia Panamericana de Educación en Salud Pública. XVI Conferencia de ALAESP. Informe Final. Rio de Janeiro, agosto de 1994.

BELISÁRIO, S. A. As múltiplas faces do médico-sanitarista. In: MACHADO, M. H. (Org.). Profissões de saúde: uma abordagem sociológica. Rio de Janeiro: Editora Fiocruz, 1995

DONNÂNGELO, M. C. F. Saúde e sociedade. São Paulo: Duas Cidades, 1976.

DONNÂNGELO, M. C. F. A pesquisa na área da Saúde Coletiva no Brasil - a década de 70. In: ABRASCO. Ensino da Saúde Pública, Medicina Preventiva e Social no Brasil. Rio de Janeiro, 1983.

FEE, E. Disease and Discovery. A history of the Johns Hopkins School of Hygiene and Public Health; 1916-1939. Baltimore: Johns Hopkins University Press, 1987.

HELLER, A. Teoria de las necesidades en Marx. Barcelona: Ediciones Península, 1986.

MACHADO, M. H (Org.). Profissões de saúde: uma abordagem sociológica. Rio de Janeiro: Editora Fiocruz, 1995.

MENDES-GONÇALVES, R. B. Práticas de saúde: processos de trabalho e necessidades. São Paulo: CEFOR, 1992. (Cadernos CEFOR - Textos, 1).

MENDES-GONÇALVES, R. B. Tecnologia e organização das práticas de saúde. Características tecnológicas do processo de trabalho da rede estadual de Centros de Saúde de São Paulo. São Paulo: Hucitec/Abrasco, 1994.

OPS/OMS. Desafios para la educación en Salud Pública. La reforma sectorial y las funciones esenciales de Salud Pública. Washington, D.C.: OPS, 2000.

OPS/OMS/ALAESP. Educación en Salud Pública. Nuevas perspectivas para las Américas. Washington, D.C: Organización Panamericana de la Salud, 2001.

OPS/OMS/CDC. Medição do desempenho das funções essenciais de Saúde Pública. Guia para a aplicação do instrumento do desempenho das funções essenciais de Saúde Pública. Washington: Organización Panamericana de la Salud, s/d.

PAHO. The crisis of Public Health: reflections for the debate. Scientific Publication, Washington. n. 540, 1992.

PADILHA, H. Saúde Pública: campo para profissionalizar em nível de graduação? (Texto elaborado para discutir o tema no ISC/UFBA). Salvador, agosto de 1997.

PAIM, J. S. As ambigüidades da noção de necessidades de saúde. Planejamento, Salvador, v. 8, n. 1/2, p. 19-46, 1980.

PAIM, J. S. A formação de recursos humanos em Saúde Coletiva. Rev. Bras. Educ. Médica, Rio de Janeiro, v. 9, n. 2, p. 88-94, 1985.

PAIM, J. S. A situação de saúde no Brasil e os modelos assistenciais. In: SBPC. $4^{a}$ Reunião Especial da SBPC - "Semi-árido: no terceiro milênio, ainda um desafio". XI Jornada Universitária da UEFS. 24 a 28 de novembro de 1996. Feira de Santana, Bahia. Anais, 1996.

PAIM, J. S. Transición paradigmática y desarrollo curricular en salud pública. In: OPS/ OMS/ALAESP. Educación en Salud Pública. Nuevas perspectivas para las Américas. Washington, D.C. 2001. 
PAIM, J. S. Saúde Política e Reforma Sanitária. Salvador: CEPS-ISC, 2002.

PAIM, J.S. \& ALMEIDA FILHO, N. A crise da Saúde Pública e a utopia da Saúde Coletiva. Salvador-Bahia: Casa da Qualidade Editora, 2000. 125p.

SCHRAIBER, L. B. (Org.) Programação em saúde, hoje. São Paulo: Hucitec, 1990.

SCHRAIBER, L. \& MENDES-GONÇALVES, R. B. Necessidades de saúde e atenção primária. In: SCHRAIBER, L.; NEMES, M. I. B.; MENDES-GONÇALVES (Org.). Saúde do Adulto. Programas e ações na unidade básica. São Paulo: Hucitec, 1996.

TEIXEIRA, C. (Org.). Promoção e Vigilância da Saúde. Salvador: CEPS-ISC. 2002. 


\section{Movimentos no campo social da saúde ${ }^{1}$}

\section{Introdução}

movimentos de idéias que influenciaram o campo social da saúde durante a emergência e o desenvolvimento do capitalismo, central e periférico, a saber: Polícia Médica, Higiene, Medicina Social, Saúde Pública, Medicina Preventiva, Saúde Comunitária, Medicina Familiar, Promoção da Saúde, Saúde Coletiva e Nova Saúde Pública. Neste sentido, apresenta os seguintes objetivos:

- Identificar certos limites dos estudos históricos sobre medicina e saúde pública, quando enfatizam a historicidade dos meios científicos e tecnológicos em detrimento da historicidade dos objetivos e finalidades das práticas de saúde;

- Descrever as características básicas dos movimentos referentes à Polícia Médica, Higiene, Medicina Social, Saúde Pública, Medicina Preventiva, Saúde Comunitária, Medicina Familiar, Promoção da Saúde, Saúde Coletiva e Nova Saúde Pública;

- Comparar essas concepções e práticas de saúde em função dos vetores relativos aos movimentos sociais e ideológicos, à ação política e à produção de conhecimentos;

- Discutir possíveis determinantes e condicionantes da emergência e desenvolvimento desses movimentos;

- Comentar sobre as tendências atuais da Saúde Pública/ Saúde Coletiva.

'Texto elaborado para a Rede Interamericana de Formação sobre os Determinantes Sociais da

Saúde (REDET). Convênio Universidade de Montreal, Quebec, Canadá/ Instituto de Saúde Coletiva da Universidade Federal da Bahia, Bahia, Brasil, 2004. 
O texto apresenta abordagens históricas no estudo do campo social da saúde, seus limites e possibilidades, explicitando um marco de referência centrado em quatro vetores: a) movimentos ideológicos; b) movimentos sociais; c) ação política; d) produção de conhecimentos. Em seguida, procura descrever as características básicas dos movimentos acima aludidos. Conclui com alguns comentários sobre as tendências atuais da Saúde Pública/Saúde Coletiva e as perspectivas de diálogo acadêmico norte-sul.

\section{Marco de referência teórico}

Os estudos históricos sobre Saúde Pública tendem a indicar um conjunto de ações sobre coletivos humanos e sobre o ambiente desde a Antiguidade: banheiros públicos e esgotamentos sanitários em Roma ou cuidados com o corpo e a forma física na Grécia (ROSEN, 1994). Ainda que tenham a importância de sugerir a historicidade das ações de saúde, apresentam o problema de limitar-se à historiografia dos meios, descuidando da historicidade dos objetivos e práticas sociais (DONNÂNGELO, 1976).

Assim, faz-se necessário distinguir a "história das condutas preventivas" ou a "história das medidas coletivas" em relação à História da Saúde Pública e da Saúde Coletiva. Na realidade, desde Hipócrates, as condutas preventivas se confundem com a própria História da Medicina e com as ações coletivas em defesa da saúde e na prevenção e controle de doenças (ROSEN, 1979; 1994).

marco teórico de referência a orientar o presente texto procura assumir a História não como uma sucessão linear de fatos, datas e nomes de luminares, mas como a superação de modos de produção, como descontinuidades, enfim, como resultado de lutas de classes e de sujeitos sociais com distintos projetos político-ideológicos, em que as personalidades ou atores detêm um espaço de iniciativa, porém são condicionados pelas estruturas e pelas circunstâncias: "A história das ciências é basicamente a história das idéias e [...] estas encontram a sua especificidade na relação que possuem com a estrutura social que as gerou e permitiu o seu aparecimento [cabendo examinar] a construção do conceito em sua dimensão histórica" (AROUCA, 1975, p. 14).

A ênfase nos sujeitos (centralização antropológica) ou nas estruturas (viés estruturalista) tem de algum modo polarizado a abordagem histórica e as correntes das ciências sociais (MINAYO, 2001): 
Essa identidade mediada dos contrários desconstrói a subjetividade soberana. Vamos encontrá-la em Marx, na relação entre o caráter reificado (objetal) da relação social (os indivíduos sendo os suportes - Träger - da estrutura) e a vontade subjetiva de mudar o mundo. $\bigcirc$ esquecimento dessa unidade contraditória leva a interpretações unilaterais abstratas, estruturalista-objetivista de uma parte (a eliminação radical do sujeito realiza-se na contemplação das maquinarias estruturais), humanista-voluntarista (reduzindo a crise da humanidade à sua "crise de direção revolucionária") de outra (BENSAïD, 1999, p. 376).

Nesta oportunidade, sem desprezar as contribuições dos sujeitos, pretende-se, contextualizar os fatos socialmente produzidos discutindo possíveis determinantes e condicionantes. Assim, poder-se-iam examinar as práticas de saúde, voltadas para o coletivo e o ambiente, em distintos modos de produção tais como o escravismo, o feudalismo, o capitalismo (GARCIA, 1972), ou mesmo, o socialismo.

Admite-se, assim, que os modos pelos quais as sociedades identificam os seus problemas de saúde, buscam a sua explicação e se organizam para enfrentá-los variam historicamente e dependem de determinantes estruturais econômicos, políticos e ideológicos. Assim, o campo da Saúde Pública que se vem desenvolvendo desde a passagem do feudalismo para o capitalismo e, especialmente, a partir da Revolução Industrial, sofre as influências desses determinantes sociais e passa por recomposições em função de novas relações entre a sociedade e o Estado (PAIM, 1992).

A partir desse marco de referência teórica, a Saúde Pública é entendida como uma prática social e, conseqüentemente, não livre das determinações da estrutura social (DONNÂNGELO, 1976), estando submetida à dinâmica interna das relações sociais predominantes num dado contexto, particularmente no que se refere às lutas entre classes e grupos sociais (THERBORN, 1989).

Na passagem do feudalismo para o capitalismo, o campo social da saúde foi atravessado por um conjunto de movimentos ideológicos e sociais, além de ação política e produção de conhecimentos que constituem vetores para a delimitação do campo da Saúde Pública e da Saúde Coletiva.

Na medida em que as ideologias e as práticas de saúde compõem a estrutura social (estrutura das práticas sociais ou práticas sociais estruturadas), contribuíram com a constituição do capitalismo ao tempo em que participaram da sua expansão e reprodução (DONNÂNGELO, 1976; MENDESGONÇALVES, 1992). 
Para atender aos propósitos que norteiam o presente texto, a Saúde Pública e a Saúde Coletiva serão analisadas a partir de um marco de referência centrado em quatro vetores: a) movimentos ideológicos; b) movimentos sociais; c) ação política; d) produção de conhecimentos.

Movimentos ideológicos podem ser definidos como conjunto de práticas ideológicas relacionadas com a mudança de crenças ou visões de mundo (AROUCA, 2003). Os movimentos sociais são constituídos por práticas sociais (econômicas, políticas e ideológicas) voltadas para o enfrentamento de necessidades sociais e para a realização de demandas políticas. Já ação política é entendida como intervenção social dirigida para a mobilização de vontades e grupos sociais visando alterar uma correlação de forças e a distribuição do poder. Finalmente, a produção de conhecimentos envolve um conjunto de praticas teóricas e científicas voltadas para a identificação, análise, explicação e interpretação de fenômenos e fatos, de acordo com as regras do método científico e com os paradigmas vigentes.

\section{Polícia Médica}

A Polícia Médica aparece no nascimento do capitalismo com a expansão do comércio mundial e com o surgimento dos Estados absolutistas europeus, particularmente nos estados germânicos:

O significado social assumido pela medicina com a emergência do capitalismo já se esboça durante o período mercantilista, articulado ao papel que ele desempenha no processo de acumulação de riqueza. Marcando a etapa de transição do modo feudal ao modo capitalista de produção, o mercantilismo como doutrina e forma de organização social a um só tempo econômica e política, implica o recurso a diferentes meios de acumulação pelas sociedades européias: o sistema colonial, o regime de dívidas públicas, os esquemas de tributação, o controle sobre a atividade produtora interna (DONNÂNGELO, 1976, p. 48).

A sua sistematização pode ser localizada na obra de Johan Peter Frank na segunda metade do século XVIII. Entendia-se a saúde do povo como riqueza e força da nação, cabendo ao Estado protegê-la (ROSEN, 1979). Abre espaço para uma intensa intervenção do Estado e de governos sobre os problemas de saúde, configurando aquilo que Foucault (1993) chamava Medicina de Estado:

"Enunciada por Thomas Rau em 1764 e desenvolvida basicamente por Johan Peter Frank, a noção de 'polícia médica' comporta, entre outros, os

120 seguintes princípios: os médicos são responsáveis não apenas pelo tratamen- 
to dos doentes, mas também pelo controle e manutenção da saúde da população; esse controle deve atingir todos os aspectos da vida dos indivíduos. Para tanto, é necessário: restringir o exercício da medicina a pessoal médico competente, produto de uma educação regular e eficiente; supervisionar o funcionamento dos hospitais; promover a educação do povo em matéria de saúde" (DONNÂNGELO, 1976, p. 50-1).

Assim, a proposição de uma Política (ou Polícia) Médica reconhece a responsabilidade do Estado como definidor de políticas, leis e regulamentos referentes à saúde no coletivo e como agente fiscalizador da sua aplicação, articulando as práticas de saúde à superestrutura jurídico-política da sociedade.

\section{Higiene}

A Higiene, impregnada das idéias de Rousseav e de certos ideais da Revolução Francesa, sobretudo no que se refere ao papel da educação, vinculava-se às doutrinas liberais, segundo as quais caberia aos indivíduos a responsabilidade com a saúde. Era constituída por conjunto de regras, normas, prescrições preventivas, recomendações, medidas etc. para conservar a saúde e a vida (a arte de bem viver), a partir do comedimento e da restrição aos excessos e vícios.

A Higiene coincide com a ascensão da burguesia no controle do poder políitico, enquanto classe que buscava a hegemonia dentro da sociedade. Nesse sentido, "ocupou um lugar na sociedade civil, enquanto sistema de normas que controlavam a saúde individual, e um lugar no Estado, enquanto normas coletivas de vida" (AROUCA, 1975, p. 116).

\section{Sanitarismo}

Este movimento tem como marcos o Relatório Chadwick, na Inglaterra, e o Relatório Shattuck nos EUA. Os reformadores sociais de então propunham uma legislação sanitária e o saneamento do meio. Embora surgido em sociedades capitalistas com predomínio do liberalismo econômico e político, defendia a intervenção do Estado nos problemas de saúde que os indivíduos e a iniciativa privada não fossem capazes de resolver. Assim, a Saúde Pública, nesse contexto, propunha medidas específicas de controle de doenças mediante instrumentalização do conhecimento produzido pela nascente epidemiologia e posteriormente pela "revolução" microbiana. 
O sanitarismo passa a ter bases de produção e de reprodução acadêmica na Europa a partir da criação das escolas de Liverpool e de Londres (London School of Hygiene and Tropical Medicine) ao final do século XIX. A LSHTP, embora inaugurada em 1899, instala-se integralmente em 1924, sob a liderança de Manson e com o apoio da Fundação Rockefeller. Esta Fundação americana apoiou, também, a criação de escolas de Saúde Pública nos Estados Unidos, a partir de propostas provenientes das universidades de Harvard, Columbia e John Hopkins (PAIM, 2001).

A proposta da Harvard, liderada por Rosenau, professor de medicina preventiva, assentava-se em um programa de agentes de saúde junto ao MIT com ênfase na engenharia sanitária, na higiene industrial, na redução da mortalidade infantil e na promoção da saúde escolar.

A proposta da Columbia, sob a liderança de Seligman, professor de ciência política, destacava a importância das ciências sociais e da economia política sobre aspectos médico-sanitários.

Já a proposta da Johns Hopkins, desenvolvida por Welch, professor de patologia, centrava-se no enfoque biomédico orientado para pesquisa científica, com ênfase em estatística, epidemiologia, bacteriologia e relação com o Hospital-escola.

Abrahan Flexner que em 1911 produziu o famoso Relatório Flexner, reorientando a educação médica e fincando as bases do modelo médico hegemônico (MMH) no mundo ocidental (PAIM, 2002), foi indicado em 1916 para decidir qual das propostas deveria ser apoiada pela Fundação Rockefeller. A escolhida foi a da Johns Hopkins, na qual a escola de Saúde Pública submetia-se ao modelo médico hegemônico em construção, vinculando-se à escola médica (FEE, 1987). A escola da Johns Hopkins, por sua vez, serviu de protótipo para institutos ou escolas de Higiene ou Saúde Pública da América Latina inaugurados na década seguinte, além de formar gerações de sanitaristas latinoamericanos ao longo do século 20.

\section{Medicina Social}

Esta expressão atribuída a Jules Guérin, na França, dissemina-se junto às lutas sociais desse país e depois na Alemanha, com as contribuições de Rudolf Virchow e Salomon Neumann. Desenvolvia uma reflexão sobre o caráter social das doenças e da prática médica, construindo um

122 vínculo com os movimentos sociais existentes naqueles países. Apresentava os 
seguintes princípios básicos: a saúde do povo é um objeto de inequívoca responsabilidade social; condições econômicas e sociais devem ser submetidas à investigação científica; medidas para promover a saúde e combater a doença devem ser sociais e médicas (ROSEN, 1979). Procurava participar da reforma geral das instituições destinada a instaurar uma nova sociedade (DONNÂNGELO, 1976).

Coube a Juan Cesar Garcia, responsável pelo programa de recursos humanos da OPS, recuperar, na passagem da década de 1960 para 1970, as contribuições desse movimento junto às lutas sociais da França (1848) e da Alemanha (1871) e estimular o confronto entre seus princípios e proposições com aqueles difundidos pela Medicina Preventiva e pela Saúde Comunitária (GARCIA, 1972; 1985).

O aparecimento desses cursos de pós-graduação inovadores no México e no Brasil parece oferecer condições "para que se desse legitimidade a Medicina Social como um campo disciplinar" a partir de uma longa tentativa de separação entre a medicina preventiva e social e saúde pública e Medicina social" (GARCIA, 1985). Assim, a criação desses cursos de pós-graduação em Medicina Social, no nível de mestrado, em Xochimilco (México) e no Rio de Janeiro (Brasil), com o apoio da OPS (GARCIA, 1985), e a produção científica desses centros e daqueles que se reorganizaram (PAIM, 2002), possibilitaram o desenvolvimento da Medicina Social Latinoamericana na década de 1970 (WAITZKIN et al, 2001 a; 2001 b), posteriormente conhecida como Saúde Coletiva.

\section{Medicina Preventiva}

Enquanto movimento ideológico, a Medicina Preventiva procura distinguir-se da Higiene e da Saúde Pública. Diferencia-se, também, da Medicina Social nos campos conceitual e histórico. No início do século XXera reconhecida como uma parte da Higiene, mas posteriormente se transforma num movimento de idéias que emerge nos países centrais e se difunde para os dependentes. Segundo Arouca (2003), utiliza como conceitos básicos o processo saúde/doença, modelo da história natural das doenças (HND) e multicausalidade. Adota, também, conceitos estratégicos tais como integração, resistência, inculcação e mudança. Ao ser introduzida nas escolas médicas através da criação de núcleos ou departamentos de Medicina Preventiva reproduz um discurso apologético, crítico e/ou tecnocrático (PAIM, 1986), buscando transformar estudantes de medicina em agentes de mudança (AROUCA, 2003). 
A Medicina Preventiva constituía um novo fenômeno no campo conceitual da área médica mediante a evolução da higiene privada. Articulava um conjunto de medidas de prevenção que resultariam em condutas que preencheriam uma atitude ausente da prática médica, ou seja, a atitude preventiva e social. Como se fora um "partido da nova atitude" (integral, preventiva e social), a Medicina Preventiva tornou-se um "centro polarizador de disciplinas não tradicionais dentro da escola médica" (AROUCA, 1975, p. 17-22). Nela, a cultura higiênica (universal) é apropriada pela profissão médica, procurando normatizar os médicos (estudantes, professores e escola de medicina) tal como a Higiene normatizava a vida das pessoas nos interstícios configurados entre a saúde pública e a medicina.

Na realidade, tratava-se, desde a sua emergência nos Estados Unidos, de uma conciliação entre a categoria médica, em sua organização privada, e o Estado (AROUCA, 1975, p. 102) como uma alternativa à proposta de participação estatal na atenção à saúde, representando uma "leitura liberal e civil dos problemas de saúde" da sociedade americana (AROUCA, 1975, p. 3-4). A constituição desse discurso preventivista descende da Higiene construída no século XIX com o desenvolvimento do capitalismo e da disseminação da ideologia liberal, mas encontra a sua difusão diante da crise de custos da atenção médica nos EUA nas décadas de 1930 e de 1940, quando em muitos países surgia o Estado interventor na passagem da fase concorrencial para a monopolista do capitalismo.

Num contexto que possibilitava a crítica à medicina liberal, a Medicina Preventiva apontava para a possibilidade da redefinição das responsabilidades médicas através de mudanças na educação médica. Este movimento ideológico, nascido nos EUA, difunde-se nos países centrais através dos Seminários de Nancy (1950) e Colorado Springs (1953), chegando à América Latina mediante os Seminários de Viña del Mar (1955) e Tehuacan (1956), apoiados pela OPS e por fundações americanas (AROUCA, 2003).

\section{Medicina/Saúde Comunitária}

Este movimento ideológico é, também, originário dos Estados Unidos na década de 1960 como resposta às tensões sociais geradas pelos movimentos dos direitos civis e contra a segregação racial, compondo posteriormente certas políticas de combate à pobreza dos governos Kennedy e Johnson (PAIM, 1986). 
No âmbito acadêmico, tratava-se de uma tentativa de operacionalização da "filosofia" ou do discurso da Medicina Preventiva, enquanto campo de demonstração. Estimulava práticas externas às unidades de saúde (ações extramuros) e a articulação da medicina privada com a Saúde Pública. Adotava os conceitos básicos desenvolvidos pela Medicina Preventiva, acrescentando outros conceitos estratégicos tais como integração docente assistencial, participação da comunidade e regionalização.

O desenvolvimento da Saúde Comunitária exibe em alguns países um momento focal, quando restringe-se a atividades experimentais vinculadas ao Centro de Saúde-Escola e um momento expansionista quando se apresenta como atenção primária à saúde (APS) e serve de referência para a formulação e implementação de programas de expansão de cobertura de serviços de saúde (PECs) voltados para populações rurais e os pobres das periferias urbanas (PAIM, 1986).

Nos Estados Unidos, o fracasso do movimento da Saúde Comunitária é reconhecido por Desrosiers (1996) ao comentar que, dado "o caráter parcial e muitas vezes temporário das experiências de medicina ou saúde comunitária, restou somente a expressão [...] no lugar da saúde pública tradicional".

\section{Medicina de Família}

Este movimento ideológico tem origem nos EUA especialmente quando a Associação Médica Americana (AMA) passa a reconhecer programas de residência nessa "especialidade" em 1966 (CEITLIN, 1982). Países como Canadá e México criam programas semelhantes na década de 1970, enquanto Cuba, na década seguinte, adota tal proposta como forma de avançar a atenção primária à saúde (PAIM, 1986). A medicina familiar foi reconhecida como o movimento dos cuidados primários à saúde sob a ótica dos países industrializados (CHAVES, 1982).

Na sua origem, tratava-se de mais uma tentativa de recomposição da prática médica liberal voltada para indivíduos e núcleos familiares contra os altos custos e o "especialismo" médico e uma busca de recuperação da humanização da medicina. No Canadá este movimento aproveitou-se da conjuntura de mudança do sistema de saúde tendo como marco o Relatório Lalonde (TERRIS, 1990), enquanto no México buscava capacitar médicos para os serviços de saúde do Instituto Mexicano de Seguridade Social (IMSS). 
No Brasil houve tentativas de promover tal movimento em 1973 e 1978 através de seminários com o apoio da Fundação Kellog e, no início da década de 1980, a Comissão Nacional de Residência Médica (CNRM) possibilitou a sua institucionalização através da regulamentação dos chamados Programas de Residência em Medicina Geral e Comunitária (PAIM, 1986).

Para além de noções como humanização, qualidade e eficiência, a medicina familiar apresenta-se conceitualmente pobre diante das formulações da Medicina Preventiva e da Medicina Comunitária que lhes antecederam.

\section{A "velha" e a Nova Saúde Pública}

Ao se examinar os antecedentes do campo da Saúde Pública podem ser identificados os quatro vetores anteriormente definidos. Assim, a Saúde Pública sofreu as influências dos movimentos ideológicos que constituíram a Polícia Médica, a Higiene e a Medicina Social. Do mesmo modo, os movimentos sociais que compuseram a Medicina Social na França e na Alemanha no século XIX e resultaram no Relatório Beveridge e nas propostas de "socialização da medicina" no século XX também representam antecedentes do campo da Saúde Pública. Como ilustração do vetor ação política: podem ser mencionados a Polícia Médica, o sanitarismo expresso no Relatório Chadwick e no Relatório Shattuck, a organização de agências de Saúde Pública, a criação da Oficina Sanitária Panamericana, de Ministérios da Saúde, de campanhas sanitárias e de Escolas de Saúde Pública, via Fundação Rockefeller e Departamento de Estado (GARCIA, 1981 a: 1981 b), além da instalação da OMS/OPS.

E quanto ao vetor da produção de conhecimentos pode ser exemplificado com os clássicos estudos de Engels, Snow, Villermé, Virchow, Farr, Goldberger, Grotjahn, Sigerist, entre outros (ROSEN, 1979; 1994).

Esta Saúde Pública que se constrói nos países desenvolvidos ao longo do séculoXX é caudatária do liberalismo econômico para o qual a ação estatal teria um caráter supletivo para aquilo (e somente aquilo) que o indivídvo e a iniciativa privada não fossem capazes de fazer. Assim, reserva as ações sanitárias consideradas de abrangência coletiva para a órbita do Estado, enquanto as dirigidas para os indivíduos deveriam ser exercidas pela medicina privada (PAIM, 1992).

Este modelo institucionalizado de Saúde Pública em que ela se torna subordinada ao modelo médico hegemônico, entra em crise e novas idéias surgem para 126 o seu fortalecimento (Institute of Medicine, 1988; OPS/OMS, 1992; 1993). 
As concepções e propostas apresentadas para a Saúde Pública americana pelo relatório da "Comissão para o Estudo do Futuro da Saúde Pública" (Institute of Medicine, 1988) parecem ratificar a dicotomia entre Saúde Pública e assistência médica. A questão política, aparentemente externa e prejudicial à prática da Saúde Pública, seria enfrentada basicamente através da formação de lideranças, capacitação gerencial, definição de níveis de responsabilidade, e da criação de conselhos de saúde, no âmbito estadual, e de saúde pública, no nível local. Tais encaminhamentos, entretanto, são muito tímidos diante da crise da Saúde Publica documentada no relatório.

Nesse processo, propõe-se uma Nova Saúde Pública enquanto Terris (1992) procura atualizar a clássica definição de Winslow na década de 1920 para a Saúde Pública:

a arte e a ciência de prevenir a doença e a incapacidade, prolongar a vida e promover a saúde física e mental mediante os esforços organizados da comunidade para o saneamento do meio, o controle de doenças (infecciosas e não infecciosas) e os acidentes, a educação do indivíduo nos princípios de higiene pessoal, a organização dos serviços para o diagnóstico, tratamento e reabilitação, e o desenvolvimento do 'maquinário social' que assegure a cada indivíduo na comunidade um nível de vida adequado para a manutenção da saúde (TERRIS, 1992, p.187-188).

Assim, estabelece 4 tarefas básicas para a teoria e a prática da nova Saúde Pública: prevenção das doenças não infecciosas; prevenção das doenças infecciosas; promoção da saúde; melhoria da atenção médica e da reabilitação.

Frenk (1992) identifica a Nova Saúde Pública como condições e respostas assentadas nas bases científicas das ciências biológicas, sociais e comportamentais tendo como áreas de aplicação populações, problemas e programas. Como sói acontecer em tais contextos, outros desafios têm sido colocados para esse movimento ideológico:

a) Aliança com os provedores de serviços para alcançar cuidados de saúde mais integrais e centrados nas necessidades e demandas das pessoas;

b) Desenvolvimento de técnicas de avaliação e monitorização das necessidades e demandas da população, de equidade no acesso aos cuidados de saúde (especialmente preventivos);

c) Produção de informação acerca de "práticas de excelência" para permitir a contratação de serviços "baseada em evidência"; 
d) Facilitar informação aos cidadãos que thes permita a maior autonomia pessoal no cuidado de sua saúde. (MUÑOZ, 1998). ${ }^{2}$

Enquanto a onda neoliberal era veiculada por organismos financeiros internacionais e imposta aos países dependentes, via política de ajuste macroeconômico e Reforma do Estado, a OPS apoiava debates sobre a teoria e a prática as Saúde Pública (OPS/OMS, 1993) e a OMS promovia discussões sobre a Nova Saúde Pública organizando um conjunto de seminários e reuniões na perspectiva da renovação da proposta de Saúde para Todos (WHO, 1995), resultando, posteriormente, no movimento das Funções Essenciais de Saúde Pública (PAIM, 2001).

\section{Saúde Coletiva}

A Saúde Coletiva latino-americana foi composta a partir da crítica à Medicina Preventiva, à Medicina Comunitária, à Medicina da Família, além de ser fertilizada pela Medicina Social do século XIX e pela saúde pública institucionalizada, seja nos serviços de saúde, seja na academia. Envolve um conjunto articulado de práticas técnicas, ideológicas, políticas e econômicas desenvolvidas no âmbito acadêmico, nas organizações de saúde e em instituições de pesquisa vinculadas a diferentes correntes do pensamento resultantes de projetos de reforma em saúde.

No caso brasileiro, esse movimento aproxima-se da proposta de democratização da saúde constituindo um subconjunto do "movimento sanitário". Este de caráter mais amplo inclui além de atores institucionais, sindicatos, entidades de saúde, organizações populares, grupos religiosos, partidos políticos etc. A Saúde Coletiva, enquanto movimento, tem tido no Centro Brasileiro de Estudos de Saúde (CEBES) e na Associação Brasileira de Pós-Graduação em Saúde Coletiva (ABRASCO) seus principais sujeitos coletivos (PAIM, 1992).

Tem sido reconhecida como um campo científico em constituição na América Latina a partir dos anos 1970, progressivamente multi/inter/ transdisciplinar. Assenta-se em um tripé de eixos disciplinares: epidemiologia, ciências sociais e planificação e gestão em saúde mantendo conexões com disciplinas auxiliares (ciências biológicas, estatística, demografia, geografia, clínica, genética, direito, comunicação etc.).

Trata-se de um campo de saber, âmbito de práticas e área de atuação 128 profissional cujo marco conceitual inicial buscava a recuperação dos princípios 
da Medicina Social, ao tempo em que produzia conhecimentos críticos que embasavam movimentos sociais e lutas políticas pela democratização da saúde e da sociedade (DONNÂNGELO, 1983; FLEURY, 1985; ALMEIDA-FILHO \& PAIM, 1999).

O desenvolvimento do campo da Saúde Coletiva pode ser sistematizado a partir dos quatro vetores antes utilizados em relação à Saúde Pública.

Assim, no que diz respeito aos movimentos ideológicos recorreu ao diálogo e à crítica em relação ao preventivismo, à Medicina Social, à Saúde Comunitária, à Medicina de Família, e, presentemente, em relação aos movimentos da Promoção da Saúde, da Nova Saúde Pública e seus desdobramentos, via Funções Especiais de Saúde Pública (FESP), apoiados pela OMS/OPS.

A Saúde Coletiva tem-se articulado aos movimentos sociais a exemplo da democratização da saúde que no Brasil passou a ser conhecido como "movimento sanitário", sujeito coletivo do Projeto da Reforma Sanitária Brasileira.

No que tange ao vetor da ação política, a Saúde Coletiva esteve associada à formulação e implementação do Projeto da Reforma Sanitária Brasileira no processo Constituinte (1987-1988), na elaboração da Lei Orgânica da Saúde e na implantação do Sistema Único de Saúde (SUS) durante a década de 1990. Experiências de países como Argentina, México, Brasil, Colômbia, Equador e Venezuela, apontam para a confluência de iniciativas entre intelectuais e os trabalhadores, enquanto força social e política, em movimentos de massa "que resultaram em lutas específicas e propostas gerais sobre saúde" (LAURELL, 1985).

Quanto ao vetor da produção de conhecimentos, tem propiciado uma reflexão teórico-epistemológica sobre o campo e suas disciplinas nucleares, a investigação científica e o desenvolvimento conceitual e tecnológico. Os estudos críticos realizados a partir dos anos 1970 permitiram a conformação de uma corrente teórica - a Epidemiologia Social que estimulou novas investigações sobre doenças na sociedade de (LAURELL, 1985; BREILH \& GRANDA, 1985) recolocando questões para a política e a planificação em saúde bem como para o desenvolvimento das ações sanitárias. Ao retomar a categoria trabalho como elemento central para o estudo da saúde, forneceram indicações relevantes tanto para a análise da produção e da distribuição das doenças na sociedade - processo de produção e reprodução socia l, (BREILH, 1990) quanto para o estudo do processo de trabalho em saúde (DONNÂNGELO, 1983; PAIM, 1992)

Ao analisar as relações entre saúde e estrutura social, muitos desses estudos têm utilizado como referência central o conceito de prática. Isto significa 
considerar os seus momentos constitutivos - objeto de trabalho, meios de trabalho e o trabalho propriamente dito (atividade humana), bem com as relações sociais.

Portanto, na América Latina, a designação Saúde Coletiva adquire, desde a década de 1970 uma conotação mais abrangente que a Saúde Pública. Inspirou-se na Medicina Social, ou seja, "uma corrente de pensamento que apareceu originalmente como contestação critica ao pensamento da saúde pública dominante" (GARCIA, 1985), porém teve o seu desenvolvimento especialmente a partir das contribuições das ciências sociais em saúde (PAIM \& ALMEIDA FILHO, 2000).

\section{Movimentos Ideológicos Contemporâneos}

A Saúde Coletiva e a Saúde Pública, presentemente, encontram-se sob a influência de três movimentos ideológicos a exigir reflexão teórica e investigação sobre a sua emergência e desenvolvimento, a saber: A Nova Saúde Pública (já referida), a Promoção da Saúde e as Funções Essenciais de Saúde Pública (FESP).

No caso da Promoção da Saúde, aparece inicialmente como uma idéia relativa a uma das tarefas da medicina e da saúde pública presente em Virchow, Winslow e Sigerist (BUSS, 2003) ou um dos níveis de prevenção de acordo com o modelo da História Natural das Doenças proposto por Leavell-Clark (TEIXEIRA, 2002). Dessa idéia aparece a formulação de uma proposta tal como configurada na Carta de Otawa, em 1986 que se desdobra em um movimento ideológico mediante Conferências Internacionais, publicações, reuniões, formação de ideólogos, difusores etc. Este movimento em diferentes países tem buscado a formulação de políticas e a sua institucionalização, buscando desenvolver práticas mediante a reorganização de processos de trabaIho em saúde, reflexão teórica e estratégias de avaliação.

A Promoção da Saúde e a Nova Saúde Pública, ao sensibilizarem organismos internacionais como a OMS/OPS, desdobram-se em outros movimentos como o das Funções Essenciais de Saúde Pública (FESP) definidas para orientar Ministérios da Saúde às voltas com processos de Reforma do Estado (PAIM, 2001). Entre tais funções destacam-se:

130

a) Incentivo à promoção da saúde;

b) Promoção do respeito à vida e à participação; 
c) Democratização do acesso e uso da informação em saúde;

d) Garantir acesso universal a serviços integrais;

e) Regulação da produção e comercialização de bens e serviços vinculados à saúde;

f) Garantir equidade, eficácia e idoneidade de intervenções em saúde;

g) Proteger a população frente a epidemias e catástrofes;

h) Garantir segurança dos insumos.

Em 2000, a OPS, durante a XIX Conferência da ALAESP, realizada em Havana (OPS/OMS/ALAESP, 2001), apresentou uma definição preliminar de funções e indicadores (Center for Disease Control and Prevention. Centro Latino Americano de Investigacion en Sistemas de Salud. Pan American Health Organization/World Health Organization, s/d), desdobrando e resignificando as FESP em que se destacam:

a) Monitoramento e análise da situação de saúde da população;

b) Vigilância epidemiológica, investigação e controle de danos e riscos;

c) Promoção da saúde;

d) Participação social e reforço do poder [empowerment] dos cidadãos em saúde;

e) Desenvolvimento de políticas e planos de saúde;

f) Regulação e fiscalização;

g) Avaliação e promoção do acesso aos serviços de saúde;

h) Desenvolvimento de recursos humanos e capacitação em saúde pública;

i) Avaliação de tecnologias sanitárias e garantia da qualidade dos serviços de saúde individuais e coletivos;

i) Investigação de novas tecnologias e soluções inovadoras em saúde pública;

k) Gestão em saúde pública;

l) Ação frente à situação de emergência e controle de desastres.

No que tange ao Monitoramento e análise da situação de saúde da população o documento propunha: Guias de monitoramento do estado de saúde; Avaliação da qualidade da informação; Apoio especializado e recursos para o monitoramento do estado de saúde; Suporte tecnológico para decisões em Saúde Pública; Assistência (cooperação) técnica aos níveis subnacionais de saúde. 
Com relação à Vigilância epidemiológica, investigação e controle de danos e riscos, recomendava: Sistema de vigilância epidemiológica para identificar ameaças à Saúde Pública; Capacidades e destrezas epidemiológicas; Capacidade dos laboratórios de Saúde Pública; Presteza para a resposta efetiva dirigida ao controle de danos ao meio ambiente e à Saúde Pública; Assistência técnica e apoio aos níveis subnacionais de Saúde Pública.

Quanto à Promoção da saúde, sugeria: Construção de legitimidade da autoridade sanitária nacional e de alianças para a promoção da saúde; Planificação e coordenação nacional das estratégias de informação, educação e promoção da saúde; Apoio às atividades comunitárias de promoção da saúde; Assistência técnica aos níveis subnacionais;

No que diz respeito à Participação social e reforço do poder [empowerment] dos cidadãos em saúde, ressaltava: Fortalecimento do poder dos cidadãos e a participação social em saúde; Experiência e capacidade para facilitar a construção de aliança; Apoio e coordenação com os níveis subnacionais para a construção de legitimidade da autoridade sanitária e facilitação de alianças com a comunidade.

No tópico referente ao Desenvolvimento de políticas e planos de saúde, destacava: Processo de melhoramento da saúde no país; Experiência e capacidade para planificar e desenvolver planos e programas de saúde; Desenvolvimento de políticas; Assistência técnica e apoio aos níveis subnacionais de saúde pública na planificação e desenvolvimento de políticas.

No que se refere à Regulação e fiscalização, sublinhava: Revisão periódica, avaliação e modificação de leis e regulamentos; Conhecimentos, habilidades e destrezas para revisar, aperfeiçoar e fazer cumprir as leis e regulamentos; Fazer cumprir leis e regulamentos; Apoio e assistência técnica aos níveis subnacionais de Saúde Pública na fiscalização do cumprimento das leis e regulamentos.

No item relativo à Avaliação e promoção do acesso aos serviços de saúde foram reforçados: Avaliação do acesso aos serviços necessários; Capacitação e desenvolvimento de habilidades para promover o acesso da população aos serviços de saúde necessários fora dos lugares habituais de atenção; Advocacy e ação para melhorar o acesso aos serviços de saúde necessários; Apoio e assistência aos níveis subnacionais.

Em relação ao Desenvolvimento de recursos humanos e capacitação em saúde pública foram enfatizados: Avaliação da força de trabalho em saúde;

132 Monitoramento da qualidade da força de trabalho; Educação continuada 
e pós-graduação; Aperfeiçoamento dos RHS para a oferta de serviços adaptados à cultura dos usuários; Desenvolvimento de lideranças em Saúde Pública; Apoio aos níveis subnacionais para os RHS.

Na função correspondente à Avaliação de tecnologias sanitárias e garantia da qualidade dos serviços de saúde individuais e coletivos, podem ser visualizados: Sistema de avaliação de tecnologias sanitárias para apoiara tomada de decisões em Saúde Pública; Disseminação de padrões e métodos de avaliação da qualidade dos serviços de saúde individuais e coletivos; Melhoria da qualidade dos sistemas de saúde e da satisfação dos usuários; Assistência técnica e apoio para avaliação nos níveis subnacionais de saúde para assegurar a qualidade dos serviços de saúde.

Para a Investigação de novas tecnologias e soluções inovadoras em saúde pública foram mencionadas as seguintes medidas: Desenvolvimento de uma agenda de investigação em Saúde Pública; Desenvolvimento da capacidade interna de investigação; Apoio para a inovação e investigação nos níveis subnacionais de Saúde Pública.

No âmbito da Gestão em saúde pública foram incluídas: Planificação e avaliação; Tomada de decisões baseada em evidências; Gestão de recursos; Gestão da cooperação internacional em Saúde Pública; Liderança e comunicação; Assistência técnica e apoio aos níveis subnacionais em matéria de gestão em Saúde Pública.

Finalmente, no que concerne à Ação frente à situação de emergência e controle de desastres, foram propostas as seguintes iniciativas: Promoção de ação frente a situações de emergência e controle de desastres; Formulação de normas que apóiem a ação frente a situações de emergência e controle de desastres; Treinamento de pessoal sanitário e de outro tipo frente à situação de emergência e controle de desastres; Coordenação e articulação com outros organismos; Mobilização da resposta sanitária em casos de desastre; Assistência técnica no âmbito subnacional para apoiar a ação frente a emergências e desastres.

Enquanto no plano político internacional funções e indicadores são propostos para a Saúde Pública, no âmbito acadêmico, novas funções têm sido indicadas para o Campo da Saúde Coletiva/Pública tais como aquelas apresentadas na I Conferência Pan-americana de Educação em Saúde Pública, no Rio de Janeiro, em 1994: Histórico-políica; Agregadora de valor; Administradora de conhecimento; Mediação estratégica; Gerência estratégica; Advocacy (I Pan-American Conference on Education in Public Health, 1995). 
Já na Il Conferência Pan-americana de Educação em Saúde Pública, realizada no México, em 1998 foram propostos os seguintes campos de atuação para as Instituições Formadoras de Saúde Pública (IFSP): Formação de Recursos Humanos; Investigação em Saúde Pública e Desenvolvimento Tecnológico; Cooperação Técnica; Ação Comunitária Direta; Liderança; Articulação Política; Alianças (OPS/OMS, 2000).

Em 2000, a XIX Conferência da ALAESP, realizada em Havana, propôs um conjunto de processos dinamizadores para a educação em Saúde Pública/ Saúde Coletiva (IFSP): Desenvolvimento curricular e novos paradigmas da saúde pública; Desenvolvimento profissional e novas competências; Desenvolvimento educacional/Educação a distância/Educação permanente; Desenvolvimento da ação e compromisso intersetorial; Desenvolvimento da qualidade (OPS/ OMS/ALAESP, 2001).

\section{Implicações contemporâneas da Saúde Pública/ Saúde Coletiva}

O desenvolvimento contemporâneo da Saúde Coletiva/ Pública impõe acionar interlocutores especiais tais como os atores vinculados às Políticas e organizações de Saúde, Educação, Ambiente, Ciência e Tecnologia, movimentos sociais, Parlamento, Judiciário/Ministério Público, órgãos de defesa da cidadania, do ambiente, do consumidor e dos direitos humanos, entre outros.

No âmbito acadêmico, cumpre avançar na reflexão teórico-epistemológica, na investigação científica e no desenvolvimento conceitual e tecnológico, como campo aberto a novos paradigmas (PAIM \& ALMEIDA FILHO, 2000). Reconhecendo a complexidade dos seus objetos de reflexão e de intervenção e que lida com problemas semi-estruturados ou não estruturados, a Saúde Pública/ Coletiva tende a se apresentar menos normativa e prescritiva, mais estratégica e comunicativa. Ao mesmo tempo é preciso atentar para que os esforços visando à delimitação do campo não se transformem em "camisa de força" para o seu desenvolvimento teórico e epistemológico diante de novos paradigmas.

Ao considerar a ação política (estratégica e comunicativa) como pertinente para intervir no coletivo, a Saúde Pública/Coletiva necessita manter o diálogo e a crítica teórica aos movimentos ideológicos antigos e novos. Enquanto prá-

134 tica social e técnico-científica articulada às demais práticas sociais - econômi- 
cas, políticas, ideológicas e culturais, a Saúde Pública/Coletiva pode participar de processos reprodutivos da estrutura social ou apostar em processos de transformação social que apontem para a desalienação dos sujeitos e para a emancipação dos seres humanos.

Os diálogos acadêmicos norte-sul, bem como os esforços históricos para a construção de uma unidade latino-americana sob os valores da paz, da solidariedade, da justiça social e da democracia têm a possibilidade de contribuir com a construção de viabilidade para tal aposta. Cabe considerar, no entanto, que cada formação social engendra a sua própria Saúde Pública/ Coletiva, embora influenciada pelas relações internacionais e inflexões das conjunturas dos respectivos países. Portanto, nada do que se refira à saúde do público pode ser estranho à Saúde Coletiva (PAIM, 1992).

\section{Notas}

${ }^{2}$ Fernando Muñoz Porras. Centro Latinoamericano de Investigaciones en Salud. Reformas de Salud y Funciones Esenciales de Salud Publica. Estrategias innovativas para la educación en salud pública. (Exposição realizada na Reunião da ALAESP, México, 1998). 


\section{Referências}

ALMEIDA FILHO, N.; Paim, J. S. La crisis de la salud pública y el movimiento de la salud colectiva en Latinoamérica. Cuadernos Médico Sociales, Rosario, n. 75, p. 5-30, 1999.

AROUCA, A. S. O dilema preventivista: contribuição para a compreensão e crítica da Medicina Preventiva. XXfl. Tese (Doutorado) - Faculdade de Ciências Médicas, Universidade Estadual de Campinas, Campinas, 1975.

AROUCA, A. S. O dilema preventivista: contribuição para a compreensão e crítica da Medicina Preventiva. São Paulo/Rio de Janeiro: Editora UNESP/Editora FIOCRUZ, 2003.

BENSAÏD, D. Marx, o intempestivo: grandezas e misérias de uma aventura crítica. Rio de Janeiro: Civilização Brasileira, 1999.

BREILH, J. Reprodução social e investigação em Saúde Coletiva. Construção do pensamento e debate. In: COSTA, D. C. Epidemiologia. Teoria e objeto. São Paulo: HUCITEC/ ABRASCO, 1990.

BREILH, J \& GRANDA, E. Os novos rumos da epidemiologia. In: NUNES, E. D. (Org.). As Ciências Sociais em saúde na América Latina.Tendências e perspectivas. Brasília. OPAS, 1985.

BUSS, P. M. Uma introdução ao conceito de promoção da saúde. In: CZERESNIA, D.; FREITAS, C. M. (Org.). Promoção da saúde: conceitos, reflexões, tendências. Rio de Janeiro: FIOCRUZ, 2003.

CENTER FOR DISEASE CONTROL AND PREVENTION. Centro Latino Americano de Investigacion en Sistemas de Salud. Pan American Health Organization/World Health Organization. La Salud Pública en las Américas. Instrumento para la medición de las funciones esenciales de Salud Pública. Version preliminar. S/d.

CEITLIN, J. (Ed). Que es la medicina familiar? Caracas: FEPAFEM/Kellog, 1982.

CHAVES, M. Saúde, uma estratégia de mudança. Rio de Janeiro: Guanabara Dois, 1982.

DESROSIERS, G. Évolution des conceptes et pratiques modernes em santé publique. Ruptures, Montréal, v. 3, n. 1, p. 18-28, 1996.

DONNÂNGELO, M. C. F. Saúde e sociedade. São Paulo: Duas Cidades. 1976.

DONNÂNGELO, M. C. F. A pesquisa na área da Saúde Coletiva no Brasil - A década de 70. In: ABRASCO. Ensino da Saúde Pública, Medicina Preventiva e Social no Brasil. Rio de Janeiro, 1983.

FEE, E. Disease and Discovery. A History of the Johns Hopkins School of Hygiene and Public Health; 1916-1939. Baltimore: John Hopkins University Press, 1987.

FOUCAULT, M. O nascimento da medicina social. In: FOUCAULT, M. Microfísica do Poder. Rio de Janeiro: Graal. 11 ed. 1993.

FRENK, J. The New Public Health. In: PAHO. The Crisis of Public Health: Reflections for the Debate. Scientific Publication, Washinton, D.C, n. 540, p.68-85, 1992.

GARCIA, J. C. La educación medica en la América Latina. OPS. Publicacion Cientifica. Washington, n. 255, p. 413, 1972.

GARCIA, J. C. História de las instituiciones de investigación en salud en America 136 Latina, 1880-1930. Edc. Med. Salud. Washington, v. 15, n. 1, p. 71-87, 1981 a. 
GARCIA, J. C. La medicina estatal en America Latina / 1 (1880-1930).Rev. Latinoamericana de Salud. Mexico, v. 1, p. 63-104, 1981 b.

GARCIA, J. C. Apresentação: Juan César Garcia entrevista Juan César Garcia. In: NUNES, E. D. (Org.). As Ciências Sociais em saúde na América Latina. Tendências e perspectivas. Brasília: OPAS, 1985.

INSTITUTE OF MEDICINE. The Future of Public Health. Washington, D.C.: National Academy Press, 1988.

LAURELL, A. C. Saúde e trabalho: os enfoques teóricos. In: NUNES, E. D. (Org.). As Ciências Sociais em saúde na América Latina. Tendências e perspectivas. Brasília: OPAS, 1985.

MENDES-GONÇALVES, R. B. Práticas de saúde: processos de trabalho e necessidades. São Paulo: CEFOR, 1992. (Cadernos CEFOR - Textos, 1).

MINAYO, M. C. S. Estrutura e sujeito, determinismo e protagonismo histórico: uma reflexão sobre a práxis da saúde coletiva. Ciência \& Saúde Coletiva. Rio de Janeiro, v. 6, n. 1p. 7-19,2001.

OPS/OMS. La crisis de la salud pública: reflexiones para el debate. Publicación Científica. Washington, D.C, n. 540, 1992.

OPS/OMS. Sobre la teoría y práctica de la salud pública: un debate, múltiplas perspectivas. Washington, D.C.: OPS, 1993. (Serie Desarrollo de Recursos Humanos, n. 98).

OPS/OMS. Desafíos para la educación en salud pública: la reforma sectorial y las funciones esenciales de Salud Pública. Washington, D.C.: OPS, 2000.

OPS/OMS/ALAESP. Educación en Salud Pública. Nuevas perspectivas para las Américas. Washington D.C: OPS, 2001.

I PAN-AMERICAN CONFERENCE ON EDUCATION IN PUBLIC HEALTH. XVI ALAESP Conference. Democracy and Equity: Rethinking Public Health. Final Report. Rio de Janeiro, August, 1994.

PAIM, J. S. Saúde, crises e reformas. Salvador: Centro Editorial e Didático da UFBA, 1986.

PAIM, J. S. La Salud Colectiva y los desafíos de la práctica. In: OPS/OMS. La crisis de la salud pública: reflexiones para el debate. Publicación Científica. Washington, D.C., n. 540, 1992. p.151-167.

PAIM, J. S. Transición paradigmática y desarrollo curricular en Salud Pública. In: OPS/ OMS/ALAESP. Educación en Salud Pública. Nuevas perspectivas para las Américas. Washington D.C: OPS, 2001.

PAIM, J. S. Saúde política e reforma sanitária. Salvador: CEPS-ISC, 2002.

PAIM, J. S.; ALMEIDA FILHO, N. de. A crise da Saúde Pública e a utopia da Saúde Coletiva. Salvador: Casa da Qualidade, 2000.

ROSEN, G. Da polícia médica à medicina social. Rio de Janeiro: Graal, 1979.

ROSEN, G. Uma história da Saúde Pública. São Paulo/Rio de Janeiro: Hucitec/Editora da Universidade Estadual Paulista/ABRASCO, 1994.

TEIXEIRA, C. (Org.) Promoção e vigilância da saúde. Salvador: CEPS/ISC, 2002.

TEIXEIRA, S. M. F. As ciências sociais em saúde no Brasil. In: NUNES, E. D. (Org.). 
As Ciências Sociais em saúde na América Latina. Tendências e perspectivas. Brasília: OPAS, 1985.

TERRIS, M. Current trends in Public Health in the Americas. In: PAHO. The Crisis of Public Health: Reflections for the Debate. Scientific Publication, Washinton, D.C, n. 540, p. 166-183,1992.

THERBORN, G. A análise de classe no mundo atual: o marxismo como ciência social. In: HOBSBAWM, E. J. História do marxismo. Rio de Janeiro: Paz e Terra, 1989.

WAITZKIN, H.; IRIART, C.; ESTRADA, A.; LAMADRID, S. Social medicine in Latin America: productivity and dangers facing the major's national groups. The Lancet. London, n. 358, p. 315-23, 2001 a.

WAITZKIN, H.; IRIART, C.; ESTRADA, A.; LAMADRID, S. Social Medicine then and now: lessons from Latin America. American Journal of Public Health, Washington, v. 91, n. 10, p. 1592-1601, 2001b.

WHO. New Public Health and WHO's Ninth General Programme of Work. A discussion paper. Geneve: WHO, 1995. 


\section{Nova Saúde Pública ou Saúde Coletiva? ${ }^{1}$}

\section{Introdução}

O campo social da saúde tem sido atravessado, desde a emergência do capitalismo, por um conjunto de movimentos ideológicos tais como: Polícia Médica; Higiene; Saúde Pública; Medicina Social; Flexnerismo; Medicina Preventiva; Saúde Comunitária; Integração Docente-Assistencial (IDA), entre outros (PAIM, 1986). Nas últimas décadas, outros movimentos podem ser identificados:

Atenção Primária à Saúde/SPT-2000; Saúde Coletiva; Medicina Familiar; Promoção da Saúde; Nova Saúde Pública/Funções Essenciais de Saúde Pública (FESP) etc. (PAIM e ALMEIDA FILHO, 2000).

Ao se apresentar, presentemente, uma demanda no sentido de caracterizar os elementos que, segundo diferentes visões, sustentam a proposição de uma nova saúde pública, seria pertinente, também, indagar o que há de "novo" na Nova Saúde Pública (AWOFESO, 2004)? Seria reconhecer os determinantes

1 Texto elaborado para o Seminário Internacional Desafios para a Saúde Pública no Século XXI: princípios e estratégias para a construção de sistemas de saúde universais e eqüitativos na América Latina e Caribe. Rio de Janeiro, 1 e 2 de agosto de 2005. sociais da saúde? Seria considerar os ambientes físico, social e "psicológico"? Seria propor colaboração intersetorial? Seria valorizar a promoção da saúde?

A rigor, poder-se-ia considerar que muitas dessas questões já eram tematizadas desde o surgimento da Medicina Social na segunda metade do século XIX, especialmente na França e na Alemanha. Do mesmo modo, uma corrente de pensamento latinoamericana que possibilite a articulação daqueles que defendem sistemas de saúde universais, de natureza pública e eqüitativos 
pode ser identificada desde a constituição da Medicina Social na América Latina na década de 1970, reconhecida atualmente como Saúde Coletiva (WAITZKIN et al., 2001). Ainda que a sua natureza essencialmente crítica e de inspiração marxista tenha se abrandado diante de questões teóricas, políticas e ideológicas contemporâneas, em nenhum momento deixou de propugnar por sistemas de saúde universais, de natureza pública e eqüitativos.

No entanto, a proposta de uma Nova Saúde Pública permite a continuidade de reflexões sobre a teoria e a prática da Saúde Pública no presente século, daí a sua relevância. Tal como se tem ressaltado desde o início da década de 1990 (PAIM, 1992), mais do que questão teórica, coloca-se o desafio da prática: política, econômica, ideológica e tecnológica. E o convite para discussão da Nova Saúde Pública possibilita experimentar o desafio de negar, construindo e construir, negando (AYRES, 2001) distintos movimentos no campo social da saúde.

Desse modo, o objetivo do presente texto é revisitar o campo da Saúde Coletiva, considerando possíveis convergências e divergências com movimentos ideológicos contemporâneos na saúde, a exemplo da Nova Saúde Pública, e com a saúde pública institucionalizada ou convencional. Nesse particular, toma-se como referência preliminar o documento do Commmitee for the Study of the Future of Public Health, (Institute of Medicine, 1988), passando pelos debates promovidos pela OPS/OMS na década de 1990 sobre a Teoria e a Prática da Saúde Pública (OPS/OMS, 1992; 1993), bem como as contribuições discutidas no VII Congresso Brasileiro de Saúde Coletiva, em 2003. Assim, a análise a ser empreendida procura levar em conta o desenvolvimento teórico-conceitual da Saúde Coletiva na América Latina e suas relações com a Reforma Sanitária Brasileira.

\section{A crise da saúde pública e o debate nas Américas}

A Nova Saúde Pública aparece como um dos produtos destacados no relatório do Commmitee for the Study of the Future of Public Health (Institute of Medicine, 1988). A Comissão admitia que o sistema e o processo político dificultavam a missão da saúde pública, ressaltando uma suposta tensão entre os políticos e os profissionais. Reconhecia que a política não se restringiria à arena legislativa e que as agências não seriam neutras. Entretanto, suas recomendações limitavam-se a sublinhar a questão das 
informações de saúde, a importância do conhecimento científico no processo de tomada de decisão e a revisão da estrutura organizacional, reiterando a dicotomia entre Saúde Pública e assistência médica. A questão política, vista como externa e prejudicial à prática da Saúde Pública, seria enfrentada basicamente através da formação de lideranças, capacitação gerencial, definição de níveis de responsabilidade etc.

Após a publicação do referido relatório, a OPS estimulou a produção de textos e debates sobre a teoria e a prática da Saúde Pública na região das Américas (OPS/OMS, 1992; 1993). Procurava, desse modo, influir sobre as instituições de formação em saúde pública (IFSP) para formularem políticas de mudanças na educação nesta área, a partir da confluência de três temáticas que atravessaram sua agenda na referida década: reforma setorial, "Renovação da Saúde para Todos" (RSPT) e a chamada "Nova Saúde Pública" (PAIM e ALMEIDA FILHO, 2000). Para tanto, apresentou cinco processos dinamizadores capazes de contribuir na construção da viabilidade dessas políticas: a) Desenvolvimento curricular/Novos paradigmas da Saúde Pública; b) Desenvolvimento professional/Novas competências; c) Desenvolvimento educacional/Educação a distância/Educação permanente; d) Desenvolvimento da ação e compromisso intersetorial; e) Desenvolvimento da qualidade (OPS/OMS, 2000; OPS/OMS/ALAESP, 2001).

Dois anos depois da realização da II Conferência Pan-Americana de Educação em Saúde Pública, realizada no México em 1998, cujo tema central foi "Reforma Setorial e Funções Essenciais de Saúde Pública" (OPS/OMS, 2000), o então Programa de Desenvolvimento de Recursos Humanos da OPAS e a Associação Latino-americana e do Caribe de Educação em Saúde Pública (ALAESP), promoveram em Havana a XIX Conferência da ALAESP para discutir o "Desenvolvimento da Educação em Saúde Pública: desafios para o século XXI" (OPS/OMS/ALAESP, 2001).

Embora no campo acadêmico não se tenham observado iniciativas mais concretas para dar seguimento àqueles cinco processos dinamizadores, considerando as deliberações da Conferência, constatam-se certos esforços para a intervenção no âmbito dos serviços de distintos países da Região. Assim, além das proposições e estratégias referentes às chamadas "reformas setoriais", a OPS tem tentado apoiar Ministérios e Secretarias de Saúde nas discussões sobre as "Funções Essenciais de Saúde Pública" (FESP) na perspectiva de revisar e modificar as suas práticas e estruturas. 
No caso brasileiro, esse debate foi incorporado pelo Conselho Nacional de Secretários de Saúde (CONASS) que tem organizado um levantamento sobre as ações empreendidas pelas secretarias estaduais de saúde na perspectiva das FESP, contando com a participação da OPAS, do Ministério da Saúde (MS) da Associação Brasileira de Pós-Graduação em Saúde Coletiva (ABRASCO) e de consultores acadêmicos (BRASIL, 2005). Contudo, o sentido pragmático voltado para a reatualização dessas instituições distancia-se do conteúdo propositivo da Nova Saúde Pública, tal como vem sendo concebida em países do hemisfério norte.

Diante da crise da Saúde Pública, encontram-se presentes elementos discursivos e extra-discursivos que merecem consideração. No caso dos elementos discursivos, cabe destacar a idéia da saúde pública hegemônica segundo a qual o desenvolvimento da saúde supõe a exclusão da doença e que a ciência e a técnica dispõem de um potencial inesgotável para superar a enfermidade. Como elementos extra-discursivos encontram-se as restrições econômicas para a atuação do Estado diante do custo crescente da atenção à saúde, particularmente a assistência médico-hospitalar, o peso ideológico da onda neoliberal e o recurso a outras formas de legitimação da ordem social vigente (PAIM e ALMEIDA FILHO, 2000). Estes elementos histórico-concretos, ideológicos, políticos e econômicos, não podem ser abstraídos pelos sujeitos históricos que pensam e constroem uma Saúde Pública alternativa.

\section{A Nova Saúde Pública}

A partir dos documentos e das iniciativas referidos (Institute of Medicine, 1988; OPS/OMS, 1992; 1993), a expressão Nova Saúde Pública passou a difundir-se, especialmente depois da Interregional Meeting on New Public Health, realizada em Genebra, 1995.

O documento básico dessa reunião, denominado Nova Saúde Pública e o $9^{\circ}$ Programa de Trabalho da OMS, admitia que muitos dos seus elementos já se encontravam presentes na Declaração de Alma-Ata, seja o reconhecimento da saúde como direito humano, seja a idéia de que as condições de vida (ambiente físico, social e econômico) representam importantes determinantes da saúde (WHO, 1995). Mais recentemente, a proposta da Nova Saúde Pública tem sido difundida na América Latina através do Projeto Saúde Pública nas Américas - SPA (OPS/OMS, s/d).

Desde a reunião de New Orleans, quando a OPS promoveu debates sobre 142 a Teoria e a Prática da Saúde Pública na Região das Américas em 1991, 
Terris (1992) propôs uma atualização da clássica definição de Saúde Pública de Winslow na década de 1920 para definir a Nova Saúde Pública.

Já na Conferência da ALAESP no México (1998), foram listadas algumas características dessa Nova Saúde Pública: aliança com os provedores de serviços para alcançar cuidados de saúde mais integrais e centrados nas necessidades e demandas das pessoas; desenvolvimento de técnicas de avaliação e monitorização das necessidades e demandas da população, de equidade no acesso aos cuidados de saúde (especialmente preventivos); produção de informação acerca de "práticas de excelência" para permitir a contratação de serviços "baseada em evidência"; facilitar informação aos cidadãos que lhes permita a maior autonomia pessoal no cuidado de sua saúde (PORRAS, 1998).

Distintas visões, portanto, vão se configurando no sentido de justificar o "novo" da Nova Saúde Pública. Uma dessas visões procura vinculá-la à Promoção da Saúde, com certos princípios endossados pela OMS: empowerment, equidade, colaboração e participação (KICKBUSCH, 2003; AWOFESO, 2004). Há o reconhecimento de que os problemas da pobreza, das doenças emergentes e dos conflitos persistentes que caracterizam o mundo hoje, requerem quadros de referência mais radicais do que o da Nova Saúde Pública (AWOFESO, 2004).

\section{Três décadas de Saúde Coletiva ${ }^{2}$}

Ao se considerar a Saúde Coletiva como alternativa à proposta da Nova Saúde Pública cabe explicitar, ainda que sumariamente, algumas características básicas. Reconhecida como campo de saber e âmbito de práticas, assumiu um marco conceitual preliminar mediante a recuperação e redefinição das concepções da Medicina Social do século XIX. Assim, foi constituída como campo multi/inter/transdisciplinar a partir dos anos 1970 baseado no triedro ideologia, saber e prática. (DONNÂNGELO, 1983; ESCOREL, 1998; PAIM e ALMEIDA FILHO, 2000).

Nesse particular, a estruturação da corrente da Epidemiolgia Social latinoamericana alimentou a constituição do referido campo a partir das suas tarefas iniciais:

demonstrar que a doença, tem caráter histórico e social; definir o objeto de estudo, que permita um aprofundamento na compreensão do processo saúde-doença como processo social; conceituar a causalidade, ou melhor, a determinação (LAURELL, 1985). 
Esta corrente de pensamento estimulou novas investigações sobre doenças na sociedade recolocando questões para a planificação e para o desenvolvimento de práticas de saúde. Ao retomar a categoria trabalho como elemento central, forneceu indicações relevantes para a análise da produção e da distribuição das doenças na sociedade (processo de produção e reprodução social) e para o estudo das práticas de saúde.

Enquanto a Saúde Coletiva se afirmava como campo científico e âmbito de práticas, contribuiu na formulação do projeto da Reforma Sanitária Brasileira e na construção da sua dimensão institucional - o Sistema Único de Saúde (SUS). Só tempos depois surgiam a Carta de Otawa, em 1986, e o documento O Futuro da Saúde Pública, em 1988.

Assim, a Saúde Coletiva pode ser vista como um movimento ideológico que gerou um campo científico, com intenso desenvolvimento nas três últimas décadas, e um âmbito de práticas contra-hegemônicas, com diferenças significativas em relação à saúde pública e ao modelo médico hegemônico. Elaborou um marco conceitual, enquanto corpo doutrinário estruturador desse campo, apresentando, recentemente, alguns pontos de encontro com os movimentos de renovação da saúde pública institucionalizada.

No Brasil, quando foram comemorados os 25 anos da Declaração de Alma Ata (Conferência Internacional sobre Cuidados Primários de Saúde), também se celebraram os 25 anos de uma reflexão sobre a pós-graduação em Saúde Coletiva (Encontro Nacional de Pós-Graduação em Saúde Coletiva, 1978), que possibilitou a formulação preliminar de um marco conceitual (PAIM, 1982) e a proposição de criação da Associação Brasileira de PósGraduação em Saúde Coletiva (Abrasco).

Essas iniciativas "coincidem" no Brasil com a constituição de novos sujeitos coletivos - especialmente a organização da classe trabalhadora do ABC (região industrial de São Paulo) e de movimentos sociais diversos, com a emergência de lideranças civis e sindicais, além de partidos políticos. Assim, a sistematização da proposta da Saúde Coletiva em 1978 (com o encontro dos cursos de pós-graduação já mencionado), enquanto braço acadêmico do movimento sanitário, nasce com a constituição de um sujeito coletivo - a organização da classe trabalhadora, mediante greves e movimentos sociais que resultaram na criação do Partido dos Trabalhadores (PT). Tal fenômeno guarda certa semelhança com o aparecimento da Medicina Social na França e na Alemanha em meados do século XIX (ROSEN, 1979; 1994). 
Assim, 2003 foi um ano especial para comemorações da Saúde Coletiva: marcava três décadas das primeiras reflexões críticas sobre o ensino da medicina preventiva (SILVA, 1973); 25 anos de Alma Ata e do primeiro encontro nacional dos cursos de pós-graduação então existentes; e 20 anos do primeiro texto publicado sobre a constituição da área de Saúde Coletiva no Brasil (DONNÂNGELO, 1983). Nesse mesmo ano, o mencionado partido ocupa a Presidência da República e diversos militantes do movimento sanitário ocupam espaços no aparelho do Estado. Nesse contexto, a Saúde Coletiva parece colocar-se diante de uma encruzilhada para a construção da sua identidade: movimento ideológico, campo científico, corporação profissional ou, simplesmente, saúde coletiva institucionalizada, parecida com o modelo sanitarista de matriz flexneriana e rockefelleriana?

\section{Saúde coletiva institucionalizada ou Saúde Pública flexner-rockefelleriana autoritária?}

Não obstante o expressivo desenvolvimento da Saúde Coletiva no Brasil durante as últimas décadas, um ponto que merece reflexão diz respeito a sua institucionalização. Uma justa preocupação reside na sua possível colonização pelo caráter autoritário de Estados e tecno-burocracias latino-americanas. Olhando-se para a tradição da saúde pública, tal colonização se vê reforçada pela polícia médica vinculada à reprodução do modelo flexneriano, pelo campanhismo concebido pela Fundação Rockefeller e pelo Departamento de Estado dos Estados Unidos e, mais recentemente, pela paranóia do bioterrorismo sustentada tecnicamente pelo CDC americano (Center for Disease Control and Prevention).

Brasil, em que pese as conquistas democráticas e o desenvolvimento do movimento da Saúde Coletiva, deparou-se em 2002 com uma Medida Provisória (MP 33) visando à criação de uma Agência Federal de Prevenção e Controle de Doenças - APEC. O Ministro da Saúde poderia declarar Estado de Quarentena Federal e dispor "sobre o isolamento de indivíduos, animais e comunidades em situação de risco", obrigando o acompanhamento médico de indivíduos de modo a se apresentarem, periodicamente, à "autoridade de epidemiologia". Nessa "quarentena federal", os cidadãos teriam os seus direitos civis e sociais passíveis de serem redefinidos por tal autoridade, insuficientemente identificada e responsabilizada. A atuação da ABRASCO junto ao Conselho Nacional de Saúde e aos parlamentares foi decisiva para a rejeição da MP 33 pelo Parlamento (PAIM, 2003). 
A Saúde Coletiva, desde a sua emergência, envolve-se com lutas teóricas, paradigmática, política e ideológica, implicando repercussões na sua delimitação e renovação. Daí a relevância de revisitar o campo, a partir da sua produção científica, tecnológica, epistemológica e político-cultural. Espera-se que, além de um profícuo debate e da contribuição dos sujeitos individuais e coletivos, possam ser identificados caminhos que permitam tornar a Saúde Coletiva um espaço cada vez mais aberto a novos paradigmas diante das necessidades de saúde, dos direitos humanos, de processos emancipatórios e da democratização da vida social (PAIM e ALMEIDA FILHO, 2000).

A natureza do campo da Saúde Coletiva está assentada em um triedro composto pelos componentes ideologia, saber e prática (Escorel, 1998). Portanto, a Saúde Coletiva não é só movimento ideológico, nem apenas prática política. É prática técnica, científica e tecnológica. $O$ seu saber não se restringe ao conhecimento científico, mas encontra-se permeável a outras tantas manifestações da sabedoria humana. A conjunção desses componentes na formulação e implantação de uma totalidade de mudanças - como a proposta da Reforma Sanitária Brasileira - ilustra a especifidade do campo. Ou seja, foram produzidos conhecimentos com base em determinados referenciais teóricos; criticados movimentos ideológicos e enfoques doutrinários que atravessam o espaço social da saúde; elaboradas visões de mundo, valores e consciências (ideologia) diante da realidade; seus intelectuais forjaram "ligas" que integram corações e mentes para as mudanças sociais; e foram realizadas práticas (políticas, institucionais, técnicas, econômicas, culturais etc.) que tomam a saúde, a qualidade de vida, a liberdade e a felicidade enquanto referentes centrais (PAIM, 2004).

Esta especificidade do campo da Saúde Coletiva demarca a sua atuação e a distancia da Medicina Preventiva e da Saúde Pública institucionalizadas. As diferenças com a Medicina Preventiva já se encontram mais nítidas, desde o clássico Dilema Preventivista (AROUCA, 2003), embora em relação à Nova Saúde Pública (quando adjetivos novos tentam maquiar substantivos desgastados) precisam ser, cada vez mais, explicitadas demonstrando-se a radicalidade da Saúde Coletiva, quanto à emancipação, à democracia e à autonomia dos sujeitos. Tais valores podem fazer a diferença com a Saúde Pública, "velha" ou "nova".

O giro filosófico em processo de construção passa, portanto, da subjetividade para a intersubjetividade, da identidade para a valorização da alteridade, 146 do controle técnico para o "logro" prático - com a contínua reconstrução de 
identidades - e da ênfase no tratamento para a dimensão do cuidado (AYRES, 2002). Como alerta o autor "cuidar da saúde [...] é mais que construir um objeto e intervir sobre o mesmo. Para cuidar se deve considerar e construir projetos" (AYRES, 2002).

\section{Saúde Coletiva ou Saúde Pública Contra-Hegemônica}

No último Congresso da Abrasco, Granda (2003) fundamentou a sua crítica à Saúde Pública convencional - cunhada de Enfermologia Pública pelo autor - a partir de três características centrais:

- O pressuposto filosófico-teórico da doença e morte como ponto de partida para a explicação da saúde;

- O método positivista para explicar o risco de adoecer na população e no estrutural-funcionalismo para compreender a realidade social;

- O reconhecimento do poder do Estado como força privilegiada para assegurar a prevenção da doença.

Assim, para explicar o risco e exorcizar a doença e a morte nos grupos humanos, esta saúde pública convencional compromete-se com uma tecnologia positivista manipulada pelo Estado: "Igual à Medicina que transforma o médico no mágico que explica a doença e que ao mesmo tempo a cura, assim também a Saúde Pública transforma o Estado no mágico que explica o risco e o previne" (GRANDA, 2003, p. 5).

A partir da crítica acima, o autor propõe estudar a potencialidade de construir uma saúde pública baseada nos seguintes pressupostos:

- Pressuposto filosófico-teórico da saúde e da vida, sem descuidar a prevenção da doença;

- Métodos que integrem diversas metáforas e proponham variadas hermenêuticas (inclusive a científica positivista) capazes de dar conta da ação social e das estruturas;

- Práticas sociais que integrem diversos atores e poderes, além do poder do Estado: o agir do indivíduo, dos públicos ou movimentos sociais que promovam a saúde, controlem socialmente o cumprimento dos deveres encomendados ao Estado, lutem por sua democratização e entrem em acordos-desacordos com os poderes supra e infranacionais. 
Admite que, mesmo diante da globalização e do neoliberalismo triunfante, seria possível avançar nessa proposta. Apresenta um conjunto de argumentos que apontam um contexto social, político e cultural aberto a alguma perspectiva de mudança, onde se destacam "novas forças sociais e políticas que aparecem no horizonte" assim como importantes inovações teóricas e práticas que "ocorrem na ciência em geral e na investigação em saúde em particular" (GRANDA, 2003, p. 7).

A partir dessa argumentação poder-se-ia admitir que as visões que sustentam a proposição de uma nova saúde pública talvez não sejam o que mais importa nesse percurso. Embora necessárias, representam a consciência possível - falsa ou verdadeira - sobre a realidade social e sobre a situação de saúde dos nossos países, em particular, e suas tendências. O fundamental, no momento, é iniciar processos, não se prendendo aos "hayquismos" dos hay que hacer. ${ }^{3}$ Consequentemente, não há funções essenciais de saúde pública em geral, nem universais, já que as práticas de saúde são determinadas social e historicamente. Essenciais são os sujeitos que se formam e os movimentos que se engendram. Essenciais são os compromissos que eles contraem no cotidiano e nas lutas do seu tempo e que fazem a História.

É possível que, presentemente, já não faça tanto sentido a preocupação com a formação de quadros como era a palavra de ordem durante as ditaduras na América Latina: quadros para a democratização da saúde, para o movimento sanitário, para a gestão democrática da saúde, para os partidos políticos e movimentos sociais, para a docência inovadora, para o socialismo e para a pesquisa comprometida com a melhoria das condições de vida do povo. Mas as conquistas eventualmente alcançadas não devem embaçar os nossos horizontes, nossos sonhos, nosso projeto. Há, portanto, que discuti-los sempre. Considerar o processo de constituição de sujeitos (da vida, epistêmico, avaliador e público), pode ser um bom caminho (TESTA, 1997).

No esforço de compreender o que é Saúde Coletiva neste início de século um dos mais comprometidos construtores deste campo na América Latina ofereceu relevantes pistas:

un decidido esfuerzo por ver más allá del horizonte que nos há legado la Salud Pública convencional; es una profunda vocación por transformar nuestra acción en el quehacer humano profundamente comprometido con la vida y con el cuidado de la enfermedad de nuestras poblacciones (una militancia sociopolítica, en las palabras de Testa); es un intento de construirnos sujetos 148 salubristas en función a respetar individualidades y apoyar la construcción de 
ciudadanos; es un intento de crear espacios de aprendizaje para multiplicar las fuerzas del compromiso; es buscar el desarrollo de las ciencias de la salud para potenciar con ellas el desarrollo de la salud y la felicidad, así como la disminución del sufrimiento de los enfermos y controlar las enfermedades controlables; es el empeño porque nuestras instituciones tengan sabor a nosotros a pesar de que cada día nos quieren convencer que no vale la pena lo humano. Esa cosa llamada Salud Colectiva, es algo que vale a pena darle cariño e impulsionar su crecimiento porque en última instancia es crear aquello que es una gran realidad: la solidariedad para generar el mundo que soñamos (GRANDA, 2003, p. 18).

Algumas perspectivas podem ser consideradas nesta construção:

a) abertura a paradigmas ético-estéticos que apreendam formas nãohegemônicas de produzir e conceber saúde/doença/cuidado;

b) produção de espaços e experiências acadêmicos e não-acadêmicos (serviços, comunitários) de exercício de transdisciplinaridade e de invenção tecnológica que assumam a articulação entre reflexão e prática concreta, pautadas em abordagens que tensionem e transcendam dicotomias do tipo individual/coletivo, afetivo/racional, qualitativo/quantitativo;

c) construção de espaços de emergência de sujeitos políticos e de desejo, comprometidos com transformações no campo da saúde coletiva, pela produção de reflexão crítica e de práticas desenvolvidas em diversas esferas da vida acadêmica e social. ${ }^{4}$

Articular o pensamento à ação supõe revisitar alguns conceitos que permitam a construção de uma cartografia da práxis. Assim, os conceitos de necessidades de saúde, sujeito e práticas poderiam dar início a esse mapa conceitual. Essas necessidades do ser vivente, seja do estômago ou da fantasia, envolvem energias e nutrientes consumidos no processo produtivo (como se ganha a vida) ou na forma com que se leva ou gasta a vida que se ganha (cultura). Enquanto as necessidade sociais de saúde implicam a reprodução do sistema, as necessidades radicais não podem ser resolvidas pelo sistema, exigindo a sua superação (HELLER, 1986). Essas necessidades radicais podem ser consideradas necessárias a um ser para que ele continue sendo um ser (MENDES-GONÇALVES, 1992).

Na medida em que as necessidades da saúde vão além das necessidades de serviços de saúde elas não se restringem a problemas de saúde, sejam 
doenças, riscos. Podem ser carências ou vulnerabilidades que expressam modos de vida e identidades. Podem ampliar-se, portanto, para o que é necessário para ter saúde, sejam os determinantes socioambientais e culturais, seja a idéia de projeto (de felicidade, qualidade de vida, gozo estético, filosofia etc.).

No que tange ao sujeito, o reconhecimento da alteridade e da intersubjetividade aponta para a superação da dicotomia individual/coletivo, pois o sujeito se constitui na relação com o outro (AYRES, 2002). Com relação às práticas de saúde, supõe-se a redefinição do seu objeto - as necessidades de saúde - e, consequentemente, a reorganização de atividades e recriação de tecnologias.

Portanto, se a práxis for concebida como articulação do pensamento e ação, no pensamento cabe considerar conceitos e teorias (necessidades, práticas de saúde, sujeitos, identidades e intersubjetividade; teorias da ação e do processo de trabalho), valores e ideologias (liberdade, autonomia, emancipação, democracia, alteridade e respeito à diferença, doutrina dos Direitos Humanos); e tecnologias e ciência. Já no âmbito da ação, cabe transcender o agir instrumental, voltado para o êxito técnico que constrói objetos; passar pelo agir estratégico, com vistas ao sucesso político (distribuição do poder); e alcançar o agir comunicativo, que visa ao alcance existencial, construindo sujeitos, além da produção de bens e serviços.

\section{Comentários Finais}

A Nova Saúde Pública proposta pelos países hegemônicos e apoiada pela OMS (WHO, 1995; KICKBUSCH, 2003) ignorou os esforços latino-americanos de construção do campo científico da Saúde Coletiva, sem conseguir, até o momento, renovar a saúde pública institucionalizada. Portanto, persistem lutas teórica, paradigmática, política e ideológica no interior desse campo (PAIM, 1992; 2001; 2004), com repercussões na sua delimitação e renovação, que não podem ser ignoradas pelos diferentes atores que se dedicam às questões da Saúde Coletiva.

A Saúde Coletiva na América Latina tem sido construída por projetos, lutas, sonhos, subjetividades, engenho, trabalho e arte. No Brasil, a duras penas, conseguimos iniciar o processo da Reforma Sanitária e implantar parte do projeto do Sistema Único de Saúde que se pretende: universal, público, democrático, culturalmente sensível, equânime, ético e solidário.

Portanto, o que talvez se faz mais necessário, presentemente, não é a gera150 ção de uma corrente do pensamento nem a estruturação de suas bases, 
muito menos a adesão acrítica ao movimento da Nova Saúde Pública, mas a articulação de sujeitos sociais em torno da Saúde Coletiva, enquanto campo cientifico e âmbitos de práticas, na formulação e condução de políticas conseqüentes.

\section{Notas}

${ }^{2}$ Este tópico baseia-se na apresentação do número especial da Revista Baiana de Saúde Pública:

Paim, J.S. 30 anos de Saúde Coletiva: A contribuição do Programa de Pósgraduação da UFBA. Rev. Baiana de Saúde Pública, v. 28 n. supl. 1, p. 9-10, 2004. Inclui, também, reflexões do termo de referência elaborado para a Mesa Redonda - A que coisa chamamos Saúde Coletiva, hoje? - do Congresso da Abrasco, Brasília, julho de 2003.

${ }^{3}$ Como diria o pensador argentino Mario Testa.

${ }^{4}$ Anotações para o Plano Diretor do Instituto de Saúde Coletiva da Universidade Federal da Bahia (ISC/UFBA), julho de 2004. 


\section{Referências}

AROUCA, A. S. O dilema preventivista: contribuição para a compreensão e crítica da Medicina Preventiva. São Paulo/Rio de Janeiro: Editora UNESP/FICRUZ, 2003.

AYRES, J. R. C. M. Conceptos y prácticas en salud pública: algunas reflexiones. Revista Facultad Nacional de Salud Pública, Cidade, v. 20, n. 2, p. 67-82, 2002.

AWOFESO, N. What's new about the «New Public Health»? Am J Public Health, Washington, n. 94, p. 705-9, 2004.

BRASIL. Conselho Nacional de Secretários de Saúde. I Encontro de gestores estaduais, provinciais e departamentais de sistemas-sul-americanos de saúde. Brasília: CONASS, 2005. (CONASS Documenta; v. 9).

BREILH, J. Nueva epidemiologia: construcción intercultural de otro paradigma de la ciencia. 226fl. Tese (Doutorado em Saúde Coletiva) - Instituto de Saúde Coletiva, Universidade Federal da Bahia, Salvador, 2002.

DONNÂNGELO, M. C. F. A pesquisa na área da saúde coletiva no Brasil - A década de 70. In: ABRASCO. Ensino da Saúde Pública, medicina preventiva e social no Brasil. Rio de Janeiro: ABRASCO, 1983.

ENCONTRO NACIONAL DE PÓS-GRADUAÇÃO EM SAÚDE COLETIVA. Mestrado em Saúde Comunitária da UFBA. Relatório Final. Salvador, 1978.

ESCOREL, S. Reviravolta da saúde: origem e articulação do movimento sanitário. Rio de Janeiro: FIOCRUZ, 1998.

GRANDA, E. A que cosa llamamos Salud Colectiva, hoy? In: VII CONGRESSO BRASILEIRO DE SALÚDE COLETIVA. Brasilia, 29 de julho a 2 de agosto de 2003.

HELLER, A. Teoría de las necesidades en Marx. Barcelona: Ediciones Península, 1986.

INSTITUTE OF MEDICINE. The Future of Public Health. Washington, D.C.: National Academy Press, 1988.

KICKBUSCH, I. The Contribution of the World Health Organization to a New Public Health and Health Promotion. Am J Public Health, Washington, n. 93, p. 383-8, 2003.

LAURELL, A. C. Saúde e trabalho: os enfoques teóricos. In: NUNES, E. D. (Org.). As Ciências Sociais em saúde na América Latina. Tendências e perspectivas. Brasília: OPAS, 1985.

MENDES-GONÇALVES, R. B. Práticas de saúde: processos de trabalho e necessidades. São Paulo: CEFOR, 1992. (Cadernos CEFOR - Textos, 1).

OPS/OMS. La crisis de la salud pública: reflexiones para el debate. Publicación Científica, Washington, D.C., n. 540, 1992.

PS/OMS. Sobre la teoría y práctica de la salud pública: un debate, múltiplas perspectivas. Washington, D.C.: OPS, 1993. (Serie Desarrollo de Recursos Humanos n. 98)

OPS/OMS. Desafíos para la educación en salud pública: la Reforma Sectorial y las funciones esenciales de Salud Pública. Washington, D.C.: OPS, 2000.

OPS/OMS. La Salud Pública en las Américas. Documento Conceptual, s/d.

OPS/OMS/ALAESP. Educación en Salud Pública. Nuevas perspectivas para las Améri-

152 cas. Washington D.C: OPS, 2001. 
PAIM, J. S. Desenvolvimento teórico-conceitual do ensino em Saúde Coletiva. In: NUTES/CLATES/ABRASCO. Ensino de Saúde Pública, Medicina Preventiva e Social no Brasil. Rio de Janeiro, 1982.

PAIM, J. S. Saúde, crises e reformas. Salvador: Centro Editorial Didático da UFBA, 1986.

PAIM, J. S. La Salud Colectiva y los desafíos de la práctica. In: OPS/OMS. La crisis de la salud pública: reflexiones para el debate. Washington, D.C.: OPS, 1992. (Publicación Científica; 540).

PAIM, J. S. Transición paradigmática y desarrollo curricular en Salud Pública. In: OPS/ OMS/ALAESP. Educación en Salud Pública. Nuevas perspectivas para las Américas. Washington D.C: OPS, 2001.

PAIM, J. S. Epidemiologia e planejamento: a recomposição das práricas epidemiológicas na gestão do SUS. Ciência \& Saúde Coletiva, Rio de Janeiro, v. 8, n. 2, p. 557-567, 2003.

PAIM, J. S. 30 anos de Saúde Coletiva: a contribuição do programa de pós-graduação da UFBA. Rev. Baiana de Saúde Pública, Salvador, v. 28, n. supl.1, p. 9-10, 2004.

PAIM, J. S.; ALMEIDA FILHO, N. de. A crise da Saúde Pública e a utopia da Saúde Coletiva. Salvador: Casa da Qualidade, 2000.

PORRAS, F. M. Reformas de Salud e funciones esenciales de Salud Publica. Estrategias innovativas para la educación en salud publica. Centro Latinoamericano de Investigaciones en Salud (CLAIS), 1998 (ponencia).

ROSEN, G. Da Polícia Médica à Medicina Social. Rio de Janeiro: Graal, 1979.

ROSEN, G. Uma história da Saúde Pública. São Paulo/Rio de Janeiro: Hucitec/EDUSP/ ABRASCO, 1994

SILVA, G. R. Origens da Medicina Preventiva como disciplina do ensino médico. R. Hosp. Clín. Fac. Med. São Paulo, São Paulo, n. 28, p. 91-6, 1973.

TERRIS, M. Current trends in Public Health in the Americas. In: PAHO. The Crisis of Public Health: Reflections for the Debate, Scientific Publication, Washinton, D.C: PAHO, n. 540, p.266-183, 1992.

TESTA, M. Saber en salud. La construcción del conocimiento. Buenos Aires: Lugar Editorial, 1997.

WAITZKIN, H.; IRIART, C.; ESTRADA, A.; LAMADRID, S. Social medicine in Latin America: productivity and dangers facing the major national groups. The Lancet, London, n. 358, p. 315-23, 2001.

WHO. New Public Health and WHO's. Ninth General Programme of Work. A Discussion Paper. Geneve, 1995. 
Este livro foi publicado no formato $17 \times 24 \mathrm{~cm}$ fontes: FuturaLt BT 1 1,5/15,5 (miolo) e Myriad Roman (títulos e subtítulos) miolo em papel $75 \mathrm{~g} / \mathrm{m}^{2}$ - tiragem 1000 exemplares

Impresso no Setor de Reprografia da EDUFBA

Acabamento e impressão ESB Serviços Gráficos 